\title{
Bilder in gedruckten Rechtsbüchern
}

\author{
I. Die Bedeutung von Schrift und Druck \\ für die Bildabstinenz der Juristen \\ 1. Das Recht am Ende der Gutenberg-Galaxis
}

Das moderne Recht ist arm an Bildern. Juristische Information besteht aus Wort und Schrift und damit aus Text und nur aus Text. Aber nach Foto, Film und Fernsehen verbreiten nun die elektronischen Medien eine Bilderflut, in der die Schriftkultur zu ertrinken droht. Das Recht ragt als eine der letzten großen Inseln aus dem Meer der Bilder. Wer in dieser Situation fragt, ob das Recht die Bilder abwehren kann oder soll, wird sofort auf die bekannten Sachsenspiegel-Handschriften hingewiesen und muss sich erklären lassen, Bilder im Recht seien doch eigentlich gar nichts Neues und Besonderes. Es sind auch gleich zwei Argumente zur Hand, die das Fehlen der Bilder im modernen Recht eher als Defizit erscheinen lassen, nämlich Bildersturm und Buchdruck. Diese Argumentationslinie führt dazu, in der möglichen Rückkehr der Bilder ins Recht eine eher wünschenswerte, beinahe natürliche Entwicklung $\mathrm{zu}$ sehen. Sie steht damit nicht nur in Kontrast zu der praktizierten Bildabstinenz des modernen Rechts, sondern sie verkennt auch, dass die Bilderlosigkeit des modernen Rechts tiefer angelegt ist, nämlich in der Verschriftlichung der Rechtskultur. Vor diesem Hintergrund bildeten die mittelalterlichen Bilderhandschriften nur eine Episode. Wenn heute der zu beobachtende Medienwandel und in seiner Folge die Allverfügbarkeit von Bildern dazu führen sollten, dass auch das Recht jedenfalls partiell auf Bildkommunikation umstellt, so handelt es sich nicht um die Fortsetzung oder Wiederaufnahme einer alten Tradition, sondern um eine prinzipiell neue Entwicklung, die die ganze Rechtskultur verändern kann. Deshalb lohnt es sich, in historischer Betrachtung den Gründen für die Bilderlosigkeit des modernen Rechts nachzugehen. 


\section{Bildersturm und Buchdruck}

Katsh sieht in der Bilderarmut des modernen Rechts eine Folgewirkung des Buchdrucks:

„One of the subtle effects of print was to change how words and images were used. Print, while providing us with many beautiful books of art, tended to support text more than images. ... Partly because of this, the print world of law is a largely image-less world. [As a result] the history of the illustrated book in the fifteenth and sixteenth centuries is an account of a losing struggle for survival. By 1550 the illustrated book [was] dead."1

Aber die Ursachen liegen früher und tiefer. Nicht erst der Buchdruck ist verantwortlich für die Ikonophobie ${ }^{2}$ des Rechts. Diese war bereits mit dem Übergang zur Literalität angelegt. Spätestens die phonetische Schrift brachte all jene "Errungenschaften", welche die Jurisprudenz an ihrem Stoff und ihrer Methode schätzt. Daher greifen auch Hibbitts ${ }^{3}$ und Jay zu kurz, wenn sie den Calvinismus für das Verschwinden der Bilder im rechtlichen Raum verantwortlich machen:

„Along with the iconoclastical removal of artwork from the courtrooms and illustrations from law books, at least in countries influenced by Reformation iconophobia, came the frequent robing of judges in sober black and white and the replacement of colorful seals by simple signatures on legal documents. No longer would signs from heaven, like those informing medieval ordeals, be sufficient; now discussion and persuasion, men giving testimony about what they knew or had witnessed and then arguing about what rule might have been violated, would be required in most instances. ... the nonhieroglyphic script of Western languages meant that visual revelations of the truth, illuminations of divine will, were no longer relevant to the decision-making process. ${ }^{4}$

Was Jay und Hibbitts hier beschreiben, ist Teil des allgemeinen Rationalisierungsprozesses am Ausgang des Mittelalters, jedoch kaum Folge eines speziell gegen Bilder gerichteten Programms. Der protestantische Bildersturm tobte in den zwanziger und dreißiger Jahren des 16. Jahrhunderts. Er richtete sich explizit gegen Heiligen- und Andachtsbilder in den Kirchen. Erst im Spätmittelalter wurde es Brauch und bis zu

\footnotetext{
${ }^{1}$ M. ETHAN KaTSH, Law in a Digital World. New York 1995, $17 \mathrm{f}$.

2 In der Psychologie wird dieser Ausdruck spezieller verwendet; dort meint er nicht die generalisierte Ablehnung von Bildern, sondern pathologische Reaktionen auf ein bestimmtes Bild. Ich rede deshalb vorzugsweise von Bilderscheu oder Bildabstinenz.

3 BERNARD J. HIBBITTS, Making Sense of Metaphors: Visuality, Aurality, and the Reconfiguration of American Legal Discourse, in: Cardozo Law Review 16 (1994), 229-356, 255 f.

${ }^{4}$ Martin JaY, Must Justice be blind?, in: COSTAS DOUZINAS/LYNDA NeaD (Hrsg.), Law and the Image. The Authority of Art and the Aesthetics of Law. Chicago 1999, 19-35, 24.
} 
einem gewissen Grade Norm, ${ }^{5}$ in Gerichtssälen und Rathäusern, wo Gericht gehalten wurde, Weltgerichtsbilder anzubringen, um die Richter daran zu erinnern, dass sie Vertreter der ewigen Gerechtigkeit seien und im Namen Gottes Recht sprachen. Der Brauch hat sich bis in das 18. Jahrhundert gehalten. Zwar sind viele dieser Bilder verloren gegangen. Aber dafür war anscheinend kein Bildersturm, sondern nur der Zahn der Zeit verantwortlich. Es ist auch nicht ganz richtig, den Verzicht auf die Siegelung von Urkunden als Verlust an visueller Ausdruckskraft anzuführen, denn die Siegel wurden durch die kaum weniger bildhaften Signets der Notare abgelöst. ${ }^{6}$

Die anderen Geisteswissenschaften waren und sind kaum bilderfreundlicher als das Recht. Daher muss eine gemeinsame Ursache gesucht werden. Die Geisteswissenschaften und mit ihnen die politischjuristische Gedankenwelt des Westens haben ihre Wiege im klassischen Griechenland. Havelock erklärt die Entstehung der gesamten griechischen und damit der von ihr abhängigen westlichen Kultur aus der Überlegenheit des griechischen Alphabets. ${ }^{7}$ Die Griechen perfektionierten die Schrift zu einem ebenso einfachen wie leistungsfähigen Kode für die kontextunabhängige Wiedergabe des gesprochenen Wortes. Es ist nicht übertrieben, die revolutionäre Bedeutung der Alphabetisierung des Aufzeichnungssystems mit derjenigen der Digitalisierung im Zeitalter des Computers zu vergleichen. Ihr gegenüber treten alle anderen Erklärungen, die sich anbieten, zurück. Das gilt insbesondere für den Verweis auf die Textcorpora, die vielfach im Mittelpunkt der Geisteswissenschaften stehen, auf heilige Schriften, Gesetze, historische Urkunden und literarische Texte, denn insoweit könnte es sich um eine Vertauschung von Ursache und Wirkung handeln. Die Griechen hatten keine heiligen

\footnotetext{
${ }^{5}$ Nach der zwischen 1330 und 1386 entstandenen Glosse zum Sächsischen Weichbildrecht (Stadtrecht) sollte im Rathaus, wo Richter und Schöffen urteilen, das "gestrenge gericht des unseres herren" gemalt werden. ALEXANDER VON DANIELS/FRANZ VON GRUBEN/FRIEDRICH JULIUS KÜHNS, Das Sächsische Weichbildrecht, in: Weltchronik und Weichbildrecht in 136 Artikeln mit der Glosse. Berlin 1858, Spalte 256. GEORG TROESCHER, Weltgerichtsbilder in Rathäusern und Gerichtssälen, in: Westdeutsches Jahrbuch fïr Kunstgeschichte 11 (1939), 139-214, beschreibt 122 Weltgerichtsbilder aus Rathäusern und Gerichtsstätten, von denen zwar einige verschollen sind, jedoch anscheinend aus Gründen, die mit dem protestantischen Bildersturm nichts zu tun haben. Vgl. auch URSULA LEDERLE, Gerechtigkeitsdarstellungen in deutschen und niederländischen Rathäusern. Dissertation. Heidelberg 1937.

${ }^{6}$ FRITZ MANSTETTEN, Das Notariatssignet, in: HeINRICH KaSPERS/WILHELM SCHMIDTTHOMÉ/HANS GERIG/FRITZ MANSTETTEN, Vom Sachsenspiegel zum Code Napoléon. Kleine Rechtsgeschichte im Spiegel alter Rechtsbücher. 2. Aufl., Köln 1965, 202-256.

7 ERIC A. Havelock, Preface to Plato. Cambridge (Mass.) 1963; DerS., Schriftlichkeit. Das griechische Alphabet als kulturelle Revolution. Weinheim 1990 (Original: The Literate Revolution in Greece and its Cultural Consequences. Princeton 1982).
} 
Schriften, sondern tradierten ihre heiligen Texte mündlich. ${ }^{8}$ Auch Platons Bildkritik im zehnten Buch der Politeia hat den Bildgebrauch allenfalls ganz am Rande beeinflusst. Das mosaische Bilderverbot und der im 8 . Jahrhundert daran anknüpfende byzantinische Bilderstreit ${ }^{9}$ haben die Bilderfrömmigkeit des Mittelalters nicht verhindern können.

Das Verschwinden der Bilder aus den Büchern hat andere Gründe als den protestantischen Bildersturm. Die Jurisprudenz der katholischen Länder, die von diesem Sturm verschont blieben, ist nicht weniger bilderscheu. Auf der anderen Seite unternahmen Staat und Kirche immer wieder den Versuch, der schnellen und weiten Verbreitung des Geschriebenen mit Zensur, Indizierung und Kanonbildung zu begegnen, ohne dass die Bilder davon profitieren konnten. Und schließlich hat auch die mit dem Buchdruck verknüpfte Idee einer sprachbasierten nationalen Kommunikationsgemeinschaft keinen negativen Effekt auf die Verbreitung von Bildern gehabt. Mit der Idee des Nationalismus sind bildhafte Symbole kaum weniger verbunden als eine einheitliche Sprache.

\section{Vom Bild zur Schrift}

Als Kommunikationsmittel sind Bilder älter als die Schrift. Bilder hatten jedoch gegenüber der Schrift zwei technische Nachteile, die zu ihrer Verdrängung beitrugen; sie waren langwieriger herzustellen und sie ließen sich schwerer kopieren. ${ }^{10}$ Doch die technischen Nachteile waren für die Entwicklung nicht annähernd so bedeutsam wie die semiotischen Qualitäten der Schrift. Diese Qualitäten setzten sich nicht nur gegenüber der Oralität durch, sondern auch gegenüber dem artifiziellen Bild. Das ist bemerkenswert, denn Schrift und Bild sind sich technisch näher als Schrift und Mündlichkeit. In oralen Kulturen wird das Wort stets von einer Vielzahl nonverbaler Signale ergänzt. Hibbitts kennzeichnet solche Oralität deshalb treffend als performance culture.11 Gesichtseindrücke und Gesten sind dreidimensional und bewegt. Schrift dagegen ist zweidimensional und statisch. Zwar ist auch das Lesen, technisch gesehen, ein visueller Vorgang. Indessen handelt es sich um eine gegenüber der "natürlichen“ sehr verengte Visualität. Insofern äh-

\footnotetext{
8 Darauf verweisen ALEIDA ASSMANN und JAN ASSMANN in ihrer Einleitung zu HAVELOCK, Schriftlichkeit (Fn. 7), 1-35, 11.

9 Dazu die maßgeblichen Quellen in englischer Übersetzung und mit einer hilfreichen Einführung DANIEL J. SAHAS, Icon and Logos: Sources in Eighth-Century Iconoclasm. Toronto 1986.

10 WILliam M. Ivins, JR., Prints and Visual Communication. 8. Aufl., Cambridge, 1992, 19.

11 Bernard J. HibBitTS, "Coming to our Senses": Communication and Legal Expression in Performance Cultures, in: Emory Law Journal 41 (1992), 883-960.
} 
nelt das Betrachten von Tafelbildern eher dem Lesen von Schrift als dem Blick in die Welt. ${ }^{12}$ Entscheidend für die Bilderlosigkeit bestimmter kultureller Bezirke ist deshalb nicht das Rezeptionsorgan, sondern die semiotische Differenz von Bild und Schrift.

Von Harold Innis stammt die These, dem jeweils dominierenden Kommunikationsmedium sei ein „bias", eine Voreinstellung zugunsten bestimmter gesellschaftlicher Interessen und Organisationsformen inhärent. ${ }^{13}$ Innis stellte dabei auf das materielle Substrat der Kommunikation - Stein oder Tontafeln, Pergament und Papyrus und schließlich Elektrizität $-a b$. Maßgebliche Eigenschaften von Stein und Tontafeln sind räumliche Bindung und Dauerhaftigkeit, die die Zeitdimension und damit Tradition und Hierarchie begünstigen sollen. Das leicht transportable Papier dagegen ermöglicht die Ausdehnung der Herrschaft in den Raum, der Druck durch preiswerte Vervielfältigung eine soziale Breitenwirkung und die Elektrizität schließlich durch ihre Geschwindigkeit den sozialen Wandel. Marshal McLuhan hat diese These ausgebaut und das Ende des Buchzeitalters, der Gutenberg-Galaxis, angekündigt. ${ }^{14}$

An die Vorstellung vom Medienwandel als Auslöser sozialer Veränderungen knüpfen auch Eric A. Havelock, ${ }^{15}$ Jack Goody ${ }^{16}$ und Walter J. Ong ${ }^{17}$ an. Aber sie stellen nicht auf die materiell-technischen Qualitäten des Mediums ab, sondern auf dessen Code-Struktur. Unter diesem Aspekt haben sie sich besonders mit dem Übergang von der Oralität zur Literalität befasst und die These populär gemacht, dass die Schrift mit ihren spezifischen semiotischen Qualitäten geeignet sei, kognitive Prozesse im Allgemeinen und speziell logisches Denken zu fördern, und damit kulturprägende Wirkungen entfaltet habe. Dagegen wird heute eingewendet, nicht die Schrift als solche habe die kulturelle Entwicklung

${ }^{12}$ HibitTTS, Coming to our Senses (Fn. 11), 885 f. Fn. 33 u. 905 ff., bezeichnet deshalb das zweidimensionale nicht bewegte Bild zusammen mit der Schrift als grafische Information.

${ }^{13}$ HaROLD A. INNIS, The Bias of Communication. Toronto 1951; DERS., Empire and Communication. Toronto 1950. Textauswahl in Ubersetzung in KARLHEINZ BARCK (Hrsg.). Harold A. Innis - Kreuzwege der Kommunikation. Wien 1997.

${ }^{14}$ Marshall Mcluhan, Die Gutenberg-Galaxis. Düsseldorf 1968 (Original: The Gutenberg Galaxy. Toronto 1962); DERS., Die magischen Kanäle. Düsseldorf 1968 (Original: Understanding Media. London 1964)

${ }^{15}$ HAVELOCK, Preface to Plato (Fn. 7).

${ }^{16}$ JACK GOODY, Literacy in Traditional Societies, Cambridge 1968; deutsche Erstausgabe unter dem Titel "Literalität in traditionalen Gesellschaften", Frankfurt am Main 1981 DERS., The Domestication of the Savage Mind. Cambridge 1977; DERS., Die Logik der Schrift und die Organisation von Gesellschaft. Frankfurt am Main 1990; DERS./JAN WATT/KATHLEEN GOUGH (Hrsg.), Entstehung und Folgen der Schriftkultur. Frankfurt am Main 1986.

17 WALTER J. ONG, Orality and Literacy. The Technologizing of the Written Word. London 1982. 
geprägt; entscheidend sei vielmehr, dass die kulturelle Gemeinschaft die Schrift zum Zentrum ihres Bildungssystems und damit zum Träger des kulturellen Gedächtnisses gemacht habe. ${ }^{18}$ Es mag dahinstehen, ob die Schrift, und zwar die Alphabetschrift, insoweit nicht doch ohne Alternative war. Tatsache jedenfalls ist, dass die westliche Kultur zur Schriftkultur geworden ist. Durch das Erlernen der Schrift wird das kognitive Potential der Individuen immer wieder aufs Neue erweitert und verändert, und mindestens große Bereiche der abendländischen Kultur, darunter das Recht, machen von diesem Dispositiv Gebrauch.

\section{Das kognitive Dispositiv der Schrift}

Schrift ist Repräsentation von Sprache. Aber die Verschriftung ließ die Sprache nicht unberührt. Sie reinigte die Sprache von Emotionen und Synästhesien. Der besondere Schrifttyp des Alphabets verlieh der Sprache durch Orthografie und Grammatik einen formalen Zuschnitt. Die Dauerhaftigkeit der Schrift in Verbindung mit dieser Formalisierung der Sprache ermöglichte eine Überprüfung von Texten auf ihre logische, syntaktische und semantische Konsistenz. ${ }^{19}$ Erst die so durchgebildete Sprache brachte die Fähigkeit zur Abstraktion, zu formallogischen Schlüssen und zu kausalem Denken hervor.

Die Kunst des Schreibens bestand und besteht darin, die Fülle der Gedanken, wiewohl sie vielfach kreuz und quer verknüpft sind, sequentiell zu ordnen. Satz folgt auf Satz. Wir sprechen bildlich von einem Faden, an dem die Gedanken aufgereiht sind. Die Linearität der Schriftsprache korrespondiert - und das ist sicher kein Zufall - mit den Ordnungsvorstellungen, die das Denken seit der Antike beherrschen. Wir ordnen die Welt mit der Hilfe linearer Konzepte. Linear ist die Vorstellung der Zeit. Linear ist die Kausalitätsvorstellung, die Ursache und Wirkung verknüpft, und linear ist schließlich auch unsere Vorstellung vom Raum jedenfalls insoweit, als sich zwei beliebige Punkte stets durch eine Gerade verbinden lassen.

Die Schrift befreite das Gedächtnis und machte so eine kritische Auseinandersetzung mit den Inhalten möglich. Schrift gestattete, die aufgeschriebenen Gedanken wie etwas Fremdes zu behandeln. Diese Objektivierung der Information führte zur. Frage nach dem Subjekt und damit zu den Anfängen eines reflektierten Selbstbewusstseins. Erst danach

${ }^{18}$ JAN ASSMANN, Das kulturelle Gedächtnis. Schrift, Erinnernng und politische ldentitit in frihten Hochkulturen. 4. Aufl, Müchen 2002, 259 ff. Vgl, femer die Einleitung von Jan und Aleida Assmann zu HAVELOCK, Preface to Plato (Fn. 7).

19 Diesen Zusammenhang betont CHRISTIAN STETTER, Schrift und Sprache. Frankfurt am Main 1997. 
konnten die Philosophen beginnen, Wahrheiten und Meinungen zu trennen. Erst mit Hilfe der Schrift entwickelten sie Taxonomien zur Ordnung des Wissensstoffes. Was Goody und Watt strukturelle Amnesie genannt haben, ${ }^{20}$ nämlich die ständige Transformation des erinnerten Wissens in Abhängigkeit von den Notwendigkeiten und Zufälligkeiten der Praxis, wurde mit Hilfe der Schrift durch ein Wissensmanagement ersetzt.

621 v. Chr. erhielt der Archon Drakon den Auftrag, das Recht auf Gesetzestafeln aufzuzeichnen, um die Willkür der adeligen Richter zu unterbinden. Die Schrift wurde zum Instrument demokratischer Kontrolle gegen "strukturelle Amnesie“. Solon, der Archon Eponymos für das Jahr 594/593, machte die Erziehung zur Staatsaufgabe. Die Kinder aller Bürger wurden im Lesen und Schreiben unterrichtet. Schrift blieb nicht länger ein Werkzeug von geheimer und magischer Kraft, ${ }^{21}$ Literalität nicht länger ein Elitestatus. ${ }^{22}$ Als Sokrates 399 angeklagt war, er leugne, dass Sonne und Mond Götter seien, und behaupte, die Sonne sei aus Stein und der Mond aus Erde, konnte er sich verteidigen, die Richter seien doch belesen genug, um zu wissen, dass diese Behauptung von Anaxagoras stamme, dessen Bücher für weniger als eine Drachme auf dem Orchestraplatz zu kaufen seien.23

Bereits die schriftkundigen Vorsokratiker hatten epistemologische Fragen aufgeworfen. Xenophanes (546-470) meinte: "Sichere Wahrheit erkannte kein Mensch und wird auch keiner erkennen." ${ }^{24}$ Für Sophisten

${ }^{20}$ GOODY, Entstehung und Folgen der Schriftkultur (Fn. 16).

${ }^{21}$ GOODY, Literalität in traditionalen Gesellschaften (Fn. 16), 283 ff.

${ }^{22}$ HAVELOCK, The Literate Revolution in Greece (Fn. 7), $71 \mathrm{f}$.

${ }^{23}$ Platon, Apologie, 14e. Das genaue Ausmaß der Lese- und Schreibfähigkeit im Altertum ist allerdings nicht ganz geklärt. Verallgemeinerungen sind schwierig, denn der Grad der Alphabetisierung war von Region zu Region sehr verschieden, und große Teile der Bevölkerung, insbesondere Frauen und Sklaven, blieben weitgehend Analphabeten. Sicher ist aber, dass die Schriftkenntnis nicht auf eine Schreiberkaste beschränkt blieb. WILlIAM V. HARRIS gibt den Alphabetisierungsgrad mit höchsten $15 \%$ an (Ancient Literacy. Cambridge 1989, 328). Diese Zahl soll allerdings Frauen einschlieBen. Sehr viel positiver, wenn auch ohne Zahlen, dafür aber mit vielen Belegen, wird die Schreib- und Lesefähigkeit von HORST BLANCK, Das Buch in der Antike. München 1991, 22 ff., eingeschätzt. Zur Kenntnis von Lesen und Schreiben in der griechischrömischen Welt ferner ALFRED BURNS, The Power of the Written Word. New York 1989; ROSALIND THOMAS, Literacy and the City-State in Archaical and Classical Greece, in: AlAN K. BoWman/Greg WOOLF (Hrsg.), Literacy and Power in the Ancient World. Cambridge 1994. Auf Prozentzahlen kommt es indessen weniger an als auf die Tatsache, dass die Nutzer der Schrift selbst zu Schreibern wurden.

24 JAAP MANSFELD, Die Vorsokratiker griechisch/deutsch. Stuttgart 1987, 225 (Nr. 38) übersetzt das von Sextus Empiricus überlieferte Fragment wie folgt: "Klares hat freilich kein Mensch gesehen, und es wird auch keinen geben, der es gesehen hat ... Bei allen Dingen gibt es nur Annahme." 
wie Protagoras (481-411) waren erkenntnistheoretischer Skeptizismus und normativer Relativismus beinahe selbstverständlich. Sie kannten die Unterscheidung von Natur und Konvention ebenso wie die von Recht und Gesetz. Als Ursache dieser Emanzipation hatte Platon die Schrift ausgemacht, und er stemmte sich der "Trennung des Wissenden vom Wissen" 25 entgegen. Die Geringschätzung der Schrift hinderte Platon aber nicht, in diesem Medium eine logische Propädeutik des wahren Redens zu entwickeln. ${ }^{26}$

Platons Schriftkritik adressiert insbesondere den Unterschied zwischen konzeptionell mündlicher und konzeptionell schriftlicher Sprache. ${ }^{27}$ Der konzeptionell schriftliche Text berücksichtigt die räumliche und zeitliche Distanz von Schreiber und Leser und treibt daher einen größeren sprachlichen Aufwand, um das Gelingen der Kommunikation im Sinne kongruenten Verstehens zu sichern. Er macht seine Gedanken explizit, entwickelt seine Argumente linear und verknüpft sie logisch und konsistent. ${ }^{28}$ Bloße Rede kann sich viel stärker auf den außersprachlichen Kontext verlassen. In einer Formulierung von David Olson: Bei der schriftlichen Kommunikation gilt, "the meaning is in the text", für die mündliche, "the meaning is in the context". ${ }^{29}$ In der Konsequenz ist der konzeptionell schriftliche Text relativ kontextunabhängig (autonom).

Aristoteles hatte die Vorbehalte seines Lehrers gegenüber der Schrift überwunden. Er nutzte die Schrift zur Entwicklung von Logik und Epis-

${ }^{25}$ HAVelock, Preface to Plato (Fn. 7), $197 \mathrm{ff}$.

${ }^{26}$ Dazu das Kapitel „Logik und Schrift: Die Ausprägung des Formalitätsprinzips in den platonischen Spätdialogen" in: STETTER, Schrift und Sprache (Fn. 19) 299-355.

27 Zu diesem Unterschied PETER KOCH / WULF OESTERREICHER, Sprache der Nähe - Sprache der Distanz: Mündlichkeit und Schriftlichkeit im Spannungsfeld von Sprachtheorie und Sprachgeschichte, in: Romanistisches Jahrbuch 36 (1985), 15-43; DEBORAH TANNEN, Oral and Literate Strategies in Spoken and Written Narratives, in: Language 58 (1982), $1-21$.

${ }^{28}$ Sprachwissenschaftler beschreiben bestimmte Dimensionen der Einheit des Textes mit den Begriffen Kohäsion und Kohärenz. Kohärenz steht für den Sinnzusammenhang des Textes, den letztlich erst der Rezipient mit Hilfe seines Vorwissens herstellt. Kohäsion dagegen ist der formale Zusammenhang von Segmenten des Textes, der vom $\mathrm{Au}$ tor produziert wird. Als Mittel zur formalen Integration des Textes dienen der systematische Gebrauch des bestimmten und unbestimmten Artikels, von Pronomen und Konjunktionen und der consecutio temporis, im Grunde also alle Elemente der Grammatik, die über die schlichte Formenlehre hinausgehen. Dazu treten kunstvollere Figuren wie Anapher und Katapher (Vorausverweisung und Zurückverweisung), Ellipsen Frage- und Antwortverknüpfungen oder auch nur die Wiederholung von Textteilen (Rekurrenz).

29 DAVID OLSON, From Utterance to Text: The Bias of Language in Speech and Writing, in: Harvard Educational Review 47 (1977), 357-381. Auf diesen Zusammenhang und die einschlägige Literatur bin ich aufmerksam geworden durch URSULA SCHÄFER, Zum Problem der Mündlichkeit, in: JOACHIM HEINZLE (Hrsg.), Modernes Mittelalter. Frankfurt am Main 1994, 357-375, $357 \mathrm{ff}$. 
temologie. Die von der Schrift erzwungene lineare Anordnung diskreter Einheiten wurde zum Maßstab der Rationalität. Seither ist (Geistes-)Wissenschaft anscheinend unauflöslich mit Schrift verbunden, und die Bilder sind, ob ausgesprochen oder nicht, einem Irrationalitätsverdacht ausgesetzt. ${ }^{30}$ In der Zeit nach Aristoteles hat sich das Begriffsinventar von Logik, Rechtsphilosophie und politischer Theorie nicht mehr grundlegend verändert. Es ist durchdrungen von jener spezifischen Rationalität eines schriftgeprägten Denkens in abstrakten Kategorien, zergliedernden Definitionen und logischen Schlussfolgerungen.

Das klassische Griechenland war keineswegs bilderfeindlich; im Gegenteil, die Griechen gelten als Augenmenschen, und es gab eine blühende Malerei und Bildhauerei. Doch in jener Zeit begann die Kultur, sich auszudifferenzieren. Den verschiedenen Medien wurden unterschiedliche Orte in der Gesellschaft zugewiesen. In Handwerk, Technik und Kunst behielten die Bilder ihren alten Platz. Die neue Philosophie dagegen und in ihrer Folge die Geisteswissenschaften konnten mit Bildern nichts mehr anfangen. In den Bildungskanon der Spätantike fanden Bilder als Wissensträger keinen Eingang mehr. Die Malerei wurde als handwerkliche Tätigkeit eingestuft und den minderen oder mechanischen Künsten zugerechnet. ${ }^{31}$ Vermutlich ging damit eine soziale Abwertung der Bilder einher. Doch auch als in der Renaissance Kunst und Technik eine enorme Aufwertung erfuhren, blieb es bei der Trennung zwischen der bilderlosen Philosophie ${ }^{32}$ und der bildenden Kunst. ${ }^{33}$ Auch für die Philosophie gilt der Befund der Bilderscheu. ${ }^{34}$ Erst neuerdings

${ }^{30}$ PetRA SCHUCK-WERSIG, Expeditionen zum Bild. Frankfurt am Main 1993, durchgehend.

${ }^{31}$ HORST KUNZE, Geschichte der Buchillustration in Deutschland. Das 16. und 17. Jahrhundert. Frankfurt am Main 1993. Bd. I (Textband), 249; SCHUCK-WERSIG, Expeditionen zum Bild (Fn. 30), 136, 140

32 LUCIEN BRAUN hat in zwei Bänden mit insgesamt 780 Beispielen eine monumentale Sammlung von mittelalterlichen Buchillustrationen, von Kunstbildern, Allegorien und Emblemen, antiken Büsten, gemalten Porträts und modernen Fotografien vorgelegt, die Philosophen und die Philosophie zum Thema haben (Iconographie et Philosophie. Vol. 1 : Essai de définition d'un champ de recherche; Vol. 2 : Commentaire et Bibliographie. 2. Aufl., Strasbourg 1996). Doch aus der Sicht der professionellen Philosophie handelt es sich eher um eine Kuriositätensammlung. Das schließt nicht aus, dass man, wie ReInHARd BRANDT, Philosophie in Bildern. Köln 2000, in Bildern Philosophie entdecken kann.

33 Olver ROBERT SCHOLZ, Bild, in: Ästhetische Grundbegriffe, Historisches Wörterbuch in sieben Bänden. Bd. 1. Stuttgart 2000, 618-669/645.

${ }^{34}$ Auch hier bestätigen Ausnahmen die Regel: Als Ausnahme gilt die Margarita Philosophica von GREGORIUS REISCH, Freiburg 1503, die immer wieder nachgedruckt worden ist. Die Margarita ist freilich eher eine Enzyklopädie der artes liberales als eine Philosophie im heutigen Sinne. Das zeigt das in ramistischer Manier gehaltene Inhaltsverzeichnis, dem dann allerdings verso die bekannte turris der artes liberales folgt. Das zweite Buch über die Rhetorik wird mit einem symbolischen Titelbild eingeleitet. Das 
kommen in populären und Lehrdarstellungen Illustrationen in Mode. ${ }^{35}$ Für die Sprachwissenschaften versteht sich die Bilderlosigkeit beinahe von selbst. Die historischen Wissenschaften kümmern sich zwar in der Neuzeit verstärkt um Bilder, jedoch geschieht das nur auf der Objektebene. Bilder werden als Geschichtsquellen ausgewertet, aber sie dienen nicht der Kommunikation über Geschichte. ${ }^{36}$

\section{Oralität und Schriftlichkeit im Mittelalter}

Über die griechischen Kolonien verbreitete sich die Alphabetschrift nach Italien und Rom. In der Folge war das elaborierte römische Recht von vornherein ein bilderloses schriftliches Recht. Bebilderte Codices gab es zwar schon in der Spätantike. ${ }^{37}$ Aber erst im Mittelalter kam die Praxis der illuminierten Rechtshandschriften auf, die heute den Eindruck erweckt, die Bilderlosigkeit des Rechts sei ein modernes Phänomen. Diese Praxis erklärt sich daraus, dass das Recht im Mittelalter den Anschluss an römische Tradition und an die klassische Philosophie

Buch über die Logik zeigt außer einem schönen Titel das Oppositionsquadrat, das auch in anderen zeitgenössischen Büchern verwendet wird. Das zwölfte Buch über die Philosophia Moralis ist vollkommen bilderlos.

35 Zum Beispiel GERMAN HAFNER, Bildlexikon antiker Personen. Düsseldorf 2001; ANTHONY KENNY, Illustrierte Geschichte der westlichen Philosophie. Frankfurt 1995; PETER KUNZMANN/Franz-PETER BurkHARD/FRANZ WIEDMANN, dtv-Atlas Philosophie. Mit 115 Abbildungsseiten in Farbe. 9. Aufl., München 2001; JEREMY WEATE, Das illustrierte Buch der Philosophie. Illustriert von Peter Lawman. Wien 1999. Philosophenporträts finden sich immer häufiger in populären Darstellungen.

36 Für die Rechtsgeschichte KARL VON AMIRA, Germanisches Recht. 4. Aufl., Berlin 1960, bearbeitet von KARL AUGUST ECKHARDT; HEINRICH BRUNNER, Deutsche Rechtsgeschichte. Bd. 1. 2. Aufl., Berlin 1906 (Nachdruck 1961), 9; ausführlicher ULRICH ANDERMANN, Das Recht im Bild. Vom Nutzen und Erkenntniswert einer historischen Quellengattung, in: ANDREA LOTHER/ULRICH MEIER/NORBERT SCHNITZLER/GERD SCHWERHOFF/GABRIELE SIGNORI (Hrsg.), Mundus in imagine. Festgabe für Klaus Schreiner. München 1996, 421-451; vgl. auch HARTMUT BOOCKMANN, Über den Aussagewert von Bildquellen zur Geschichte des Mittelalters, in: KARL-HEINZ MANEGOLD (Hrsg.), Wissenschaft und Technik. Studien zur Geschichte. Wilhelm Treue zum 60. Geburtstag. München 1969, 29-37; GERNOT KOCHER, Rechtsarchäologie - eine "Nebenquelle" der Rechtsgeschichte, in: MANFRED HAINZMANN/DIETER KRAMER/ERWIN POCHMARSKI (Hrsg.), Mitteilungen der Archaeologischen Gesellschaft Graz 2 (1988), 154-160; GERNOT KOCHER, Rechtsarchäologie, Rechtliche Volkskunde und die Österreichische Rechtsgeschichte, in: HANS CONSTANTIN FAUBNER/GERNOT KOCHER/HELFRIED VALENTINITSCH (Hrsg.), Die Österreichische Rechtsgeschichte. Graz 1991, 193-203; MARTIN LÜKES, Bild und Recht. Zum Aufbau eines Bildarchivs zur Reichskammergerichtsgeschichte. Mitteilungen des Wetzlarer Geschichtsvereins. Wetzlar 1994, 35-55.

37 BLANCK, Buch der Antike (Fn. 23), 102 ff. Reproduktionen bei ANTHONY MELNIKAS, The Corpus of the Miniatures in the Manuscripts of Decretum Gratiani I-III, in: Studia Gratiani 16, 17, 18. Rom 1975. 
verloren hatte. Schon im 3. nachchristlichen Jahrhundert waren Leseund Schreibfähigkeit wieder auf dem Rückzug. ${ }^{38}$ Die Aufzeichnung der Stammesrechte (leges) in fränkischer Zeit (475-802) hatte relative geringe Bedeutung für das praktische Rechtsleben, denn die Kunst des Lesens und Schreibens war nicht allgemein verbreitet und - um in modernen Begriffen $z u$ reden - die Wiedergewinnungsrate war schlecht, da die Rechtsaufzeichnung durch kein Registratur- und Archivwesen abgesichert war. Die leges gerieten spätestens im 11. Jahrhundert in Vergessenheit.

Die Gesellschaft des Mittelalters war eine orale ${ }^{39}$ und als solche, verglichen mit dem klassischen Altertum, geradezu regressiv. Geschrieben und gelesen wurde fast nur noch in den Klöstern. Die politische Elite konnte nicht mehr oder noch nicht lesen, und ein professioneller Juristenstand fehlte. Die Urkunden des frühen Mittelalters waren anfangs nur Besitztitel und Privilegien, die für den Inhalt auf orale Rechtsgewohnheit verwiesen. Für die Praxis blieb die mündliche Überlieferung entscheidend. Die Schrift hatte zunächst nur subsidiären Charakter. Mit Bildern versuchte man, Authentizität und Performanz der Oralität in die Manuskripte hinüberzuretten.

Im 11. und 12. Jahrhundert entwickelten sich außerhalb der Klöster Laienskriptorien, und erst im 13. Jahrhundert begannen Laien für den eigenen Bedarf zu schreiben. Zugleich drang die Volkssprache in alle wichtigen Bereiche der Schriftkommunikation vor ${ }^{40}$ Davon zeugen für das Recht Sachsenspiegel und Schwabenspiegel. Das folgende Jahrhundert wurde zur Epoche der Verschriftlichung der europäischen Kultur. Im 15. Jahrhundert folgte die gewerbliche Produktion von Büchern, zunächst von Manuskripten und in der zweiten Hälfte auch von Drucken. Jetzt erst war der Anschluss an die Antike wieder erreicht. Bis dahin war die Schrift jedoch etwas Minderwertiges, Sekundäres. Wo immer möglich, verliehen ihr Bilder etwas von der Authentizität des Mündlichen.

\footnotetext{
${ }^{38}$ HARRIS, Ancient Literacy (Fn. 23), $312 \mathrm{ff}$.

${ }^{39}$ MiChael CLANCHY, From Memory to Written Record: England 1066-1307. 2. Aufl., Oxford 1993; HeLGa HajDu, Lesen und Schreiben im späten Mittelalter, Verlagsanstalt Danubia. Pècs-Fünfkirchen 1931; BRIAN STOCK, The Implications of Literacy: Written Language and Models of Interpretation in the Eleventh and Twelfth Century. Princeton 1983; HANNAH VOLLRATH, Das Mittelalter in der Typik oraler Gesellschaften, in: Historische Zeitschrift 223 (1981), 571-594.

40 CHRISTA BERTELSMEIER-KIERST, Von der ,vocalité zur schriftgestützten Kommunikation. Zum volkssprachlichen Literalisierungsprozeß (1200-1300), in: HANS-JOCHEN SCHIEWER/ Karl StaCKMaNN (Hrsg.), Die Präsenz des Mittelalters in seinen Handschriften. Tübingen 2002, 49-63. Die Autorin hat die Veröffentlichung einer Habilitationsschrift mit dem Titel "Kommunikation und Herrschaft. Zum Verschriftlichungsprozeß des Rechts im 13. Jahrhundert" angekündigt.
} 


\section{Die jurisprudentia picturata des Mittelalters}

Unter Rechtshistorikern war zu Beginn des 19. Jahrhunderts von der jurisprudentia picturata ${ }^{41}$ oder illustrata (des Mittelalters) die Rede. Man interessierte sich für die Bilder allerdings nur als zusätzliche historische Quelle, und das hat sich bis heue nicht geändert. Als "Nebenquellen" der Rechtsgeschichte werden solche Bilder zusammen mit Gebrauchsgegenständen wie Siegeln, Wappen und Münzen, Straf- und Folterwerkzeugen oder mit Thing- und Richtstätten und öffentlichen Gebäuden, aber meistens nur in der Abteilung „Rechtsarchäologie und rechtliche Volkskunde" behandelt. ${ }^{42}$

Die historische Rechtsikonografie hat heute wieder Konjunktur, so dass man beinahe glauben könnte, in historischer Zeit hätten zum Recht immer auch Bilder gehört. Aber die jurisprudentia picturata des Mittelalters war nur eine Episode. Ohnehin waren die wenigsten juristischen Handschriften illustriert. Nach der Erfindung des Buchdrucks, etwa zeitgleich mit der von Bologna ausgehenden Romanisierung und Professionalisierung der Jurisprudenz, wurden Bilder in juristischen Texten schnell zum bloßen Beiwerk. Soweit in gedruckten Rechtsbüchern überhaupt noch Bilder vorkamen, fehlt die ikonografische Kontinuität zu den mittelalterlichen Bilderhandschriften.

\footnotetext{
${ }^{41}$ Dieser Begriff stammt anscheinend von CHRISTIAN ULRICH GRUPEN, Deutsche Alterthïmer, zur Erleuterung des Sächsischen auch Schwäbischen Land-und Lehn-Rechts, Wobey der Gebrauch der Dreßdenschen, Wolfenbïttelschen, und Oldenburgischen, zum Druck kommenden Codicum Picturatorum durch einige Abbildungen, die das Sächsische Land- und LehnRecht erleutern, unter Augen gestellt werden. Hannover 1746. Der Begriff wurde dann zu Beginn des 19. Jahrhunderts wieder aufgenommen, als das historische Interesse an den mittelalterlichen Bilderhandschriften erwachte; vgl. ERNST P. SPANGENBERG, Beiträge zur Kunde der teutschen Rechtsalterthiimer und Rechtsquellen, enthaltend Mittheilungen aus Dreyer's und Grupen's handschriftlichem Nachlasse und ungedruckte Rechtsquellen des Mittelalters. Mit Kupfern und Steindrïcken. Hannover 1824. Spangenberg gibt ein seinerzeit in der Göttinger Universitätsbibliothek aufbewahrtes Manuskript von JOHANN CARL HEINRICH DREYER mit dem Titel Jurisprudentia Germanorum picturata wieder, das wiederum Bildquellen unter Einschluss von Skulpturen zur Rechtsgeschichte beschreibt. Ferner enthält das Buch fünf Abhandlungen von CHRISTIAN ULRICH GRUPEN, die Texte verschiedener Handschriften und Bilder des Sachsenspiegels vergleichen. Vgl. ferner ULRICH FRIEDRICH KOPP, Bilder und Schriften der Vorzeit. Mannheim 1819. Kopp beschreibt in Abhandlung II, 43-164, die Heidelberger Bilderhandschrift des Sachsenspiegels mit 30 Kupferstichen, davon 26 kolorierten. Weitere Nachweise bei KARL VON AMIRA, Germanisches Recht. 4. Aufl., Berlin 1960, bearbeitet von KARL AUGUST ECKHARDT. Der Ausdruck jurisprudentia picturata ist nicht mehr gebräuchlich, aber auch nicht vergessen, vgl. HEINRICH BRUNNER, Deutsche Rechtsgeschichte. Bd. 1. 2. Aufl., Berlin 1906 (Nachdruck 1961), 11; GERNOT KOCHER, Zeichen und Symbole des Rechts. Eine historische Ikonographie. München 1992, 8.

42 Nachweise in Fn. 36.
} 


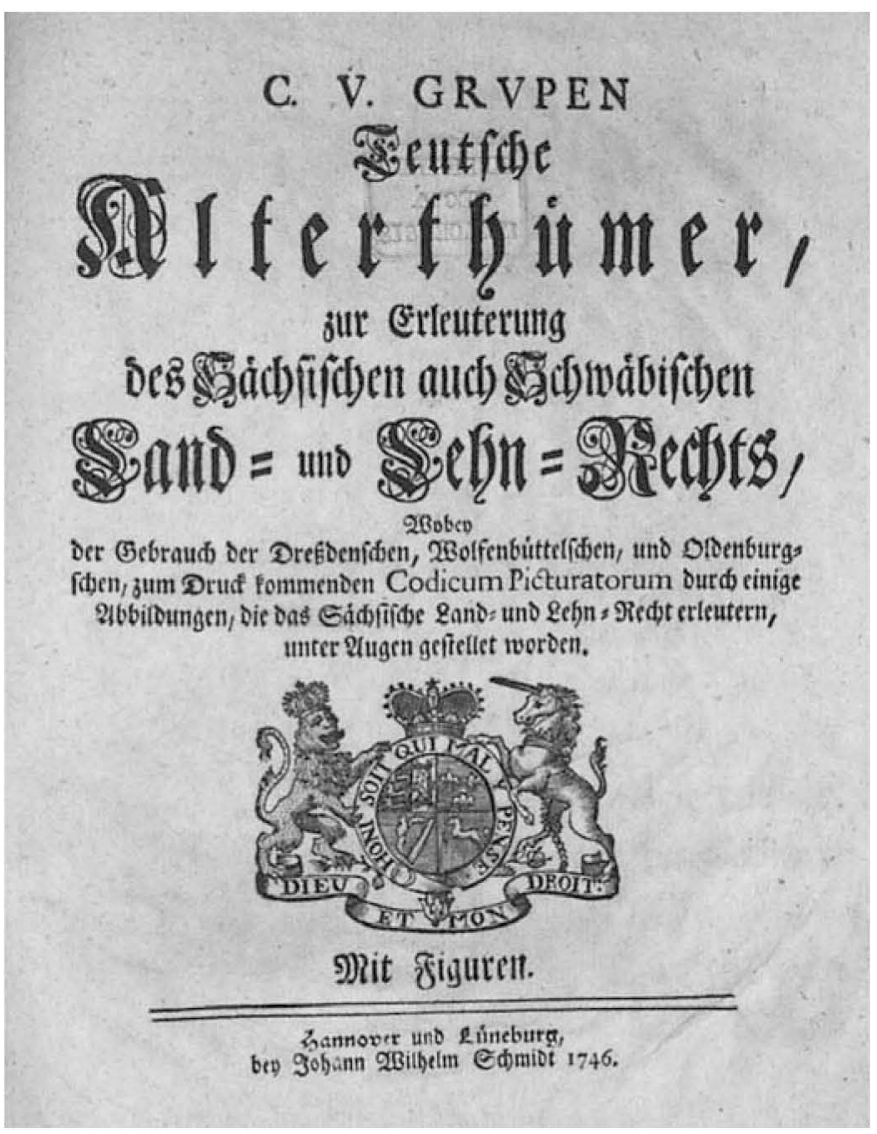

Abb. 1: Mit Christian Ulrich Grupen setzte das historische Interesse an den mittelalterlichen Bilderhandschriften ein. Grupen verwendete anscheinend als Erster den Begriff Codex picturatus (vgl. Fußnote 41).

Das Mittelalter war auf Bilder geradezu versessen. Die illuminierten Handschriften hatten ihren Ursprung in Kirchen und Klöstern. Zunächst wurden vor allem die Bibel, Stundenbücher und Chroniken bebildert. Von dort sprang die Praxis der Illumination auch auf einige Rechtsbücher über. Bilder finden sich in mittelalterlichen Manuskripten des römischen und des kanonischen Rechts. ${ }^{43}$ Prominenter sind die Bil-

\footnotetext{
${ }^{43}$ FRIEDRICH EBEL/ANDREAS FIJAL/GERNOT KOCHER, Römisches Rechtsleben im Mittelalter. Heidelberg 1988; GERNOT KOCHER, Sachsenspiegel, Institutionen, Digesten, Codex Zum Aussagewert mittelalterlicher Rechtsillustrationen, in: RUTH SCHMIDT-WIEGAND (Hrsg.), Text - Bild - Interpretation. Untersuchungen zu den Bilderhandschriften des Sach-
} 
derhandschriften des Herforder Rechtsbuchs (um 1375), ${ }^{44}$ des Soester Nequam-Buchs, gleichfalls aus dem 14. Jahrhundert, und des Hamburger Stadtrechts von 1479.45 Noch lange nach der Verbreitung des Buchdrucks entstand 1504 das Volkacher Salbuch, eine bebilderte Strafprozessordnung. 46 Alle werden sie übertroffen von den Bilderhandschriften des Sachsenspiegels. ${ }^{47}$ Die älteste, die vor 1295 , also etwa 70 Jahre nach der Niederschrift des Textes durch Eike von Repgow, im Bistum Halberstadt entstand, ist verloren gegangen. Sie gilt als Vorbild der vier überlieferten, nämlich der Heidelberger, der Dresdener, der

senspiegels. Band I (Textband). München 1986, 117-128; MELNIKAS, The Corpus of the Miniatures (Fn. 37).

44 THEODOR HELVERT-CORVEY, Rechtsbuch der Stadt Herford. Faksimile-Ausgabe und Kommentarband. Bielefeld 1989.

45 BeAte Binder, Illustriertes Recht. Die Miniaturen des Hamburger Stadtrechts. Hamburg 1988.

${ }^{46}$ WOLFGANG SCHILD, Alte Gerichtsbarkeit: Vom Gottesurteil bis zum Beginn der modernen Rechtsprechung. 2. Aufl., München 1985, 167; MARIO HEINRICH, Zum Volkacher Stadtrecht am Ende des Spätmittelalters und zu Beginn der Neuzeit unter besonderer Berücksichtigung des Salbuches. Dissertation. Würzburg 1980.

${ }^{47}$ Grundlegend KARL VON AMIRA, Die Dresdener Bilderhandschrift des Sachsenspiegels. Bd. I (Faksimile), Leipzig 1902, Neudruck Osnabrück 1968, Bd. II, 1 und 2 (Erläuterungen). Leipzig 1925/26, Neudruck Osnabrück 1969; DeRS., Die Genealogie der Bilderhandschriften des Sachsenspiegels. Abhandlungen der königlich Bayerischen Akademie der Wissenschaften. Bd. XXII, II. Abtheilung. München 1902, 327-385; DERS., Die Bruchstïcke der großen Bilderhandschrift von Wolframs Willehalm. Farbiges Faksimile in zwanzig Tafeln nebst Einleitung. München 1921. Von Amira hat die Annahme begründet, dem verloren gegangenen Original habe „im großen und ganzen als Muster eine viel reich haltigere Bilderhandschrift des Willehalm von Wolfram von Eschenbach gedient". Vgl ferner JULIANUS B. M. VAN HOEK, Zwischen Eike von Repgow und Johann von Buch leuchtet das lehrreiche Bild, in: RUTH SCHMIDT-WIEGAND (Hrsg.), Text - Bild - Interpretation (Fn. 43), 59-76; GERNOT KOCHER, Rechtsillustrationen, in: Forschungen zur Rechtsarchäologie und rechtlichen Volkskunde 3 (1981), 5-34; WALTER KOSCHORRECK, Die Heidelberger Bilderhandschrift des Sachsenspiegels. Faksimile und Kommentar. 2 Bände, Frankfurt am Main 1970; DERS., Eine Bilderhandschrift des Sachsenspiegels, in: Heidelberger Jahrbïcher 15 (1971), 57-72; NORBERT OTT, Vorläufige Bemerkungen zur "Sachsenspiegel"-Ikonographie, in: SCHMIDT-WIEGAND (Hrsg.), Text - Bild - Interpretation (Fn. 43), 33-43; WOLFGANG SCHILD, Nutzen und Wert von Rechtsarchäologie und Rechtsikonographie für die mittelalterliche Rechtsgeschichte, in: PAUL DE WIN (Hrsg.) Rechtsarcheologie en Rechtsiconografie - Rechtsarchäologie und Rechtsikonographie. Akten eines Brüsseler Kolloquiums vom 27. April 1990. Brüssel 1992, 60-74; RUTH SCHMIDTWIEGAND, Die Wolfenbütteler Bilderhandschrift des Sachsenspiegels und ihr Verhältnis zum Text Eikes von Repgow, in: Wolfenbiitteler Hefte 13 (1983); DIES., Text und Bild in den Codices picturati des "Sachsenspiegels". Überlegungen zur Funktion der Illustrationen, in: DIES. (Hrsg.), Text - Bild - Interpretation (Fn. 43), 11-31; DIES., Rechtssprichwörter und ihre Wiedergabe in den Bilderhandschriften des Sachsenspiegels, in: DIES., Text - Bild - Interpretation (Fn. 43), 593-629; DIES., Die Bilderhandschriften und ihre Bedeutung für die Wirkungsgeschichte des Sachsenspiegels, in: HEINER LÜCK (Hrsg.), Recht und Rechtswissenschaft im mitteldeutschen Raum. Symposion für Rolf Lieberwirth. Köln 1998, 9-27. 
Wolfenbütteler und der Oldenburger Bilderhandschrift. Die Wolfenbütteler Handschrift, die vor 1371 angefertigt wurde, ist die jüngste. ${ }^{48}$ Vermutlich gab es noch zwei Zwischenglieder. Die Dresdener ist mit 924 Bildstreifen ${ }^{49}$ die reichhaltigste. Bereits diese Genealogie deutet darauf hin, dass es sich bei den Sachsenspiegelhandschriften um Solitäre aus einer einzigen Familie handelt. Tatsächlich haben sie unter den etwa 460 bekannten Handschriften des Sachsenspiegels eine Ausnahmestellung.

Die Prominenz, zu der die Bilderhandschriften des Sachenspiegels gelangt sind, lässt leicht vergessen, dass die große Mehrzahl der mittelalterlichen Rechtsbücher bilderlos war. Oppitz hat 1673 Handschriften von mittelalterlichen Rechtsbüchern erfasst. Davon enthalten 373 Buchschmuck. Ganz überwiegend handelt es sich nur um Zierinitialen, Wappen und vereinzelte Miniaturen. Etwas häufiger kommen isolierte Kaiserbilder und Weltgerichtsbilder ${ }^{50}$ vor. Zehn Mal notiert Oppitz einen Verwandtschaftsbaum. ${ }^{51}$ Von den letzteren abgesehen sind die Illustrationen nicht direkt auf den Text bezogen. Es handelt sich in der Tat um bloßen Buchschmuck.

Durchgängig illustriert war außer den vier bekannten Handschriften des Sachsenspiegels und ihren drei verlorenen Vorläufern anscheinend nur die wegen ihres Aufbewahrungsorts sogenannte Brüsseler Handschrift des Schwabenspiegels. Immerhin kennt man noch fünfzehn weitere Handschriften des Schwabenspiegels, die einzelne auf den Rechtstext bezogene Illustrationen aufweisen. ${ }^{22}$ Eine Sonderstellung nimmt der Belial des Jacobus de Theramo ein, ein Bestseller des 15. Jahrhunderts. Von den mehr als 80 deutschen Handschriften waren 19 illustriert. Einige weitere zeigen Lücken für vorgesehene Federzeichnungen. ${ }^{53}$

${ }^{48}$ DAGMAR HÜPPER, Funktionstypen der Bilder in den Codices picturati des Sachsenspiegels, in: Hagen Keller/Klaus Grubmüller/Nikolaus Staubach (Hrsg.), Pragmatische Schriftlichkeit im Mittelalter. München 1992, 231-249, 233.

49 Eine neue Faksimile-Ausgabe, herausgegeben von HEINER LÜCK, ist 2002 bei der Akademischen Druck- und Verlagsanstalt Graz erschienen. Einige qualitätvolle Bilder finden sich unter http://www.tu-dresden.de/slub/proj/sachsenspiegel/sachs.html\#faks.

${ }^{50}$ TROESCHER, Weltgerichtsbilder (wie Fn. 5), $155 \mathrm{f}$.

${ }^{51}$ Diese Zahl liegt sicher zu niedrig. Der Kunsthistoriker HERMANN SCHADT hat 650 Beispiele aus 450 juristischen Handschriften gesammelt (Die Darstellungen der Arbores Consanguinitatis und der Arbores Affinitatis: Bildschemata in juristischen Handschriften. Wasmuth 1982).

52 HARALD RAINER DERSCHKA, Der Schwabenspiegel. Übertragen in heutiges Deutsch mit Illustrationen aus alten Handschriften. München 2002, 309.

${ }^{53}$ NORBERT H. OTT, Rechtspraxis und Heilsgeschichte. Zur Überlieferung, Ikonographie und Gebrauchssituation des deutschen „Belial". München 1983, 193. 


\section{Vom Manuskript zum Druck}

Im 15. Jahrhundert entwickelte sich die serienmäßige Herstellung von Manuskripten zum städtischen Gewerbe, in dem sich Schreiber und Illustratoren die Arbeit teilten. Namentlich bekannt ist etwa die Werkstatt Diebold Laubers aus Hagenau im Elsass, ${ }^{54}$ aus der die Brüsseler Handschrift des Schwabenspiegels und eine Handschrift des Belial stammen. Im Zuge der Kommerzialisierung wurde das Lateinische weiter durch die Volkssprache ersetzt. Insoweit waren die Sachsenspiegelhandschriften ihrer Zeit voraus. An die Stelle des Pergaments trat das billigere Papier. Als Illustrationstechnik löste die mehr oder weniger kolorierte Federzeichnung die in Deckfarben gearbeiteten Miniaturen mit Goldgrund und Rahmung ab. Die neue Technik zeigte sich alsbald routiniert, aber vergleichsweise kunstlos. Damit änderte sich auch das Verhältnis von Text und Bild, denn die flüchtige Federzeichnung konnte sich leichter dem Text anpassen. Auch diese Möglichkeit hatten die Bilderhandschriften des Sachsenspiegels schon hundert Jahre vorher ausgeschöpft.

Die mechanische Vervielfältigung von Bildern ging dem Schriftdruck voraus; sie zog ihn gleichsam nach sich. Etwa um 1400 wurde der Holzschnitt erfunden. ${ }^{55}$ Der Kupferstich folgte in der zweiten Hälfte des 15. Jahrhunderts. Der Holzschnitt gestattete erstmals die Vervielfältigung von Bildern in größerer Auflage. ${ }^{56}$ Er diente zunächst zur Herstellung von Andachtsbildern, Flugblättern und anderer Gebrauchsgrafik, bevor er in den Buchdruck Eingang fand. Holzschnitte boten sich zur Kombination mit dem Typendruck an, weil es sich bei beiden um ein Hochdruckverfahren handelt. Die Schnitte konnten mit den Lettern auf einer Platte zusammengestellt und in einem Arbeitsgang gedruckt werden. Kupferstiche waren nicht nur selbst in der Herstellung aufwändiger, sondern forderten auch einen zweiten Druckvorgang mit einer anderen Presse. Erst seit der Mitte des 16. Jahrhunderts verdrängten sie nach und nach den Holzschnitt aus der Buchillustration.

\footnotetext{
${ }^{54}$ WERNER FECHTER, Der Kundenkreis des Diebold Lauber, in: Zentralblatt fiur Bibliothekswesen 55 (1938), 121-146; RUDOLF KAUTZSCH, Diebolt Lauber und seine Werkstatt in Hagenau, in: Zentralblatt fuir Bibliothekswesen XII (1895), 1-32 und 57-113.

${ }^{55}$ HANS KORNER, Der früheste deutsche Einblattholzschnitt. Mittenwald 1979.

${ }^{56}$ Zur Entwicklung der Druckmedien vgl. etwa RENÉ HIRNER/KUNSTMUSELM HILDESHEIM, Vom Holzschnitt zum Internet. Die Kunst und die Geschichte der Bildmedien von 1450 bis heute. Ostfildern-Ruit 1997; HARRY ROBIN, Die wissenschaftliche Illustration. Von der Höhlenmalerei zur Computergraphik. Basel 1992 (Original: The Scientific Image: From Cave To Computer. New York 1992); BEAT WYSS, Die Welt als T-Shirt. Zur Ästhetik und Geschichte der Medien. Köln 1997.
} 
Ein neues Medium imitiert anfangs die Formensprache seines Vorgängers, bevor es eine eigene Gestalt entwickelt. ${ }^{57}$ Gutenberg hat größte Sorgfalt darauf verwandt, im Druck das Schriftbild der Manuskripte nachzuahmen. Um Randausgleich und gleichmäßige Wortabstände zu erreichen, benutzte er unterschiedlich geschnittene Buchstaben, Ligaturen und Abbreviaturen. Doch die Nachahmung beschränkte sich nicht auf die Kalligrafie. Ebenso wie in den Handschriften wurde der Buchschmuck nachträglich durch Rubrikatoren und Miniatoren eingebracht. Ein Beispiel gibt die Ausgabe des Decretum Gratiani von Peter Schöffer in Mainz von 1472. Sie ist auf Pergament gedruckt und mit Rubriken, zahlreichen farbig ausgearbeiteten Schmuckinitialen und 38 den Text illustrierenden Miniaturen versehen. Die ganze Ausstattung folgt so sehr dem Vorbild der Prachthandschriften, dass Schöffer in der Schlussschrift (Kolophon) stolz erklären konnte, er habe das Buch nicht mit Tintenfeder oder Schreibrohr, sondern durch die großartige Kunst des Druckens vollendet (,arte quadam ingeniosa imprimendi“). ${ }^{58}$ Doch es lag in der Natur der Sache, dass die Drucker alsbald auch die nachträgliche manuelle Ausstattung der Bücher ersetzten. Als Erster verband wohl ab 1461 Albrecht Pfister in Bamberg Typendruck und Holzschnitt. 59

Zeitweise liefen die Produktion von Manuskripten und der Buchdruck nebeneinander her. Auch im Buchdruck wurde das teure Pergament durch das billigere Papier abgelöst. Damit verschwanden auch dort die Deckfarben und das Gold. In der Folge entstanden die Bilder zunächst aus Umrissholzschnitten, die auf nachträgliche Kolorierung angelegt waren. Sie ähnelten damit stärker der getuschten Federzeichnung als der Deckfarbenminiatur. Doch schon vor der Wende zum 16. Jahrhundert befreite sich der Buchdruck endgültig von der Handschrift als seinem ästhetischen Vorbild. Mit einer neuen, einheitlicheren Typografie gewann das gedruckte Buch ein eigenes Gesicht. Gleichzeitig wandelte sich der Stil des Holzschnitts. Schon im letzten Jahrzehnt des 15. Jahrhunderts hatten die Holzschnitte allmählich ihre frühere Steifheit und Rohheit verloren, und sie gewannen durch einfache Schattenstriche auch schon eine gewisse Tiefe. Das erste Viertel des 16. Jahrhunderts wurde dann

${ }^{57}$ Zum Weg von der Nachahmung der Handschriften zur Verselbständigung des gedruckten Buches ausführlich FERDINAND GELDNER, Inkunabelkunde. Wiesbaden 1978, $67 \mathrm{ff}$.

58 WINOLD VOGT, Arte quadam ingeniosa imprimendi. Sechzehn frïhe Drucke aus der Bayerischen Staatsbibliothek. Hannover 1991. Fast gleichlautend schon das Kolophon zu einem 1457 von JOHANN FUST und PETER SCHOFFER gedruckten Psalterium (GELDNER, Inkunabelkunde (Fn. 57), 92).

${ }^{59}$ GELDNER, Inkunabelkunde (Fn. 57), 78. Zur Entwicklung der Buchillustration RICHARD MUTHER, Die Deutsche Buchillustration der Gothik und Friihrenaissance (1460-1530). 2 Bände. München 1922 
zur Blütezeit des Holzschnitts und der Buchillustration. Binnen weniger Jahre hatten Albrecht Dürer (1471-1528) und andere Zeichner und Formschneider die Holzschnitt-Technik zu einem künstlerischen Ausdrucksmittel entwickelt. Augsburg, Nürnberg und Basel wurden zu Zentren des kunstreichen Buchholzschnitts. Schraffuren und Strichlagen, die Licht und Schatten andeuten, verhalfen dem Bild zu einer Plastizität, die eine Kolorierung ersetzte. Der unkolorierte Holzschnitt blieb nicht länger bloß defizitärer Buchschmuck, sondern er wurde als Schwarz-Weiß-Bild zu einem neuen Medium.

In der ersten Hälfte des 16. Jahrhunderts änderte sich die Gestaltung des Titelblatts. Das Impressum, das in den Handschriften am Schluss, im sogenannten Kolophon, zu finden war, rückte an den Anfang. Mit Angaben über Verfasser, Titel und Drucker diente es der Information des Kaufinteressenten. Zunehmend wurden auf dem Titel auch Verzierungen oder thematisch einschlägige Bilder zu Werbezwecken eingesetzt. ${ }^{50}$ Der Drucker brachte fast ausnahmslos auch seine in Holz geschnittene Druckermarke an. Es wurde üblich, von bekannteren Autoren zu Werbezwecken ein Porträt in die Titelei aufzunehmen. ${ }^{61}$

Der Holzschnitt als Mittel der Buchillustration behielt seine Dominanz bei der Buchillustration nur bis zur Mitte des 16. Jahrhunderts. Danach verwendete man für anspruchsvollere Bilder mehr und mehr den Kupferstich, den als künstlerische Technik gleichfalls schon Dürer zur höchsten Vollendung gebracht hatte. Der Holzschnitt behauptete sich nur noch bei der Illustration populärer Massenware. Elitärere Bücher, die nicht auf Illustrationen angewiesen waren, verzichteten auf Textillustrationen und erhielten nur noch dekorative Titelkupfer und Autorenporträts.

\section{Das Buch der Renaissance}

Die Konsequenzen der Literalität kamen erst mit der Erfindung Gutenbergs voll zur Geltung. ${ }^{62}$ Text-Bücher wurden zum Symbol des Rechts. Im Deutschen spricht man bezeichnenderweise vom Buchstaben des

${ }^{60}$ KUNZE, Geschichte der Buchillustration (Fn. 31), 56.

61 Ebd., 57.

${ }^{62}$ HAvelock, Preface to Plato (Fn. 7), 71; Olson, From Utterance to Text (Fn. 29), $268 \mathrm{f}$. $\mathrm{Zu}$ den Folgen des Buchdrucks ausführlicher ELIZABETH L. EISENSTEIN, Die Druckerpresse. Kulturrevolutionen im friihen modernen Europa. Wien 1997 (Original: The Printing Revolution in Early Modern Europe. Cambridge 1983); MICHAEL GIESECKE, Der Buchdruck in der friihen Neuzeit: Eine historische Fallstudie über die Durchsetzung neuer Informationsund Kommunikationstechnologien. Frankfurt am Main 1991; MCLuHAN, Die GutenbergGalaxis (Fn. 14). Eine wertvolle Bibliographie zur historischen Buchwissenschaft hat URSULA RAUTENBERG zusammengestellit (http://www.phil.uni-rlangende/ p1bbk/Mate rialien/vorlhand.html). 
Gesetzes, vom Gesetzbuch oder von juristischem Schrifttum, im Englischen von law books, black letter law ${ }^{63}$ oder legal writing. Doch es war nicht erst die Drucktechnik, welche die Bilder aus der Jurisprudenz und den Geisteswissenschaften vertrieben hatte. In anderen kulturellen Bereichen erfuhren Bilder durch die Drucktechnik sogar eine neue Blüte. Das gilt für Kunst und Handwerk ebenso wie für Medizin, Naturwissenschaft und Technik. Eine fehlerfreie Bildkopie ist von Hand viel schwerer zu bewerkstelligen als die Abschrift eines Textes. Holzschnitt und Kupferstich in Verbindung mit der Drucktechnik boten die Möglichkeit zur massenhaften Vervielfältigung von Bildern. ${ }^{64}$ Nun fiel eher der zweite "technische" Nachteil der Bilder ins Gewicht, nämlich die im Vergleich zum Text schwierigere Herstellung. Überall dort, wo die Sache keine instruktiven Bilder erforderte, die den Aufwand rechtfertigten, war die Schrift im Vorteil.

Es mag zutreffen, dass Alphabetisierung und Buchdruck mit der spontanen Rede auch die nonverbalen Kommunikationsmittel, Gesten, Töne, aber auch Geruch, Geschmack und Berührung, verdrängt und sozial entwertet haben. ${ }^{65}$ Das gilt jedoch nicht in gleicher Weise für das artifizielle Bild. Deshalb wendet sich Elizabeth Eisenstein gegen die Vorstellung einer "Bewegung vom Bild zum Wort". Der Buchdruck habe im Gegenteil „eine Vermehrung des Anschauungsmaterials, eine Kodifizierung von Zeichen und Symbolen und eine rasche Entwicklung verschiedener Formen ikonografischer und nichtphonetischer Kommunikation" gebracht. Dürers Karriere zeige, dass Buchdruck, Holzschnitt und Kupferstich die künstlerischen Möglichkeiten eher erweitert hätten. Die imaginären Bilder der rhetorischen Mnemotechnik hätten den Inhalt für prächtige Emblembücher und für kunstvolle barocke Illustrationen geliefert und als neues Genre gedruckter Literatur das didaktische Bilderbuch für Kinder inspiriert. Grundlegende antike Texte von Ptolemäus, Vitruvius, Galenus und anderen hätten die im Laufe der Jahrhunderte durch wiederholte Handkopien verlorenen Illustrationen durch den Buchdruck zurückgewonnen. ${ }^{66}$ Vor allem entstand in Abkehr von mittelalterlichen Traditionen die moderne beschreibende und realistisch illustrierte Fachliteratur. Giesecke sieht darin eine der großen informationstechnischen

\footnotetext{
63 Black letter ist eigentlich der englische Name für das im 15. Jahrhundert verwendete gotische Typenalphabet Textura. Mit dieser der strengen gotischen Prunkschrift des späten Mittelalters nachgebildeten Type war die 42zeilige Gutenberg-Bibel gedruckt worden (GELDNER, Inkunabelkunde (Fn. 57), 57).

${ }^{64}$ William M. IVINS, JR., Prints and Visual Communication. 8. Aufl., Cambridge (Mass.) 1992.

${ }^{65}$ Das betont HiBBITTS, Comining to our Senses (Fn. 11), 882 f. gegen M. ETHAN KaTSH, The Electronic Media and the Transformation of Law. New York 1989.

${ }^{66}$ GIESECKE, Der Buchdruck in der frühen Neuzeit (Fn. 62), $34 \mathrm{ff}$.
} 
Neuerungen des 16. Jahrhunderts. ${ }^{67}$ Die Geisteswissenschaften und in ihrer Mitte das Recht blieben von dieser Entwicklung jedoch ausgenommen. Sie waren auf die Bilder nicht angewiesen.

Eine neue bilderlose Buchtradition wuchs mit der Renaissance in Italien. Sie nahm ihren Anfang in der ersten Hälfte des 15. Jahrhunderts in den handschriftlichen Kopien klassischer lateinischer Texte. In der zweiten Hälfte des Jahrhunderts folgte der Buchdruck. Die großen Rechtsbücher wurden nicht in Bologna gedruckt, sondern in Venedig und später in Lyon. In Venedig erwarb der deutsche Drucker Nicholaus Jenson Ruhm mit juristischen Werken: 1473 druckte er die Dekretalen von Alexander Nevo, 1474 das Gratianische Dekret, 1475 die Dekretalen von Gregor IX. und 1476/77 eine der ersten Druckausgaben des Corpus Juris.

Das wissenschaftliche Buch der Renaissance erhielt sein Gesicht durch den berühmtesten Drucker, Verleger und Herausgeber seiner Zeit, den Venetianer Aldus Manutius (1452-1516). ${ }^{68}$ Zwischen 1494 und 1515 produzierte Aldus 134 Bücher, in der Mehrzahl Erstausgaben lateinischer und griechischer Klassiker, darunter die editio princeps des Aristoteles. Seinen Ruhm begründete er durch die Qualität der verlegten Texte und die makellose Typografie, die auf alles Ornamentale verzichtete, dennoch aber durch neu geschnittene Typen eine Ästhetik erreichte, die bis heute als vorbildlich gilt. Die mittelalterliche gotische Schrift wurde nun endgültig durch die römische Antiqua verdrängt. ${ }^{69}$ Aldus und mit ihm die meisten Humanisten standen der Illustration ihrer Bücher eher ablehnend gegenüber. Allenfalls ihr eigenes Porträt oder das Bild eines fürstlichen Gönners wurden akzeptiert. ${ }^{70}$

Das Buch, in dem der Text von Bildern begleitet wurde, die sich auf den Text bezogen, war ein mittelalterliches Konzept. Es wurde von der humanistischen Tradition der Renaissance nicht übernommen. Die Schrift hatte sich inzwischen so durchgesetzt, dass sie nicht länger einer Beglaubigung durch Bilder bedurfte. Das humanistische Buch wandte sich in Latein an diejenigen, die mit der Sprache auch das Lesen und Schreiben beherrschten. Bilder gab es nur noch in volkssprachlichen Büchern. Bilder zur Illustration des Textes hätten die lateinkundigen Humanisten der Renaissance mit Illiteralität assoziiert. ${ }^{71}$ Die Bildabstinenz war aber auch durch eine theoretische Abwertung des Bildes be-

${ }^{67}$ GIESECKE, Der Buchdruck in der frühen Neuzeit (Fn. 62), 342, 628.

${ }^{68}$ MARTIN LOWRY, The World of Aldus Manutius: Business and Scholarship in Renaissance Venice. Oxford 1979.

${ }^{69}$ Zur Vielfalt der verwendeten Drucktypen etwas näher KASPERS/SCHMIDT-THOMÉ/ GERIG/MANSTETTEN, Vom Sachsenspiegel zum Code Napoleon (Fn. 6), 259 f.

${ }^{70} \mathrm{KUNZE}$, Geschichte der Buchillustration (Fn. 31), 247.

${ }^{71}$ ERnST PH. GoldsChMidT, The Printed Book of the Renaissance. 2. Aufl., Amsterdam 1966, 50. 
gründet, die mit der Kunsttheorie ihrer Zeit zusammenhing. Ihr Vorbild war die Einordnung des Bilderwesens in der Antike. Dort zählten die bildenden Künste zu den artes mecanicae, die sich den artes liberales unterordnen mussten, die im Altertum nur den Freien, nicht den Sklaven zugänglich waren. ${ }^{72}$

Die Bildabstinenz der Renaissance beschränkte sich jedoch auf die Geisteswissenschaften in der Tradition der artes liberales. Es entstand in dieser Zeit sogar der neue Buchtyp des Bildbandes, indem die Schrift zur Nebensache wird und nur noch der Erläuterung der Bilder dient. ${ }^{73}$ Die Bücher Dürers, in denen die Bilder nicht mehr als Pendant zum Text, sondern um ihrer selbst Willen gezeigt wurden, beweisen, dass der Humanismus nicht per se bilderfeindlich war. Den besten Beleg dafür lieferte der italienische Rechtsgelehrte Andreas Alciatus, Herausgeber bilderloser Ausgaben des Corpus Juris, ${ }^{74}$ der mit seinem 1531 in Augsburg gedruckten Emblematum Liber - in Anknüpfung an die RenaissanceHieroglyphik ${ }^{75}$ - einer alsbald beliebten und verbreiteten Richtung der Bildkunst den Namen gab. ${ }^{76}$ Vor allem aber die technisch und naturwissenschaftlich orientierte Literatur - Medizin, Botanik, Geografie, Architektur - machte von den technischen Möglichkeiten der Buchillustration reichlich Gebrauch.

\section{Visuelle Darstellungen in der humanistischen Jurisprudenz}

\section{Die ramistische Klammertechnik}

Aus der italienischen Renaissance wuchs die humanistische Jurisprudenz. ${ }^{77}$ Sie konzentrierte sich mit philologischen Methoden auf den

\footnotetext{
72 KUNZE, Geschichte der Buchillustration (Fn. 31), 249; SCHUCK-WERSIG, Expeditionen zum Bild (Fn. 30), 136, 140.

${ }^{73}$ GOLDSCHMIDT, The Printed Book of the Renaissance (Fn. 71), 27.

${ }^{74}$ Dazu ausführlich HANS ERICH TROJE, Graeca Leguntur. Die Aneignung des byzantinischen Rechts und die Entstehung eines humanistischen Corpus juris civilis in der Jurisprudenz des 16. Jahrhunderts. Köln 1971, 217 ff.

75 DIETRICH WALTER JÖNS, Das „Sinnen-Bild”. Stuttgart 1966, 4 ff.

${ }^{76}$ ALCIAT im Internet: http://www.mun.ca/alciato.

77 Dazu TROJE, Graeca Leguntur (Fn. 74); DERS., Die Literatur des Gemeinen Rechts unter dem Einfluss des Humanismus, in: HeLmUT COING (Hrsg), Handbuch der Quellen und Literatur der neueren Europäischen Privatrechtsgeschichte. Bd. Il/1. München 1977, 615-795.
} 
Text. Als visuelle Hilfen akzeptierte sie nur tabellarische Darstellungen und logische Bilder, insbesondere Baumstrukturen (arbores)..$^{78}$

Die tabellarische Darstellung war ein spezifisches Kennzeichen der ramistischen Methode, die im 16. Jahrhundert auch unter Deutschlands Juristen sehr beliebt war. ${ }^{79}$ Das Gleiche gilt für die Klammertechnik, bei der es sich der Sache nach um eine in die Horizontale gedrehte Baumstruktur handelt. Mit Klammern gebildete tabulae waren schon vor Ramus bekannt, gewannen durch diesen jedoch an Bedeutung. ${ }^{.0}$ Das klassische Beispiel gibt die Synopsis Juris Civilis von Giulio Pace. ${ }^{81}$ Das Buch enthält auf insgesamt 102 Seiten 45 überwiegend ganzseitige Klammertabellen. Da die Qualität des von der Universitätsbibliothek München gelieferten Microfiches nicht ausreicht, zeigt Abbildung 2 eine eigene Aufnahme einer solchen Klammertabelle von Freigius.

Stärker noch als Schrift organisieren Tabellen ihr Material linear und klassifizieren es bevorzugt in Gegensatzpaaren (Dichotomien) und Hierarchien. Jack Goody hat analysiert, wie die Verwendung von Tabellen durch Ethnologen zur Ordnung und Klassifizierung ihrer Beobachtungen dazu führen kann, dass die Realität oraler Kommunikation bis zur Unkenntlichkeit verändert wird, so dass die tabellarische Anordnung das Verständnis eher erschwert als erleichtert. ${ }^{82}$ Es ist kein Zufall, dass Walter J. Ong, bevor er sich allgemeiner mit dem Verhältnis von Oralität und Literalität befasste, ${ }^{83}$ Petrus Ramus (1515-1572) ein Buch gewidmet hat. ${ }^{84}$

\footnotetext{
${ }^{78}$ Karl Heinz BuRMEISTER, Das Studium der Rechte im Zeitalter des Humanismus im deutschen Rechtsbereich. Wiesbaden 1974, 84, 230. Schaubilder von Personen, Sachen, Obligationen und actiones sind als Falttafeln in die Arbeit von FRANZ FROSCH eingeheftet (Isagoge in juris civilis studium, in: Varia opuscula de exercitatione iurisconsultorum, herausgegeben von JOHANNES WINKEL, Straßburg 1554). Auch SEBASTIAN DERRER ( 1583) soll solche Bilder verwendet haben (RODERICH STINTZING, Geschichte der populären Literatur des römisch-kanonischen Rechts in Deutschland am Ende des fiunfzehnten und im Anfang des sechzehnten Jahrhunderts. Leipzig 1867, 256 ff.). Ich habe allerdings nur in DERRERS Jurisprudentia liber primus von 1544 ein bebildertes Titelblatt gefunden. Es bietet mit elf in einen Torbogen hineinkomponierten Einzelbildern ein Universum der Jurisprudenz mit der Subscriptio „Unde, quid \& quo Jus clauditur limite, dictu Difficile: at ypạivws ecce Tabella docet."; also etwa: Woher das Recht kommt, was es ist, und wo seine Grenzen liegen, lässt sich schwer sagen. Die Tabelle zeigt es mit grafischen Mitteln.

${ }^{79}$ STINTZING, Geschichte der populären Literatur des römisch-kanonischen Rechts (Fn. 78), $144 \mathrm{ff}$.

${ }^{80}$ TrOJE, Graeca Leguntur (Fn. 74), 178.

${ }^{81}$ GULIO PACE, Synopsis Juris Civilis. Lugdano 1588.

${ }^{82}$ GOODY, The Domestication of the Savage Mind (Fn. 16), $52 \mathrm{ff}$

${ }^{83}$ ONG, Orality and Literacy (Fn. 17).

84 WALTER J. ONG, Ramus, Method and the Decay of the Dialogue. New York 1974.
} 




Abb. 2: Klammertabelle aus Thomas Freigius, De perfecto Jurisconsulto, 1589

Ramus war nach dem Urteil von Yates der "prominenteste oder in der Selbstdarstellung geschickteste“ pädagogische Reformer im sechzehnten Jahrhundert. ${ }^{85}$ Ramus setzte an die Stelle der Gedächtniskunst der Örter und Bilder eine "dialektische" Ordnung, heute würden wir sagen, ein deduktives System. Durch Gliedern und Zusammenfassen des Stoffes sollten die emotional eindrucksvollen, das Gedächtnis stimulierenden Bilder durch eine der Vernunftnatur des Gedächtnisses entsprechende Ordnung abgelöst werden. Ramus, selbst Protestant, habe damit, so meint jedenfalls Yates, ${ }^{86}$ den protestantischen Bildersturm durch eine Art ,inneren Ikonoklasmus" fortgesetzt.

\footnotetext{
85 FRANCES A. YATES, Gedächtnis und Erinnern. Mnemonik von Aristoteles bis Shakespeare. 3. Aufl., Berlin 1994, 214 (Original: The Art of Memory. London 1966).

86 YATES, Gedächtnis und Erinnern (Fn. 85), 217.
} 
Mit seiner Methode wollte Ramus ein universelles Werkzeug für alle Materien der Wissenschaft anbieten. Dazu soll jedes Thema vom Allgemeinen zum Besonderen hin entwickelt werden. Praktisch sind zu diesem Zweck zunächst Definitionen zu bilden. Sodann ist der Gegenstand zweifach zu unterteilen und danach jede Unterteilung erneut zu dichotomisieren, und so fort, bis am Ende das Thema in einer Kaskade von Dichotomien erschöpft ist. Der grundlegende Unterschied zur Methode der Scholastik besteht darin, dass nicht länger nach einem ersten Prinzip gesucht wird, das die Wissenschaftlichkeit der folgenden Differenzierungen garantiert. Alles und jedes kann jetzt zum Ausgangspunkt einer wissenschaftlichen Untersuchung genommen werden. Das zeigt sich visuell im Übergang von der scholastischen Baumstruktur zur Klammertechnik. Als Graphen, also rein logisch betrachtet, sind Baumstruktur und Klammern gleichwertig. Aber die Metapher des Baumes hatte auch inhaltliche Bedeutung. Der Baum wächst aus einem Grundprinzip, aus einer gesunden Wurzel. Der Begriff, der vor der ersten Klammer steht, kann dagegen willkürlich gewählt werden. Die waagerechte Anordnung der Klammern vermeidet auch die Suggestion einer natürlichen Hierarchie, die von der Baumstruktur ausgeht.

Ramus wurde in Deutschland vor allem durch den Freiburger Pädagogen und Juristen Johann Thomas Freigius (1543-1583) bekannt gemacht, ${ }^{87}$ der von der Mathematik zur Jurisprudenz gekommen war; 88

\footnotetext{
87 JOHANn ThOMas Freigius, P. Rami Professio regia. Basel 1566; Ders., P. Rami dialecticae institutiones - Item Aristotelicae animadversiones: a prima aeditione nuspiam hac methodo visae - Tam pridem a pos postliminio revocatae - atque in lucem editae opera Joan. Thom. Basel 1575; DERS., P. Rami Professio regia, hoc est Septem artes liberales in Regia cathedra/per ipsum Parisiis apodicta docendi genere propositae, et per loan. Freigium in tabulas ... rel. ... editae. Basel 1576.

${ }^{88}$ RODERICH STINTZING, Geschichte der Deutschen Rechtswissenschaft. Erste Abtheilung. München, Leipzig 1880, 300, 440-449. Von FREIGIUS habe ich in der Anna-Amalia-Bibliothek in Weimar die folgenden juristischen Bücher gefunden: Methodica actionum juris repetitio ... / Cum praefatione Joannis Tho. Basel 1569; Thomae Freigi Partitiones Juris Utriusque Hoc est, Omnium Juris Tam Civilis Quam Canonici Materiarum, In Tabulas ... digestio ... Basel 1571; Neiiwe Practica Juris und Formulen oder Concepten allerley, in zwen theil abgetheilet. Auß welchen der erst in sich begreifft der Practick, so im Rechten gebreiichlich ... Basel 1574; Joannis Thomae Freigii Quaestiones Justinianeae in Institutiones juris Civilis. Basel 1578, Nachdruck 1591; Joan Thomae Freigii Partitiones juris utriusque, hoc est: omnium juris tam civilis quam canonici materiarum, in tabulas apta et illustris digestio ... Basel 1581; Joan Thom. Freigii de logica jureconsultorum libri duo. Basel 1582, editio postrema 1590; Cheiragogia, Sive Cynosura Juris. Speier 1588, mit Appendix von 1589: De perfecto Jurisconsulto: itemque de claris iurisperitis Italiae, Galliae, Germaniae; Jo. Thomae Freigii Idea Boni Et Perfecti Jurisconsulti, 1589]. Ferner hat er sich als Herausgeber betätigt: ZASIUS JOAN. ThOMAE FreIGII, Hoc Est: In Pandectas Juris Civilis Commentarii: $\grave{A}$... Uldarico Zasio Olim Diffusé Tractati: Nunc veró: Secundum leges Methodicas in compendium redacti ... Basel 1576.
} 
Freigius edierte Arbeiten des Ramus und schrieb dessen Biografie. ${ }^{89}$ Bei Freigius, den Troje "nur dem Mittelfeld humanistischer Juristen“ zurechnet, ${ }^{90}$ kommen sich der bilderlose Protestantismus und die Jurisprudenz wohl am nächsten. Indessen war die Bilderlosigkeit schon längst viel breiter in der humanistischen Art des Umgangs mit Texten angelegt.

\section{Arbores Juris ${ }^{91}$ und andere Bildschemata}

Schematische Darstellungen (stemmata), die wir heute als logische Bilder einordnen, haben in der Jurisprudenz eine lange Tradition. Es gab sie schon in vorjustinianischer Zeit. In den Institutionen (3. 6. 9.92) werden sie besonders erwähnt. Praktisch ging es dabei um Verwandtschaftstafeln für erbrechtliche Zwecke. In der großen Mehrzahl der Handschriften handelte es sich um einfache Strichzeichnungen ohne ornamentalen oder figuralen Schmuck. ${ }^{93}$ In mittelalterlichen Handschriften wurden diese Graphen mehr und mehr mit Ornamenten und Figuren ausgestaltet und darüber hinaus zu einem Gesamtbild geformt. Das römische Recht benutzte zur Darstellung von Verwandtschaftsverhältnissen architektonische oder geometrische Bilder, insbesondere das Bild eines Hauses oder einer abgestumpften Pyramide. ${ }^{44}$ Geläufig war aber auch die Darstellung in Gestalt einer Fahne (vexillum). Nicht ganz selten wurden die Zellen oder Knoten in einen menschlichen Körper hineingezeichnet. Schon die abstrakte Dreiecksform der Pyramide erinnert an einen Baum. So trat seit Isidor von Sevilla (um 570-636) das Bild des Baumes in

${ }^{89}$ Petri Rami Vita von FreIgIUS ist zusammen mit den Praelectiones in Ciceronis Orationes octo consulares von PETRUS RAMUS zuerst 1575 bei Petrus Perna in Basel erschienen und dort 1580 und bei Egenolph in Marburg 1599 nachgedruckt worden. Ein Reprografischer Nachdruck, herausgegeben von WALTER J. ONG, ist 1969 bei Olms in Hildesheim erschienen. Der Band enthält am Ende auch die Vita Petri Rami von Freigius.

90 TROJE, Die Literatur des Gemeinen Rechts (Fn. 77), 641; etwas näher zu Freigius und zum Ramismus ebd., $733 \mathrm{ff}$.

${ }^{91}$ Im Juristendeutsch wurde die arbor juris zeitweise als Maskulinum behandelt. Heute wird wieder die grammatisch richtige weibliche Form benutzt (vgl. SCHADT, Die Darstellungen der Arbores Consanguinitatis (Fn. 51), 15, Fn. 14).

92 Sed cum magis veritas oculata fide quam per aures animis hominum infigitur, ideo necessarium duximus post narrationem graduum etiam eos praesenti libro inscribi, quatenus possint et auribus et inspectione adulescentes perfectissimam graduum doctrinam adipisci. (Weil aber die Wahrheit sich dem menschlichen Geist mehr durch das Auge als durch das Ohr einprägt, so haben Wir für nötig erachtet, nach der Aufzählung der Abstufungen diese auch in das vorliegende Buch einzutragen, so dass der Jüngling sowohl durch das Ohr wie auch durch die Anschauung die vollkommenste Übersicht der Abstufungen erlangen könne.)

93 SCHADT, Die Darstellungen der Arbores Consanguinitatis (Fn. 51), 14.

94 STINTZING, Geschichte der populären Literatur des römisch-kanonischen Rechts (Fn. 78), 151. 
den Vordergrund. ${ }^{95}$ Mit der Etablierung des Kirchenrechts im Hochmittelalter wechselte die Thematik vom Erbrecht zum Eherecht. Nunmehr übernahmen Baumdarstellungen die Aufgabe, die verwandtschaftlichen Ehehindernisse des Kirchenrechts anschaulich zu machen. Eheschließungen zwischen Verwandten waren bis zum sechsten Glied verboten. Daher zeigt der „Baum der Blutsverwandtschaft" (arbor consanguinitatis) die Verwandtschaftsgrade für jeweils vier Generationen in aufsteigender und in absteigender Linie sowie die seitlichen Verwandten bis hin zu den Nachkommen desselben Urgroßvaters. Entsprechendes gilt für die Schwägerschaft in der arbor affinitatis.

Die Baumdarstellungen erlebten ihre Blütezeit in mittelalterlichen Handschriften. Der Kunsthistoriker Schadt hat 650 Beispiele aus 450 juristischen Manuskripten gesammelt. ${ }^{96}$ Im Buchdruck verbreiteten sich die Baumbilder vor allem durch die vielfach nachgedruckte "Lectura super arboribus consanguinitatis et affinitatis" von Johannis Andreä.97 Verwandtschaftsbäume blieben zwar das hauptsächliche Thema. Doch in einigen Corpus-Juris-Ausgaben des 16. Jahrhunderts finden sich auch sehr schöne Begriffsbäume, so in einer Ausgabe aus Lyon eine arbor jurisdictionum, eine arbor civilis, eine abor super interesse und eine arbor de interdictis. Anfangs zeigten auch die gedruckten arbores noch vielfach vegetabile Formen, Ornamente und Figuren. Im 17. Jahrhundert wurden die Baumdarstellungen nüchterner. Man kehrte zu rein geometrischen Schemata zurück.

\footnotetext{
95 STINTZING, Geschichte der populären Literatur des römisch-kanonischen Rechts (Fn. 78), 152.

${ }^{96}$ SCHADT, Die Darstellungen der Arbores Consanguinitatis (Fn. 51).

${ }^{97}$ Dazu ausführlich STINTZING, Geschichte der populären Literatur des römisch-kanonischen Rechts (Fn. 78), 151-185.
} 


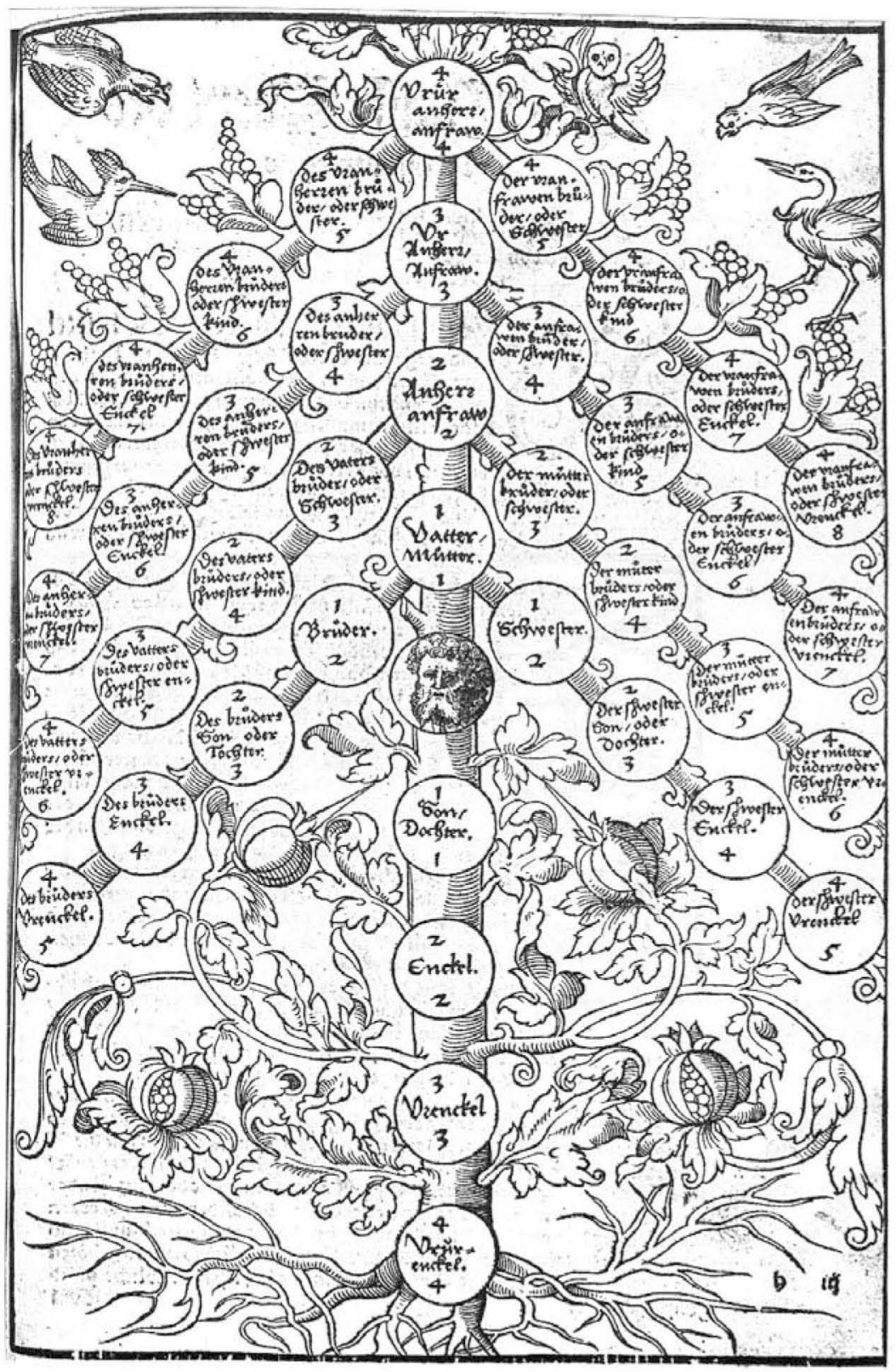

Abb. 3: "Von Graden der Sippschafft/Verwandtschafft oder Freundschafft" aus: Justin Gobler, Der Rechten Spiegel. Frankfurt am Main 1558 (Aufnahme Franziska Wieczorek) 


\section{Mnemonische Bilder mit Rechtsbezug}

\section{Die Renaissance der antiken Gedächtniskunst}

Eine gewisse Bedeutung hatten die Bilder zeitweise als Hilfsmittel der Mnemotechnik. Die gedächtnisstimulierende Bildwirkung war bereits der antiken Rhetorik vertraut gewesen, dann aber in Vergessenheit geraten. Im ausgehenden Mittelalter wurde die Gedächtniskunst der Örter und Bilder (loci et imagines) wiederentdeckt. ${ }^{98}$ Versuche, die bildgestützte ars memorativa auch für die Jurisprudenz nutzbar zu machen, blieben jedoch ohne nachhaltigen Erfolg.

Im Spätmittelalter lebte die theoretische Auseinandersetzung mit der antiken Mnemonik wieder auf. Man schätzt, dass zwischen 1450 und 1700 etwa 600 Autoren über 900 Schriften zur Gedächtniskunst verfassten. ${ }^{99}$ Darunter befanden sich allerdings nur wenige juristische Arbeiten. Die meisten behandelten historische oder biblische Themen. Die Druckausgabe der deutschen "Ars memorativa" von Johannes Hartlieb von 1490 nennt als Anwendungsmöglichkeiten der Gedächtniskunst „ein gancz Rechtpuoch oder die Bibel od die Cronica“. ${ }^{100}$

Das zu seiner Zeit am weitesten verbreitete Buch zur Gedächtniskunst stammt von dem Juristen Petrus Ravennaltus], dem seine Vorlesungen in Italien den Beinamen Petrus a memoria eingebracht hatten. ${ }^{101}$ Ravenna sagte von sich selbst, er habe Tausende von Örtern memoriert und habe Text und Glossen von „totum codicem juris civilis“ seinem Gedächtnis anvertraut. Er wurde an die Universität Greifswald berufen und ging von dort nach Wittenberg und Köln. Sein erstmals 1491 in Venedig erschienener "Phoenix, sive Artificiosa Memoria“ wurde um 1500 in Leipzig sowie ab 1506 in Köln gedruckt. Ravenna erklärt darin in zwölf conclusiones, wie die antike Lehre von den Örtern und Bildern anzuwenden ist. Freilich geht es dabei nur um Bilder im Kopf. Das Buch selbst ist bilderlos. ${ }^{102}$ In der ersten conclusio wird etwa gesagt, welche loci man sich

\footnotetext{
98 HELGA HAJDU, Das Mnemotechnische Schrifttum des Mittelalters. Amsterdam 1967 (Neudruck der Ausgabe Leipzig 1936); YATES, Gedächtnis und Erinnern (Fn. 85); HERWIG BLUM, Die antike Mnemotechnik. Hildesheim 1969; BARBARA KUHN, Gedächtniskunst im Unterricht. München 1993.

${ }^{99}$ GERHARD STRASSER, Emblematik und Mnemonik der Frïhen Neuzeit im Zusammenspiel. Johannes Buno und Johann Justus Winckelmann. Wolfenbütteler Arbeiten zur Barockforschung. Bd. 36. Wiesbaden 2000, 27.

100 Augsburger Faksimileausgabe, 7 (nach KUHN, Gedächtniskunst (Fn. 98), 62).

101 YATES, Gedächtnis und Erinnern (Fn. 85), 112-114.

102 Ich habe nur einen Nachdruck von 1608 in der Alten Bibliothek Greifswald gefunden (Sign. 520/Ho 277): Pietro TOMmai (Petrus Ravennatus), Phoenix sive ad artificialem
} 
aussuchen soll, um die Bilder zu deponieren. Sie sollen viele Fenster, Säulen oder Nischen haben, nicht zu weit entfernt liegen, aber auch nicht zu nahe, usw. In der dritten conclusio wird erklärt, wie man die Buchstaben des Alphabets durch Personen kodiert (Antonius für A, Benedictus für $B$ usw.). Dann werden ähnliche Merkregeln für Silben und Zahlen angegeben. Mit der achten conclusio wendet Ravenna sich dem Recht zu, indem er einen Farbenkode für die verschiedenen Teile des Corpus Juris entwickelt. Für die Decretalen dient der Papst selbst als Merkbild und für die Clementinen „puella cui nomen clemens". Die letzten zwölf von 32 Seiten bestehen aus Eigenlob. Das war wohl notwendig, denn im Rechtsunterricht hat Ravenna anscheinend keine Spuren hinterlassen. ${ }^{103}$

\section{Thomas Murner}

$\mathrm{Zu}$ Beginn des 16. Jahrhunderts erregte der Franziskaner Thomas Murner, ${ }^{104}$ der in Basel die Rechte studiert hatte, ${ }^{105}$ mit einem neuen didaktischen Konzept einiges Aufsehen: Solvite problema ludentes. Um seinen Studenten den Lernstoff einprägsam zu vermitteln, entwarf er eine Reihe von Karten-, Brett- und Würfelspielen, darunter als Erstes 1502 ein Kartenspiel, das mit Hilfe von geläufigen Symbolen den Studenten das Erlernen der „Institutionen“ Justinians erleichtern sollte.106 Das juristi-

memoriam comparandum brevis quidem et facilis, sed re ipsa et usu comprobata introductio e vetustissimo exemplari transscripta. Köln 1608.

103 STINTZING, Geschichte der populären Literatur des römisch-kanonischen Rechts (Fn. 78), 147, nennt das „Alphabetum aureum Petri Ravenni” eine völlig planlose Sammlung juristischer Notizen" und spricht von der "wüsten Gelehrsamkeit" eines Mannes, der die Zeitgenossen vor allem durch seine Gedächtniskunst beeindruckt habe. Ich habe noch eine kleine Biografie von CARL CHRISTIAN GERCKEN, Fata Petri Ravennatis per Germaniam. Dresden 1777, gefunden, in der der Autor den Weg Ravennas von Greifswald über Wittenberg nach Köln verfolgt. Darin wird der "Phoenix“ nur in einer Fußnote erwähnt.

104 Über ihn ADALBERT ERLER, Thomas Murner als Jurist. Frankfurt am Main 1956; JOSEF PAUSER, „Welch Frevel! Jetzt erscheinen die kaiserlichen Edikte gar noch als Spielkarten." - Thomas Murners juristisches Lehrkartenspiel über die "Institutionen" Justinians, in: Zeitschrift fiir Neuere Rechtsgeschichte 18 (1996), 196-225; LUDWIG SIEBER, Thomas Murner und sein juristisches Kartenspiel. Beiträge zur vaterländischen Geschichte 10. Basel 1875, 273-316; MORIZ SONDHEIM, Die Illustrationen zu Thomas Murners Werken, in: Elsaß-Lothringisches Jahrbuch XII (1933), 5-23; LUDWIG VOLKMANN, Ars memorativa, in: Jahrbuch der Kunsthistorischen Sammlungen in Wien. Neue Folge 3 (1929), 111$200,135 \mathrm{ff}$.

105 STRASSER gibt an, Murner sei dort zum doctor utriusque juris promoviert worden STINTZING, Geschichte der populären Literatur des römisch-kanonischen Rechts (Fn. 78), $462 \mathrm{f}$., meint, Murner sei nur als Theologe promoviert gewesen.

106 Dazu ausführlich mit eingehender Beschreibung des Kartenspiels PAUSER, Welch Frevel! (Fn. 104). 
sche "Chartiludium" bestand aus zwölf Spielfarben oder Serien zu je zehn Karten und einer Heroldskarte. Die zwölf As-Karten zeigten den Kaiser und elf Reichsfürsten. Doch standen die Symbole und Bilder in keiner Beziehung zur Sache. Die Farbzeichen der Karten verwiesen vielmehr auf eine entsprechend ausgezeichnete Zusammenfassung der 606 Paragrafen von Justinians Institutionen. Die Bilder dienten nicht selbst als Gedächtnisstütze; vielmehr sollte das Spiel die Studenten lediglich dazu bringen, beim Ziehen einer Karte den passenden Paragrafen zu repetieren.

Nach jahrelanger praktischer Verwendung erschien das Spiel, den Text wie bisher zusammenfassend, 1518 in einer Buchausgabe als "Chartiludium Institute summarie doctore Thoma Murner memorante et ludente". In dieser revidierten Ausgabe sind in die zwölf Kartenzeichen jeweils schlagwortartig die Inhalte der Lehren hineingeschrieben. So beginnt das Personenrecht mit dem Stichwort "Juris prudentia“, das dann im Textteil erläutert wird: „Est divinarum atque humanarum rerum noticia, justi atque injusti scientia" usw. Murners Kartenspiele waren bei Studenten überaus beliebt:

„Der Erfolg dieser Lehrart war so glücklich, dass man Murnern anfänglich für einen Zauberer hielte ... Die Sache ging so weit, dass sich Murner genöthiget sahe, zu seiner Rechtfertigung den Lehrern der Universität Cracau sein neu erfundenes Spiel zu offenbaren, die es nicht allein billigten, sondern auch als eine göttliche Erfindung bewunderten. ${ }^{.107}$

107 JOHANn SCHeible, Das Kloster. Weltlich und geistlich. 4. Bd., Stuttgart 1846, 543 (nach KuHN, Gedächtniskunst (Fn. 98), 88). 

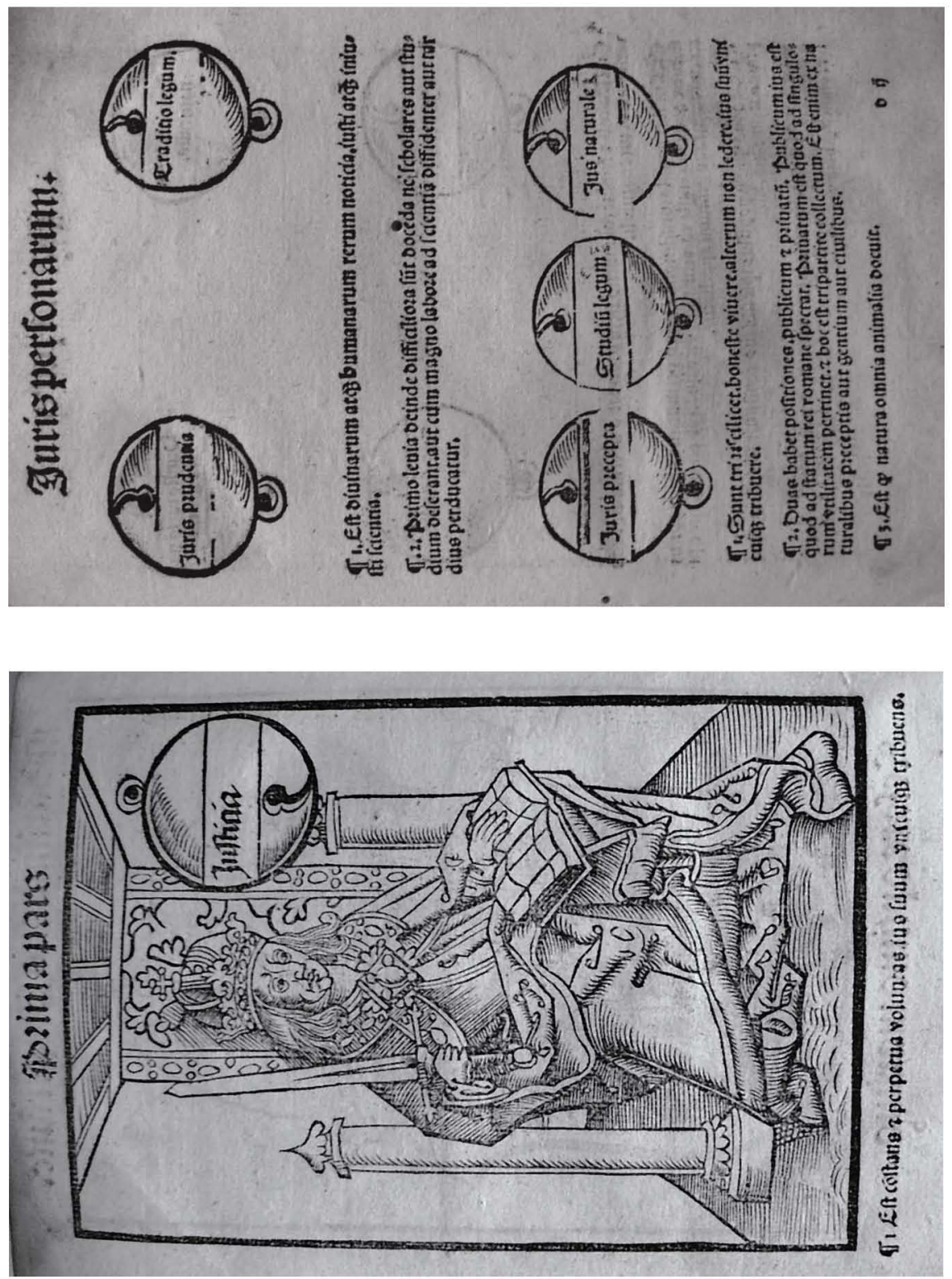

Abb. 4: Aus Thomas Murner, Chartiludium Institute. Der Kaiser als JusticiaKarte und zugehörige Kartenzeichen. Ein schönes Exemplar der Buchausgabe, aus dem diese Aufnahme stammt, haben Stephan Prinz und Franziska Wieczorek in der Stadtbibliothek Trier gefunden. 
Murner hat auch das Verdienst, erstmals die Institutionen verdeutscht $z$ u haben. ${ }^{108}$ Vor allem darauf bezog sich die Kritik der Zeitgenossen. So meinte Zasius zwar, die Jurisprudenz dürfe keine Geheimlehre werden, aber, so fuhr er „mit unverblümtem Bezug auf Murner ${ }^{\prime 109}$ fort:

„Wir erachten daher jene für strafwürdig, welche die Rechtswissenschaft geschwind unter die Leute bringen wollen, kaum daß sie ihre Vorhalle betreten und einige Worte ihrer Sprache gelernt haben. Durch lückenhafte und mißverständliche Übersetzungen in die Landessprache oder mit allerlei Spielereien glauben manche dieser Übereifrigen, die Erkenntnisse des Rechts verbreiten zu können. Aber sie sind Hohlköpfe, die auch andere nur zu Narren machen."110

Noch Stintzing fällt 1867 ein vernichtendes Urteil; Murners juristische Tätigkeit stelle sich dar

„nicht sowohl als eine hülfreiche für die Bedürfnisse des Lebens und die Noth der ungelehrten Praktiker: sondern als die gemeine Art, nach Ruhm und Popularität $\mathrm{zu}$ haschen, durch servile Dienstleistung für die Masse derjenigen, deren Trägheit vor ernster Anstrengung zurückschreckte, in einer Zeit, welche schon höhere Anforderungen stellen durfte. ${ }^{\prime 111}$

Erst im 20. Jahrhundert findet Murner sowohl als Pädagoge wie als Jurist die verdiente Anerkennung. ${ }^{112}$

\section{Johannes Buno}

Wie kein anderer hat der Pädagoge und Theologe Johannes Buno (1617-1697) die klassischen Rechtstexte in mnemonische Bilder umgesetzt. ${ }^{113}$ Buno und der zu seiner Zeit als Bildmnemoniker wohl bekann-

108 THOMAS MURNER, Instituten ein warer ursprung unnd fundament des Keyserlichen rechtens. Basel 1519; 2. Druck 1520, neu aufgelegt in Frankfurt 1536 und 1537.

${ }^{109}$ STINTZING, Geschichte der populären Literatur des römisch-kanon. Rechts (Fn. 78), 467.

${ }^{110}$ ULRICH ZASIUS, Von wahrer und falscher Jurisprudenz. Aus Schriften, Reden und Briefen 1507-1526. Herausgegeben von ERIK WOLF, Frankfurt am Main 1948, 17 [aus: Lubricationes, 1518, 17]. Von weiteren Schmähungen durch Zasius berichtet ERLER, Thomas Murner (Fn. 104), 22.

111 STINTZING, Geschichte der populären Litexatur des römisch-kanon. Rechts (Fn. 78), 470.

112 So bei SONDHEIM, Die Illustrationen zu Thomas Murners Werken (Fn. 104) und ERLER, Thomas Murner als Jurist (Fn. 104).

113 Zu BUNO ausführlicher KUHN, Gedächtniskunst (Fn. 98), 139 ff.; MARGRET KRAUL, Johannes Buno. Ein Lüneburger Pädagoge des 17. Jahrhunderts, in: Lüneburger Blätter 23 (1977), 115-128; GERHARD F. STRASSER, Johannes Bunos mnemotechnische Verfahren, in: JÖRG JOCHEN BERNS/WOlFGANG NEUBER (Hrsg.), Seelenmaschine. Wien 1999, 639-660; DERS., Emblematik und Mnemonik der Friihen Neuzeit im Zusammenspiel. Johannes Buno und Johann Justus Winckelmann (Fn. 99); ERICH STROBACH, Johannes Buno (1617-1697), ein Zeitgenosse des Comenius. Gedanken eines Kinderarztes und Kinderbuchsammlers zum Problem des Bildes, in: Die Schiefertafel, Jahrgang II, Heft 1 (Dezember 1979), 72-87; VOLKMANN, Ars memorativa (Fn. 104), 181 ff.; Rudolf 
tere Johann Justus Winckelmann (1620-1699) hatten zusammen in Marburg studiert. Dort hatte sie der Pädagoge Johann Balthasar Schupp (1610-1661) mit der Mnemonik in Berührung gebracht. Schupp meinte, dass die Ars Mnemonica "nicht ohne Unterschied bey allen in allen Sachen und zu allen Zeiten könne gebraucht werden". Doch empfahl er sie gerade auch für die Jurisprudenz: „Allein wenn man sich dieser löblichen Kunst gebrauchet in der Chronologie, Geographie, Sprachen, Tituli Juris, und in der Bibel, kann man dadurch gleichsam Wunder thun." 114

Buno kam der Empfehlung seines Lehrers in ganzem Umfang nach. 1647 erschien das bildmnemonische Geschichtswerk "Tabulum mnemonicarum ... clavis", das ihm einen Ruf nach Danzig eintrug. Dort verfasste er drei mnemonische Bildwerke, ein $\mathrm{ABC}$ - und Lesebüchlein, eine deutsche und eine lateinische Grammatik. 1653 wechselte Buno als Rektor der Schule St. Michael nach Lüneburg, 1660 wurde er Professor und Rektor des dortigen Gymnasiums und 1672 auch noch Prediger an der Hauptkirche. Ihm eilte von seiner früheren Wirkungsstätte in Danzig ein großer Ruf als Reformpädagoge voraus, dem er aber vor Ort in der Praxis anscheinend nicht gerecht wurde.

Bereits 1670 hatte Buno ein unbebildertes juristisches Repetitorium ${ }^{115}$ verfasst. Danach erschienen in schneller Folge seine drei bebilderten Memorialia zum Corpus Juris: 1672 das Memoriale Institutionum Juris, 116 1673 das Memoriale Juris Civilis ${ }^{117}$ und wieder ein Jahr später das Memoriale Codicis Justinianei. ${ }^{118}$

WINDEL, Über die emblematische Methode des Johannes Buno, in: Zeitschrift fiir Geschichte der Erziehung und des Unterrichts 3 (1913), 243-252, $246 \mathrm{ff}$.

114 JOHANN BalthaSAR SCHUPP, Ambassadeur Zipphusius [Vom Schulwesen, 1660], mit Einleitung und Anmerkungen. Herausgegeben von PAUL STÖTZNER. Leipzig 1891, 93 f. Es handelt sich um einen fiktiven Dialog im Parnass über die Erziehung, in dem ausführlich auch von der Ars Mnemonica die Rede ist. Dabei zitiert Schupp, ohne die Quelle zu nennen, ausführlich aus der Vorrede der 1651 in Danzig erschienenen "Neuen lateinischen Grammatica in Fabeln und Bildern" seines Schülers Buno.

115 Examen seu Specimen Juris ... ductu Johannis Bunonis. Lüneburg 1670 (52 Seiten und 18 Seiten Titelei).

${ }^{116}$ Memoriale Institutionum Quod Librorum IV Titulos et Singulos eorum paragraphos ... Nicolaus Nissen. Ratzeburg 1672, 140 Seiten, fünf doppelblattgroße Kupfertafeln, 30 Seiten Dedicatio und Praefatio und 8 Seiten Korrigenda und Addenda.

117 Memoriale Juris Civilis Romani ... ad minuendos in studio juris labores, Georg Rebenlin. Hamburg 1673, 115 Seiten und fünf doppelblattgroße Kupfertafeln.

118 Memoriale Codicis Justinianei, Authenticarum Seu Novellarum et Consuetudinum Feudorum ..., Georg Rebenlin. Hamburg 1674, 82 Seiten und 14 doppelblattgroße Kupfertafeln. 


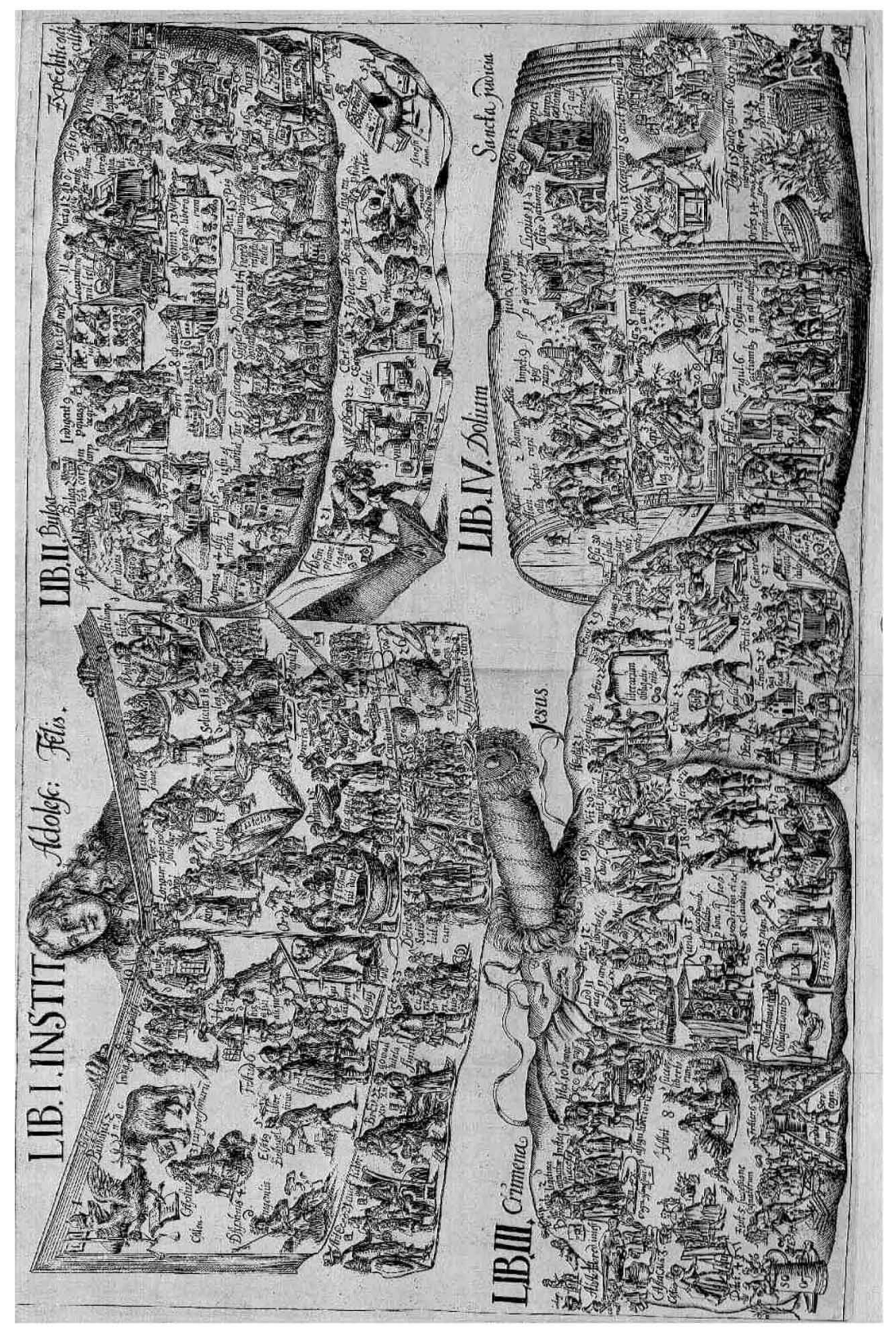

Abb. 5: Aus Johannes Buno, Memoriale Institutionum. Merkbilder Adolescens - Felis zu Buch I - VI der Institutionen 
Neben einer Überarbeitung seines Geschichtswerks veröffentlichte Buno später noch verschiedene Bilderbibeln.

Wie kommt ein Theologe und Schulmeister dazu, juristische Themen $z u$ behandeln? Buno meinte, auf diese Weise lernten die Schüler gutes Latein und einen wertvollen Stoff; er berief sich auf seinen Zeitgenossen Hermann Conring, der vorgeschlagen hatte, man solle in den Schulen "loco sententiarum, quae ex poetis et oratoribus sumptae in scholis vulgo traderentur", die vorzüglichen und leicht zu verstehenden Gesetze „ex Digestorum libris" lehren. So wollte Buno ausgewählte Schüler des Gymnasiums auf ein juristisches Examen vorbereiten. Sie sollten nicht nur den Inhalt der vier Bücher der Institutionen lernen, sondern auch den der beiden Digesten-Titel De verborum significatione und De diversis regulis iuris. Das erste Werk, das Buno zu diesem Zweck verfasste, war ein Repetitorium noch ohne Bilder. Darin wurde der Inhalt der einzelnen Titel in kurze Fragen aufgelöst. Die von ihm selbst so genannte emblematische Methode benutzte Buno für juristische Inhalte erst in einem zweiten Buch von 1672 mit dem langen Titel "Memoriale institutionum iuris, quod librorum IV titulos et singulos eorum paragraphos, itemque duorum ex digestis copiosissimorum titulorum de verborum significatione, et de diversis regulis iuris leges singulas emblematibus et imaginibus ita efficta continet, ut una cum titulorum legumque materiis eorum etiam numeri facili negotio memoriae imprimantur". Es geht also um ein Memoriale zu den Institutionen des Gajus und den beiden schon genannten Digesten-Titeln, das so mit Bildern versehen ist, dass sich Überschriften, Inhalte und Nummern der einzelnen Teile dem Gedächtnis leicht einprägen. Insgesamt sind in dem Buch im Format von 15,3 x 18,4 $\mathrm{cm}$ fünf Kupferstichtafeln unterschiedlicher Größe eingeklebt. An Beispiel dieses ersten juristischen Memoriale sei Bunos Technik etwas näher erläutert.

Zunächst kodiert Buno die Zahlen von eins bis zwanzig mit Hilfe von Buchstaben. $1=\mathrm{A} ; 2=\mathrm{B} ; 3=\mathrm{C}$ usw.; $20=\mathrm{V}$. Bei 21 beginnt die Buchstabenreihe erneut mit einem nachgestellten $\mathrm{E}(21=\mathrm{AE} ; 22=\mathrm{BE} ; 23=\mathrm{CE}$ usw. bis $40=V E$ ). Von 41 bis 60 hat die Buchstabenreihe ein nachgestelltes $\mathrm{I}(41=\mathrm{AI})$ von 61 bis 80 ein nachgestelltes $\mathrm{O}(61=\mathrm{AO} ; 80=\mathrm{VO})$ und von 81 bis 100 mit ein nachgestelltes $U(81=A U ; 100=V U)$. Dieser Buchstabencode wird dann zur Generierung von Merkwörtern verwendet. 1 = ArcA, 2 = BArbatus; 3 = CAesar; $20=$ VAgabundus. Das zusätzliche große A soll verdeutlichen, dass es sich um die Zahlen bis zwanzig handelt. Die drei weiteren Zwanzigergruppen haben ohnehin ihren kennzeichnenden Vokal. 22 etwa wird BrEvis; 42 BIgarius; 62 Bona, 82 BUtyrium und 100 VUlpes. 
Die erste Bildertafel findet sich nach Seite 32. Darauf wird der Buchstabencode in Bilder umgesetzt derart, dass die einzelnen Bilder einen Gegenstand zeigen, dessen Name mit dem Zahlenbuchstaben beginnt.

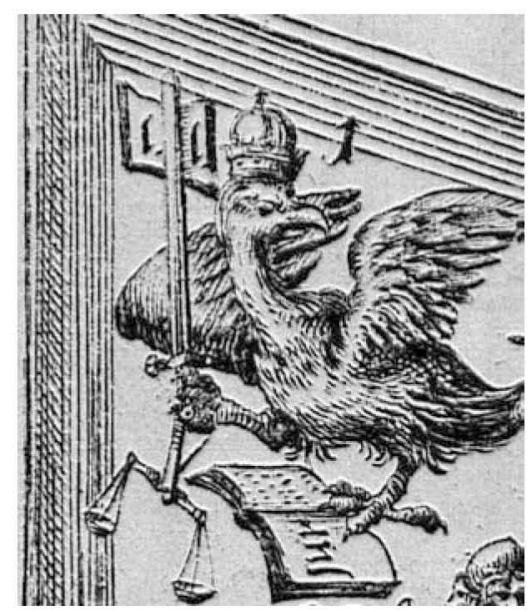
$\mathrm{Da} 1=\mathrm{A}$, muss das Bild für den ersten Titel mit A anfangen. Der „primus titulus institutionum iuris de iustitia et iure" wird deshalb "per Aquilam", also durch einen Adler, dargestellt, der als Zeichen der iustitia Schwert und Waage erhält. In der Imaginum Explicatio heißt es dazu: "Gladium E Libram habet justitia signa: \& Librum cui jure inscriptum." Der Zahlencode wird hier also mit einem Bild verbunden, das andeutungsweise auf den Inhalt der Textstelle verweist. Da

$2=B$, ist für den zweiten Titel ein Wort notwendig, das mit B beginnt. "Secundus titulus, de iure naturae gentium et civili" wird deshalb dargestellt "per Bubalum, qui iure naturae bubalae suae iungitur" (bubalus = Büffel). Der dritte Titel "De iure personarum" erhält das Bild von "Captivos catenis vinctos" (Gefangenen in Ketten). So geht es weiter bis zum 26 und letzten Titel des ersten Buches. Entsprechend dem Buchstabencode FE für 26 wählt Buno das Bild einer Katze (felis), die als Vormund über eine Mäuseschar wacht. Der Titel handelt nämlich "de suspectis tutoribus".

Die 26 Miniaturbildchen sind wiederum in einer Umrisszeichnung, nämlich in einem aufgeschlagenen Buch, zusammengefasst, das von einem Jüngling = Adolescens gehalten wird. Erneut steht hier das A für eine 1, nämlich für das erste Buch der Institutionen. Die 17 Bildchen für das zweite Buch stecken in einer Bulga (Sack), 27 Bildchen für das dritte Buch in einer Jagdtasche (Crumena) und weitere 17 Bilder für das vierte Buch in einem Dolium (Weinfass). Das alles ist auf einer Tafel von 39,5 $x$ $24 \mathrm{~cm}$ untergebracht und daher im Detail kaum ohne Lupe zu erkennen.

Mit 40,8 × $33 \mathrm{~cm}$ etwas größer ist die zweite Tafel (zwischen S. 66 und S. 67) mit der Überschrift De diversis regulis juris antiqui. Auf ihr sind in 16 Reihen übereinander jeweils bis zu 16 Bilder angeordnet, die kleinsten etwa 2,8 x 2,5 cm. In diesem Titel lautet etwa das zweite Gesetz: „Feminae ab omnibus officiis civilibus et publicis remotae sunt etc., item impubes." Das wird in ein Bild umgesetzt, auf dem die barttragenden Richter 
bartlose Frauen und Knaben davontreiben (,barbati iudices imberbes feminas, pueros").

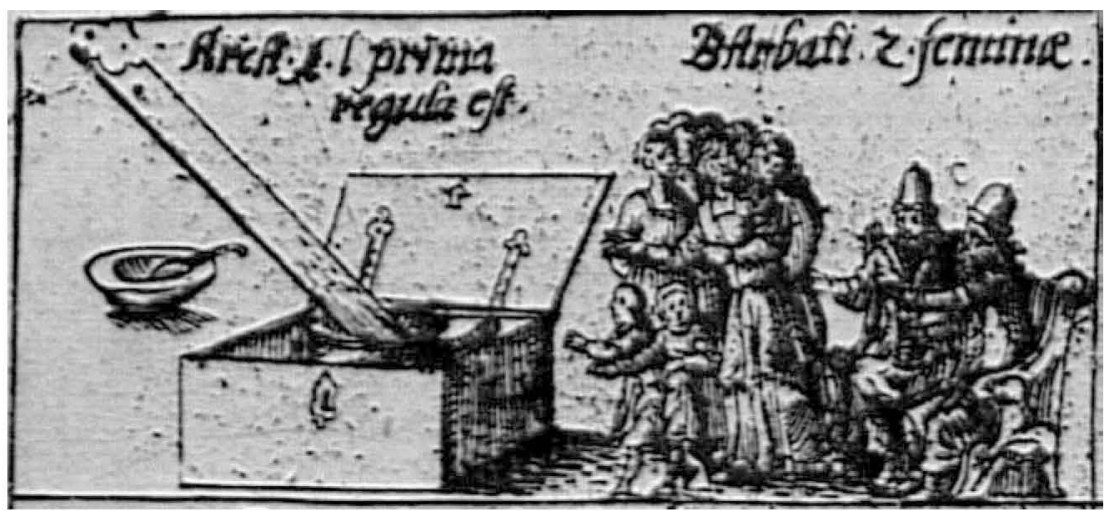

Abb. 6: Aus Bunos Memoriale institutionum iuris von 1672: Die bärtigen Richter vertreiben die bartlosen Frauen aus dem Amt. Der Ausschnitt misst im Original etwa $2,5 \times 7 \mathrm{~cm}$.

Die dritte bis fünfte Tafel illustrieren in drei Centurien (Hundertschaften) aufgeteilt den Titel De verborum significatione mit insgesamt 246

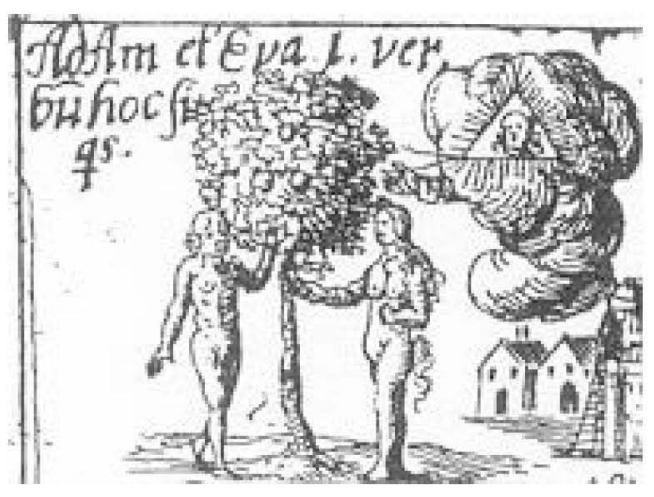

Gesetzen. Die Tafel Centuria I zwischen Seite 92 und 93 misst 22 x 33,8 cm im Hochformat. Das erste Gesetz lautet: Verbum hoc, "si quis" tam masculos quam feminas complectitur. (Wenn es heißt, „Wer ...", so sind Männer und Frauen gemeint.) Das zugehörige Bild zeigt Adam und Eva unter dem verbotenen

Baum, wo Gott zu ihnen aus den Wolken spricht: Si ... quis comederit etc., weil das Verbot beide, Adam und Eva, angeht. Die Tafel Centuria II zwischen Seite 108 und 109 misst $22 \times 33,7 \mathrm{~cm}$, die Tafel Centuria III zwischen S. 128 und $129(21,6 \times 18,4 \mathrm{~cm})$. 
In ähnlicher Weise sind in dem Memoriale iuris civilis romani von 1673 die Digesten mit fünf Kupferstichtafeln und in dem Memoriale Codicis Justianei von 1674 die Novellen und die Consuetudines Feudorum mit 14 Kupferstichtafeln illustriert.

Die zeitgenössischen Pädagogen blieben ob der verwirrenden Bilderfülle skeptisch. Sie kritisierten Buno, weil er der Wendung zum pädagogischen Realismus nicht gefolgt war. ${ }^{119}$ Auch die Anerkennung der Juristen blieb Buno versagt. Christian Thomasius schrieb dazu in seinen Monats-Gesprächen ${ }^{120}$ :

„Ich bin für weniger Zeit über des Bunonis seine Tabellen kommen / die er über die Jurisprudenz verfertiget/ und habe nur zur Lust zwey Stunden darin geblättert/ und dann und wann die Erklährung etlicher närrischer Bilder mit darzu gelesen. Ich muß bekennen/ daß durch diese eintzige Einbildung/ die ich bey dieser attenten Lesung mir gemacht/ alles dasjenige/ was ich durchlesen hatte/ dermassen in mein Gedächtnis ware gedruckt worden/ daß ich es etliche Tage nicht draus loß werden konte; Ich muß aber auch bekenn/ daß mir die wunderlichen Bilder/sowohl wenn ich bey Tage etwas meditirte, als des Nachts/ wenn ich schlieffe/ stets für Augen schwebten/ daß ich nicht alleine abgehalten und stets divertiret würde/ auff was solides und ernsthaftes zu gedencken/ sondern auch im Schlaff mit so närrischen Träumen gemartert wurde/ daß ich den lieben GOTT danckte/ als ich diese phantastischen Grillen wieder vergessen."

In der Stadtbibliothek Trier haben Stefan Prinz und Franziska Wieczorek ein Konvolut mit 30 in Kupferstich ausgeführten Bildtafeln gefunden, die im Katalog ohne nähere bibliografische Angaben als „Das Corpus juris civilis et canonici in einer Menge niedlicher Kupfer figürlich erklärt. [18. JH.]" ausgewiesen waren. Die ersten 23 Blätter stammen aus den drei Corpus-Juris-Memoralia von Johannes Buno. Es fehlt nur die Tafel Centuria II aus dem Memoriale institutionum iuris. Aber auch die weiteren sieben Blätter scheinen von der Hand Bunos zu stammen. Sie illustrieren das Corpus Juris Canonici. Ein entsprechendes Werk Bunos ist jedoch bisher in der Literatur nicht bekannt und war auch in den Katalogen nicht aufzufinden. Daher will ich hier die Blätter kurz beschreiben in der Hoffnung, dass sich ihre Herkunft früher oder später klären lässt. Zwei Blätter haben das Decretum Gratiani zum Gegenstand. Das erste behandelt Teil I des Dekrets, der Natur und Quellen des Rechts, kirchliche Personen und Ämter betrifft. Es zeigt für jede der 101 Distinctiones ein kleines Bildchen. Teil II und III des Dekrets werden zusammen auf einem Blatt behandelt. Die oberen zwei Drittel zei-

119 KuHN, Gedächtniskunst (Fn. 98), 156 ff.

120 CHRISTIAN THOMASIUS, Lustiger und Ernsthafter Monats-Gespräche Anderer Theil. Elfter Monat oder November. Halle 1688, 618 f. (hier zitiert nach dem Nachdruck im Athenäum Verlag, Frankfurt am Main 1972). 
gen den Umriss eines Fisches, um den herum und in den hinein Bilder zu den 36 Causae angeordnet sind. Das untere Drittel des Blattes ist zweigeteilt. Die linke kleinere Hälfte enthält unter der Überschrift "Decreti pars III. de consecr.[atione]" fünf Bilder zu den fünf Distinktionen dieses Buches. Der rechte größere Teil bietet unter der Überschrift "Canones" nur zwei Bilder, die von verhältnismäßig viel Freiraum umgeben sind. Weitere fünf Blätter entsprechen den fünf Büchern, in denen die Dekretalen gesammelt sind. Das Erste trägt die Fußzeile "Decretal. Lib. 1 Alvearia. Civiles". 43 Bilder sind in und um zwei Bögen angeordnet. Das dritte Blatt ist in einer Kassette in der rechten unteren Ecke als „Decretal. Lib. 3. Casa Justitiaria“ bezeichnet. 49 Bildchen sind auf fünf Felder verteilt. Die Felder umgibt eine Rahmung, die ich nicht deuten kann. Blatt vier (Abbildung 7) trägt die Unterschrift „Decretal. Lib. IV. Decalogg. AmEntes" und illustriert die Regeln über Verlobung und Ehe (de sponsalibus).

Die 20 Bilder sind bis auf eines, das neben der Subscriptio platziert ist, in zwei Torbögen zusammengefasst. Der Maßstab ist etwa doppelt so groß wie der auf den vorhergehenden und auf dem folgenden Blatt. Das letzte Blatt ist überschrieben "Decret. Lib. V Epitaphium". Hier geht es um Verbrechen und Strafen. Die Bilder sind in einem Rahmen zusammengefasst, wie er für ein Epitaph verwendet wurde. Alle die vielen kleinen Bilder verweisen mit einer Überschrift und einer arabischen Zahl auf die zugehörige distinctio, causa oder capitula. 


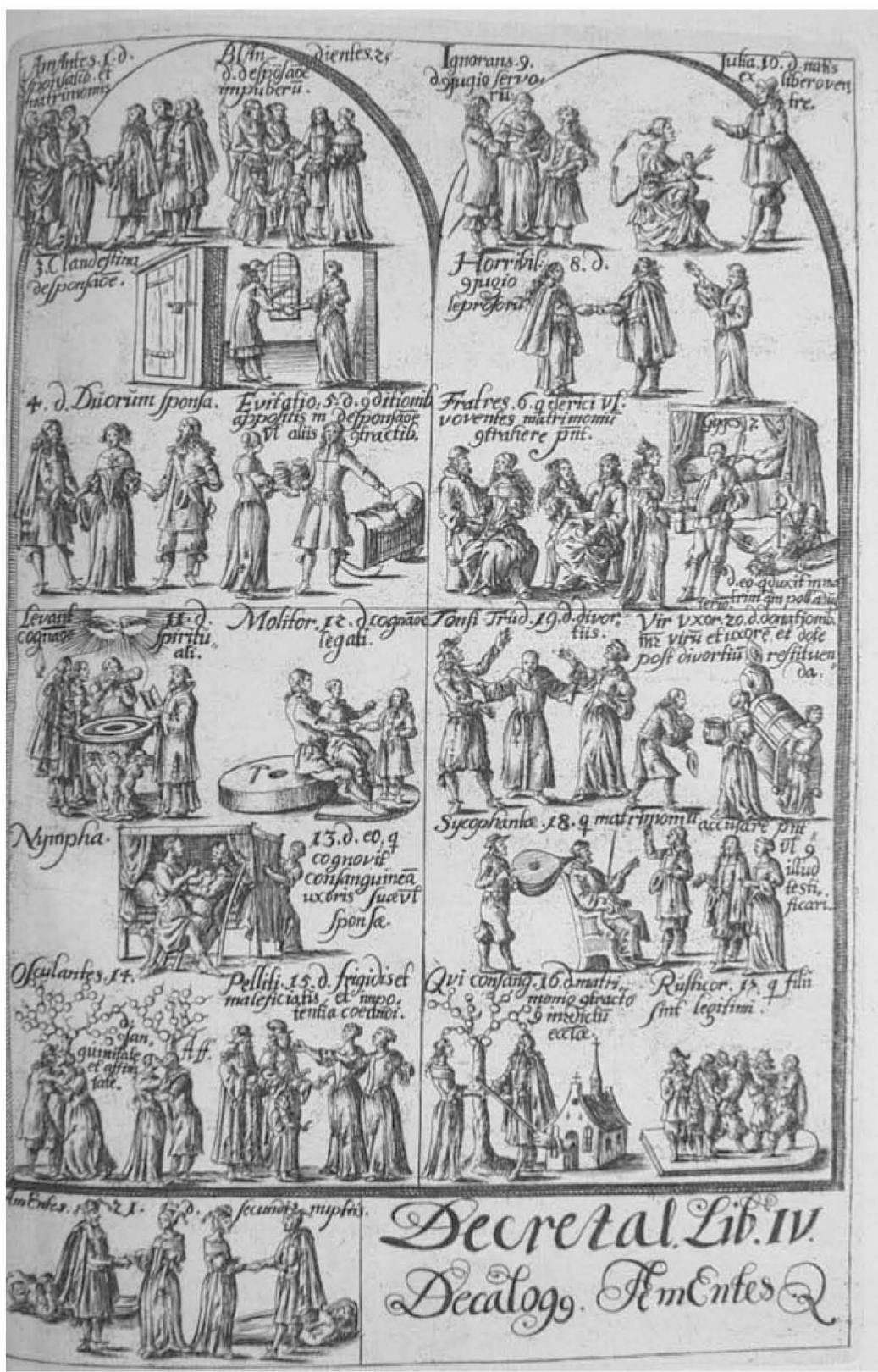

Abb. 7: Johannes Buno (?), Dekretalen-Memoriale aus der Stadtbibliothek Trier. (Aufnahme Stephan Prinz) 


\section{4. Überschneidungen}

Die antike Mnemo(tech)nik arbeitete ausschließlich mit mentalen Bildern. Aber - in einer schönen Formulierung von Berns ${ }^{121}$ - „auf dem langen Weg von der Antike bis in das Spätmittelalter und in die Frühe Neuzeit waren die imagines agentes und die locus-Systeme sozusagen von innen nach außen gewandert." Die imagines der Mnemonik wurden zeichnerisch oder malerisch in symbolhaft belehrende Bilder umgesetzt. So kam es im Mittelalter zu einer „Überlappung von Kunst und Gedächtniskunst". ${ }^{222}$

Eine ähnliche Überlappung gab es auch zwischen mnemonischen und logischen Bildern. Die Scholastiker verwendeten zur Darstellung ihrer Begriffe und Abgrenzungen räumlich-tabellarische Darstellungen in drei verschiedenen Grundtypen, nämlich als turres (turmartige Gebilde), arbores (Baumstrukturen) und rotae (Räder). Die Raddarstellungen ließen durch eine Kombination von konzentrischen Kreisen und radialen Segmenten komplexere Darstellungen zu. In den kombinatorischen Rädern des Raimundus Lullus (1235-1316) waren die Ringe sogar beweglich. Die turres und arbores waren keine bloßen Graphen, sondern richtige Bilder. Die Stamm und Zweige der Bäume und die Bestandteile der Türme waren beschriftet und zeigten darüber hinaus mehr oder weniger ornamentalen und figuralen Schmuck.

Kuhn sieht in den turres und arbores Frühformen des mnemonischen Bildes; die einzelnen Bestandteile dienten als loci, die sie beschriftenden Wörter allegorisierten das Gesamtbild und ließen es zur imago werden. ${ }^{123}$ Diese Deutung überzeugt nicht. Die fraglichen Darstellungen bleiben der Sache nach primär logische Bilder, die der Veranschaulichung von Distinktionen und Relationen dienen. Die Gedächtnisfunktion ist allenfalls sekundär. Von der ikonografischen Gestalt her ist die Verbindung zur Bildmnemonik nicht erkennbar.

Auch die bebilderten Handschriften des Sachsenspiegels werden von Kuhn als mnemonische Bildschriften interpretiert. ${ }^{124}$ Kuhn betont, bei dieser Bebilderung habe es sich nicht um dekorativen Buchschmuck im traditionellen Sinne gehandelt, sondern um eine Art Glossierung des Textes durch eine Abfolge mnemonischer Bilder.

121 JÖRG JOCHEN BERNS, Umrüstung der Mnemotechnik im Kontext von Reformation und Gutenbergs Erfindung, in: JÖRG JOCHEN BERNS/WOLFGANG NeUBer (Hrsg.), Ars memorativa. Zur kulturgeschichtlichen Bedeutung der Gedächtniskunst 1400-1750. Tübingen 1993, 35-72, 38.

122 KuHN, Gedächtniskunst (Fn. 98), $20 \mathrm{ff}$

123 Ebd., $25 \mathrm{f}$.

124 Ebd., 36 ff. 
„Die einzelnen Bilder sind dabei keine detailreiche Wiedergabe ausgewählter Textszenen, sondern eine fortlaufende, stichwortartige Erinnerung an den gesamten Textinhalt. Kennzeichnend ist dabei die Entstehung und Verwendung eines durchgängigen mnemonischen Bildkodes. Durch ihre ausgeprägt memorative Funktion diente die Bebilderung dem schriftkundigen Leser als zusätzliche Orientierungsmarke im Textverlauf, als Mittel der Textgliederung, als Stichwort und Zusammenfassung zugleich; dem schriftunkundigen Betrachter hingegen erschlossen sie das ganze Buch."

Kuhn stellt die Sachsenspiegelhandschriften insoweit in eine Reihe mit den Bibliae pauperum. ${ }^{125}$ Das ist von der Ikonografie her wenig plausibel. Das strenge Bildprogramm der Armenbibeln hat keine Ähnlichkeit mit den Sachsenspiegelmanuskripten. Aber daran muss die Analogie nicht scheitern, ebenso wenig daran, dass die mittelalterliche Bildmnemonik Andachts- und Erbauungsmnemonik war. So zählt auch Hajdu die Armenbibel in die Reihe der mnemotechnischen Hilfsmittel. ${ }^{26}$ Die memorative Funktion kann sich mit verschiedenen anderen verbinden. An die Stelle von Andacht und Verehrung trat bei den Sachsenspiegelhandschriften eine didaktische Zielrichtung.

Hinweise auf die didaktische Funktion der illustrierten Sachsenspiegel finden sich auch in der rechts- und kunsthistorischen Literatur. ${ }^{127}$ Der chiffrenhafte Charakter der Bilder kann ebenso wie die symbolhaft wiederkehrenden Farben als Merkmal mnemonischer Bilder gelten. Bedenkt man dazu die eher mittelmäßige künstlerische Qualität und deren $\mathrm{Ab}$ stand zu den Prachthandschriften des Mittelalters wie den Grandes Chroniques de France, so leuchtet die Interpretation als mnemonisch-didaktisches Bildwerk ein. Sie ist hier stimmiger als bei den turres, arbores und rotae der Scholastik, weil für die Sachsenspiegelillustrationen sonst keine

125 Diese Interpretation wird indirekt von Goldschmidt gestuitzt, wenn er betont, das illustrierte Buch des Mittelalters sei in der Hauptsache als Hilfe für Leseunkundige gedacht gewesen, GolDSCHMIDT, The Printed Book (Fn. 71), 50. Überwiegend ist man aber heute der Ansicht, dass die Bennennung als Biblia Pauperum, die jünger ist, als die Buchgattung, in die Irre führt; vgl. GERHARD SCHMIDT, Die Armenbibeln des XIV. Jahrhunderts. Graz 1959, $117 \mathrm{ff}$

126 HAJDU, Das Mnemotechnische Schrifttum (Fn. 98), 51.

127 JULIANUS B. M. VAN HOEK, Zwischen Eike von Repgow und Johann von Buch leuchtet das lehrreiche Bild, in: RUTH SCHMIDT-WIEGAND (Hrsg.), Text - Bild - Interpretation (Fn. 43), 59-76; DAGMAR HUPPER, Funktionstypen der Bilder in den Codices picturat des Sachsenspiegels (Fn. 48), 231-249, 248; GERNOT KOCHER, Bild und Recht. Überlegungen zur Rolle des Bildes in der privatrechtsgeschichtlichen Lehre und Forschung in: HANS-WOLF THUMMEL (Hrsg.), Arbeiten zur Rechtsgeschichte. Festschrift fiur Gustav Klemens Schmelzeisen. Stuttgart 1980, 142-165, 144, RUTH SCHMIDT-WIEGAND, Die Bilderhandschriften und ihre Bedeutung für die Wirkungsgeschichte des Sachsenspiegels, in: HEINER LUCK (Hrsg.), Recht und Rechtswissenschaft im mitteldeutschen Ratum. Köln $1998,9-27$. 
wirklich einleuchtende Deutung verfügbar ist, während jene gut als logische Bilder verstanden werden können.

Wenn die Bilderhandschriften des Sachsenspiegels (und die Bibliae pauperum) überhaupt als mnemonische Bildschriften gedeutet werden können, so waren sie doch ohne direkten Anschluss an die antike Tradition entstanden und von dieser Tradition allenfalls inspiriert. ${ }^{128}$ Diese Deutung wäre auch kaum erschöpfend. Mögen die Sachsenspiegelmanuskripte auch nicht so prachtvoll ausgestattet sein wie manche Handschriften zum römischen und kanonischen Recht, so sind sie doch immerhin so anspruchsvoll gearbeitet, dass man auch Repräsentationsund Identifikationsabsichten annehmen muss. ${ }^{129}$ Dieser Repräsentationsanspruch steht indessen ebenso wenig in Widerspruch zu der Anlage der Manuskripte als mnemonische und zugleich didaktische Bildschriften wie der Umstand, dass Ausstattungsniveau und Erhaltungszustand darauf hindeuten, dass die Bände kaum ihrer Anlage entsprechend genutzt worden sind. ${ }^{130} \mathrm{Ob}$ sich die Bilder nur an Leser oder auch oder gar nur an Schriftunkundige wenden, 131 ist umstritten. Schmidt-Wiegand hat auf die dominierende Rolle des Textes hingewiesen, den das Bild nicht zu ersetzen vermag, und sieht in den Bilderhandschriften deshalb Fachbücher, in denen das Bild auf den Text hinführt.132 Die Hinführung zum Text ist eine didaktische Funktion. Memorative und didaktische Funktionen sowie der repräsentative Aufgabe der Bilderhandschriften sind jedoch im Grunde sekundär. Im Vordergrund steht die Beglaubigungswirkung der Bilder für die immer noch misstrauisch beobachtete Schrift.

${ }^{128}$ GOLDSCHMIDT, The Printed Book (Fn. 71), 51.

${ }^{129}$ OTT, Vorläufige Bemerkungen zur "Sachsenspiegel“-Ikonographie (Fn. 47), 40 ff.

130 OTT, Vorläufige Bemerkungen zur "Sachsenspiegel“-Ikonographie (Fn. 47), $42 \mathrm{f}$.

131 So WALTER KOSCHORRECK, Eine Bilderhandschrift des Sachsenspiegels. Über CPG 164 der Universitätsbibliothek Heidelberg, in: Heidelberger Jahrbuicher 15 (1971), 57-72, 58.

132 RUTH SCHMIDT-WIEGAND, Text und Bild in den Codices picturati des "Sachsenspiegels" (Fn. 43), 11-31. 


\section{Bilder für die Pädagogik}

Die Bildpädagogik kommt aus dem Raum der Kirche, die über viele Jahrhunderte als öffentliche Institution der Erziehung konkurrenzlos

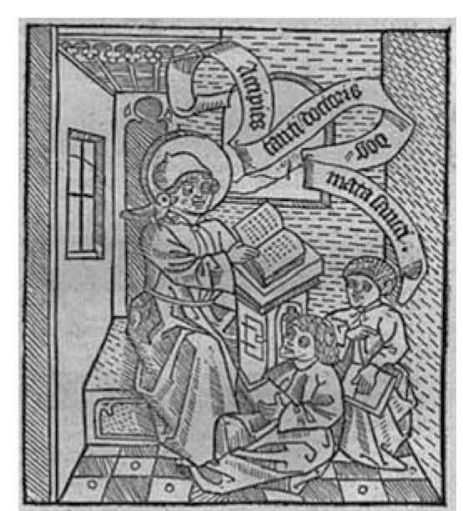

war. Das nebenstehende Bild ist ein sog. Accipies-Bild, wie es in einer Reihe von Wiegendrucken vorkam. Der Lehrer ist Papst Gregor der Große (ca. 540-604), der Patron der Schule im Mittelalter, kenntlich an der auf der rechten Schulter sitzenden Taube. Das Spruchband lautet "Accipies tanti doctoris dogmata sancti". Papst Gregors berühmten Aufruf zur Laienbelehrung ${ }^{133}$ durch Bilder mag man als Beginn einer Volkspädagogik verstehen. Er fand Erfüllung unter anderem in den als Bibliae pauperum bekannten Bildwerken.

Eine besondere Rolle spielte das illustrierte Buch im 16. und 17. Jahrhundert für die Verdrängung des lateinischen durch die Volkssprache. ${ }^{134}$ Die Rezeption der Bilder für die Schulpädagogik ist mit dem Namen von Johann Amos Comenius (1592-1670) und seiner Lateinfibel „Orbis sensualium pictus" von 1658 verbunden, obwohl auch schon vorher und gleichzeitig andere für die Verwendung von Bildern in der Erziehung eintraten. Unmitttelbare Vorläufer des "Orbis pictus" waren zwei Kinderbücher, die "Cristliche gottselige Bilderschule" von Sigismund Evenius und das "Lesebüchlein" von Johannes Saubert d. Ä., die mit mnemonischen Bildern arbeiteten. ${ }^{135}$ Die Pädagogen grenzten sich deutlich von den Bildmnemonikern ab, indem sie Anschauungsbilder verwendeten. ${ }^{136}$ Nur noch zum Erlernen des Lesens und Schreibens dienten einige Phantasiebilder als Merkhilfe für Buchstabenform und Lautgestalt. In der Hauptsache repräsentierten die Bilder jedoch einzelne Begriffe oder Realien. Comenius verwendete neben realistischen viele allegorische und emblematische Bilder. Von anderen wurden Bilder mehr und mehr zur

133 "Nam quod legentibus scriptura, hoc idiotis praestat pictura cernentibus ..." Die einschlägigen Briefe Gregors werden ausführlich zitiert bei BERNS, Umrüstung der Mnemotechnik (Fn. 121), $43 \mathrm{ff}$

134 KUNZE, Geschichte der Buchillustration (Fn. 31), 92.

135 Nach HEINER HÖFENER, Nachwort zum Nachdruck des Orbis pictus im Verlag Harenberg Kommunikation. Dortmund 1978, 6.

136 KUHN, Gedächtniskunst (Fn. 98), 100 ff. 
Wiedergabe des im 17. Jahrhundert gewaltig anwachsenden Sachwissens gebraucht. Aber die Vorliebe für Bilder war auch in der Pädagogik nicht annähernd so groß und vorbehaltlos, wie man vermuten könnte. Auch hier blieb es bei dem absoluten Vorrang des Textes. Die Zahl der Bilder nahm mit dem Alter der Schüler ab. Das Bild war auch in der Pädagogik nur Notbehelf für noch Leseunkundige oder Ersatz für Realien, die man nicht zur Verfügung hatte. ${ }^{137}$

Bis in die Juristenausbildung ist die Bildpädagogik nie vorgedrungen. Juristen und Pädagogen scheinen gleichermaßen das antiautoritäre und anarchische Potential der Bilder zu fürchten. „Das Bild, dessen Rezeption zu einem guten Teil frei ... verläuft und nur in Grenzen kontrolliert werden kann, eignet sich für die pädagogische Arbeit nur in begrenztem Umfang, kann es doch die Autorität des Pädagogen untergraben. "i38 Das gilt freilich nicht für die naturkundlichen Fächer.

Ein weiteres im Vergleich zum Mittelalter neuartiges Bildprogramm diente der ernsthaften ebenso wie der heiteren Unterhaltung. ${ }^{139}$ Giesecke nennt als Beispiel vor allem Bücher von Albrecht Pfister in Bamberg, den "Ackermann von Böhmen" (zwischen 1450 und 1460), den „Edelstein" von 1461, deutsche und lateinische Ausgaben der Biblia pauperum und eine deutsche Übersetzung der Fabelsammlung des Jacobus de Theramo. Bald ein halbes Jahrhundert jünger ist Sebastian Brants "Narrenschiff". Damit schließt sich jedenfalls über die Person der Autoren der Kreis zu der bebilderten Rechtsliteratur des 16. Jahrhunderts.

\section{Bilder in gedruckten Rechtsbüchern}

\section{Zum Umfang der gedruckten Rechtsliteratur vor 1800}

Bei der Suche nach Bildern in der juristischen Fachliteratur kann man sich nicht damit zufrieden geben, dass in dem großen von Coing herausgegebenen "Handbuch der Quellen und Literatur der neueren europäischen Privatrechtsgeschichte", das die Zeit vom Mittelalter bis in das 19. Jahrhundert abdeckt, von Bildern keine Rede ist; denn nicht einmal die fraglos wichtigen Bilderhandschriften des Sachsenspiegels werden darin gewürdigt. Das ist ein Beleg für die Geringschätzung der Bilder durch die moderne Jurisprudenz, aber noch kein Beweis für das Fehlen der Bilder in historischer Zeit.

\footnotetext{
137 SCHUCK-WERSIG, Expeditionen zum Bild (Fn. 30), 141.

138 Ebd., 149.

139 GIESECKE, Der Buchdruck in der frühen Neuzeit (Fn. 62), 298 ff.
} 
Es lässt sich ohne weiteres übersehen, dass die Rechtsliteratur des 19. und erst recht die des 20. Jahrhunderts ohne Bilder auskommt. Für die Zeit zwischen der Erfindung Gutenbergs und dem Ausgang des 18. Jahrhunderts bedarf es jedoch einiger Nachforschungen. Es stellt sich insbesondere die Frage, wie weit die mittelalterliche Praxis der bebilderten Manuskripte in den Buchdruck übernommen wurde. Auf der Suche nach Bildern in gedruckten Rechtsbüchern hat Franziska Wieczorek aus verschiedenen Bibliotheken und Archiven annähernd tausend Bilder zusammengetragen. ${ }^{140}$ Diese Zahl besagt indessen wenig angesichts der Menge einschlägiger Bände, die während dreier Jahrhunderte erschienen sind.

Gutenberg druckte seine berühmte Bibel zwischen 1452 und 1455. Bis zum Ende des Jahrhunderts verbreitete sich der Buchdruck ähnlich rasant wie in der zweiten Hälfte des 20. Jahrhunderts die Computertechnologie. Hains Repertorium ${ }^{141}$ führte 16.299 Bücher auf, die vor dem 1. Januar 1500 gedruckt wurden (und üblicherweise als Inkunabeln oder Wiegendrucke bezeichnet werden) ${ }^{142}$. Nach neueren Schätzungen sollen im 15. Jahrhundert bereits 40.000 Bücher erschienen sein. ${ }^{143}$ Für das 16. Jahrhundert schätzt Kunze die Zahl der bibliografischen Einheiten international auf 200.000, davon 80.000 bis 90.000 im deutschsprachigen Raum. ${ }^{144}$ Die Schätzung liegt wohl noch zu niedrig. Für das "Verzeichnis der im deutschen Sprachbereich erschienenen Drucke des XVI. Jahrhunderts" (1983 ff.) geht man von einer Grundgesamtheit von 140.000 bis 150.000 aus; davon sind 90.000 erfasst. Für das 17. Jahrhundert nennt Kunze eine Gesamtzahl von 300.000 Bänden. Davon soll annähernd die Hälfte in deutschsprachigen Ländern entstanden sein. ${ }^{145}$

Als ältestes gedrucktes Rechtsbuch gilt eine Ausgabe der glossierten Institutionen Justinians, gedruckt 1468 von Peter Schöffer in Mainz. ${ }^{146}$

${ }^{140}$ Es handelt sich um Vorarbeiten zu einer noch nicht abgeschlossenen Bochumer Dissertation.

141 LUDWIG HAIN, Repertorium Bibliographicum. Bd. 1 und 2. Stuttgart 1826 und 1831.

142 Inkunabeln sind eigentlich Windeln oder Bänder, mit denen Wiegenkinder gewickelt werden. Wenn SEBASTIAN BRANT im 15. Jahrhundert von den "incunabula juris" sprach, so meinte er jedoch nicht Erzeugnisse des frühesten Buchdrucks, sondern ein Buch zur Einführung in die Jurisprudenz (GELDNER, Inkunabelkunde (Fn. 57), 1).

143 KUNZE, Geschichte der Buchillustration (Fn. 31), VIII. Nach dem „Gesamtkatalog der Wiegendrucke" (Neubearbeitung 1972 ff.) sind es wohl nur 27.000 (GELDNER, Inkunabelkunde (Fn. 57), 10).

144 KUNZE, Geschichte der Buchillustration (Fn. 31).

145 Ebd., VIII f., 34

146 PETER WeIMAR Die legistische Literatur der Glossatorenzeit, in: COING (Hrsg.), Handbuch der Quellen und Literatur der neueren europäischen Privatrechtsgeschichte (Fn. 77), Bd. II/1, 129 ff., 150; zu dieser Ausgabe ERNST P. J. SPANGENBERG, Einleitung in das Römisch-Justinianische Rechtsbuch. Hannover 1817, Nachdruck Aalen 1970, 650 ff.; 
Danach nahm die Zahl der juristischen Bücher rasch zu. Das MaxPlanck-Institut für Europäische Rechtsgeschichte in Frankfurt am Main besitzt aus der Zeit bis 1526121 Titel und aus den nächsten 75 Jahren weitere 2.157 Bücher. ${ }^{147}$ In Frankfurt am Main sind zwischen 1570 und 1630 sieben- bis achthundert, bis zum Ende des 17. Jahrhunderts wahrscheinlich knapp tausend Nachdrucke außerdeutscher Rechtsbücher entstanden. Zusammen mit den Werken niederländischer und deutscher Autoren sollen es vom Beginn des Buchdrucks in Frankfurt bis zum Ende des alten Reiches mindestens 1.500 juristische Drucke gewesen sein. ${ }^{148}$ Becker-Moelands hat ermittelt, dass in den Niederlanden zwischen 1600 und 1750 mehr als 1.000 Titel in über 1.500 Ausgaben erschienen sind. ${ }^{149}$ Spangenberg hat insgesamt 529 Ausgaben des Corpus Juris aufgelistet, die zwischen 1468 und 1816 gedruckt wurden. ${ }^{150}$ Davon sind nahezu 200 Wiegendrucke. Die Zahl der Druckausgaben des Corpus Juris Canonici oder seiner verschiedenen Teile war kaum geringer. ${ }^{151} 44$ Ausgaben des Decretum Gratiani erschienen bereits im 15. Jahrhundert. In Italien wurden vor 1500 vor allem die Postglossatoren gedruckt. Von Bartolus de Saxoferrato gab es 191 Wiegendrucke. ${ }^{152}$ Nach dem Codex nundinarius ${ }^{153}$ sollen sich für die Zeit von 1564 bis 1630 fast 6.500 juristische Titel auszählen lassen.154 Die genannten Zahlen geben nur Impressionen. Aber

KASPERS/SCHMITT-THOMÉ/GERIG/MANSTETTEN, Vom Sachsenspiegel zum Code Napoleon (Fn. 6), 265, nennen als ältestes Rechtsbuch eine Ausgabe der "Clementinae", eines Teils des Corpus Juris Canonici mit den Constitutionen des Papstes Clemens V., die 1460 von Johann Fust und Peter Schöffer in Mainz gedruckt wurde. Ausführlichere Angaben zu den Wiegendrucken juristischen Inhalts bei GELDNER, Inkunabelkunde (Fn. 57), $209 \mathrm{ff}$.

147 DOUGLAS J. OSLER, Catalogue of books printed on the continent of Europe from the beginning of printing to 1600 in the library of the Max-Planck-Institut fiir Europäische Rechtsgeschichte. Frankfurt am Main 2000.

148 ERNST HOLTHÖFER, Frankfurts Rolle in der Geschichte des juristischen Buchdrucks, in: Frankfurt am Main als Druckort juristischer Literatur. Begleitheft zur Ausstellung der Stadt- und Universitätsbibliothek Frankfurt am Main 23. September bis 18. Oktober $1986,5-28,20$.

149 MARGARIET A. BECKER-MOELANDS, De juridische titelprent in den zeventiende eeuw: het Hof van Holland. Muiderberg 1985, $10 \mathrm{f}$.

150 SPANGENBERG, Einleitung in das Römisch-Justinianische Rechtsbuch (Fn. 146), 650929.

151 Zahlenangaben bei KASPERS/SCHMIDT-THOMÉ/GERIG/MANSTETTEN, Vom Sachsenspiegel zum Code Napoleon (Fn. 6), $108 \mathrm{f}$.

152 GELDNER, Inkunabelkunde (Fn. 57), 213.

153 Gemeint ist GUSTAV SCHWETSCHKE, Codex nundinarius Germaniae literatae bisecularis. Meßjahrbücher des deutschen Buchhandels von dem Erscheinen des ersten Meßkataloges im Jahr 1564 bis zur Grïndung des ersten Buchhändlervereins im Jahre 1765. Halle an der Saale 1850-1877.

154 REINER SCHOLZ, Die frühen Verleger juristischer Literatur in Frankfurt am Main, in: Frankfurt am Main als Druckort juristischer Literatur. Begleitheft zur Ausstellung der 
man darf wohl ganz grob schätzen, dass die Zahl der gedruckten Rechtsbücher in Europa bis 1800 mindestens in der Größenordnung von 20.000 zu suchen ist. Das wären gerade drei Prozent der bis dahin insgesamt gedruckten Bücher.

Es ist praktisch ausgeschlossen, alle gedruckten Rechtsbücher systematisch auf Bilder durchzusehen. Auch die Bildung und Durchsicht einer Zufallsstichprobe lässt sich kaum bewerkstelligen, da sich nicht einmal die Grundgesamtheit hinreichend klar beschreiben lässt. Wir sind daher einen anderen Weg gegangen, indem wir allen Hinweisen auf Illustrationen in einschlägigen Büchern nachgegangen sind und in möglichst vielen erreichbaren Büchern nach weiteren Bildern gesucht haben. Die Suche wurde abgebrochen, als sich keine neuen Bilder mehr entdecken ließen. Ex ante haben wir die Schwierigkeiten der Bildersuche nicht übersehen. Ex post sind wir mit dieser Methode nicht zufrieden. Sie kann nicht gewährleisten, dass wirklich ein repräsentativer Überblick über die vorhandenen Buchillustrationen gelungen ist. Dennoch haben wir den Eindruck gewonnen, dass es möglich ist, das Auftreten und Verschwinden der Bilder in gedruckten Rechtsbüchern annähernd richtig zu beschreiben, denn es ließen sich nur noch wenige einschlägige Bücher auffinden, die nicht bereits in der rechtsikonografischen Literatur erwähnt waren. Die kunsthistorische Literatur war dagegen wenig hilfreich. Richard Muthers großes Werk über die deutsche Buchillustration der Gotik und Frührenaissance beschreibt immerhin 1.822 illustrierte Bücher aus der Zeit von 1460 bis $1530 .{ }^{155}$ Darunter finden sich aber, je nachdem, ob man Nachdrucke mitzählt, nur zehn oder zwanzig Rechtsbücher.

Das Gesamtergebnis der Suche lässt sich wie folgt zusammenfassen: In der ersten Generation juristischer Bücher im ausgehenden 15. Jahrhundert blieb der Bildschmuck spärlich. Erst seit Beginn des 16. Jahrhunderts gab es auch in gedruckten Rechtsbüchern bemerkenswerte Bilder. Etwa hundert Jahre hielt sich die Bildausstattung auf beträchtlichem Niveau. Danach ging die Zahl der Bilder schnell wieder zurück. Bald dienten sie nur noch als Titelbild, als Blickfang oder Schmuck. Im 17. Jahrhundert erschien die Mehrzahl der Rechtsbücher ganz ohne Bilder. Es ist kein gedrucktes Buch aufzufinden, das nach dem Vorbild der Codices picturati mit einer durchgehenden Bebilderung des Textes aufwartet. Vergleicht man die Bilder in den Rechtsbüchern des 16. Jahrhun-

Stadt- und Universitätsbibliothek Frankfurt am Main 23. September bis 18. Oktober $1986,29-44,29$.

155 RICHARD MUTHER, Die Deutsche Buchillustration der Gothik und Friihrenaissance (14601530). 2 Bände. München 1922. 
derts mit den mittelalterlichen Bilderhandschriften, so zeigt sich ein Bruch, jedenfalls keine Kontinuität. ${ }^{156}$

\section{Zur Bildausstattung der Bücher im 15. und 16. Jahrhundert}

Die Bilderhandschriften des Sachsenspiegels haben im Buchdruck keine Nachahmung gefunden. Vor der Wende zum 16. Jahrhundert gab es bereits neunzehn verschiedene Druckausgaben des Sachsenspiegels, der damit eines der am häufigsten gedruckten Bücher jener Zeit war. ${ }^{157}$ Ein früher Druck aus der Werkstatt von Bartholomäus Unkel in Köln von 1480 begnügte sich mit einem halbseitigen Widmungsbild, das an drei Stellen wiederkehrt. Es zeigt den König umgeben von weltlichen und geistlichen Würdenträgern. ${ }^{158}$ Ein Augsburger Druck von Anton Sorg war mit 203 Holzschnittinitialen ausgestattet. ${ }^{159}$ In einer Ausgabe von 1517 wird die Textpassage zur Zwei-Schwerter-Lehre von einem winzigen Holzschnitt in Rot-Schwarz-Druck begleitet: Der Papst sitzt auf einem Pferd; der Kaiser hält ihm den Steigbügel; über beiden hängen gekreuzte Schwerter. ${ }^{160}$ Ein Augsburger Druck von 1516 zeigt ein Titelblatt mit einer üppig dekorierten Rahmung. ${ }^{161}$ Später beschränkt sich der Buchschmuck auf Wappen, Druckersignets und Zierinitialen. Auch der Schwabenspiegel wurde anscheinend ohne besonderen Bilderschmuck gedruckt. ${ }^{162}$ Eine 1482 in Ulm von Johann Zainer gedruckte Ausgabe enthält immerhin einen blattgroßen Holzschnitt vom $\mathrm{Co}^{-}$ lumna-Meister und zehn Initialen. ${ }^{163}$

Weniger durch die Zahl als durch die Qualität ihrer Bilder ragen die verschiedenen Stadtrechtsbücher heraus. ${ }^{164}$ Dafür gab es in der Manu-

156 KARL VON AmIRA/ClaUdius FRH. VON SCHWERIN, Rechtsarchäologie. Gegenstände, Formen und Symbole des germanischen Rechts. Berlin 1943, 119.

157 KASPERS/SCHMIDT-THOMÉ/GERIG/MANSTETTEN, Vom Sachsenspiegel zum Code Napoleon (Fn. 6), 37; dort auch zu weiteren Druckausgaben der zahlreichen Abkömmlinge dieses Rechtsbuchs.

158 KASPERS/SCHMIDT-THOMÉ/GERIG/MANSTETTEN, Vom Sachsenspiegel zum Code Napoleon (Fn. 6), 35, und bei SCHILD, Alte Gerichtsbarkeit (Fn. 46), 127.

159 Verband Deutscher Antiquare, Wertvolle Bücher usw., 41. Verkaufsausstellung 2002 in Stuttgart, Katalog, 50.

160 KASPERS/SCHMIDT-THOMÉ/GERIG/MANSTETTEN, Vom Sachsenspiegel zum Code Napoleon (Fn. 6), 32.

161 Abbildung bei KUNZE, Geschichte der Buchillustration (Fn. 31), Bd. 2 (Bildband), 9.

$162 \mathrm{Zu}$ den Druckausgaben etwas näher KASPERS/SCHMIDT-THOMÉ/GERIG/MANSTETTEN, Vom Sachsenspiegel zum Code Napoleon (Fn. 6), 43 ff.

163 KASPERS/SCHMIDT-THOMÉ/GERIG/MANSTETTEN, Vom Sachsenspiegel zum Code Napoleon (Fn. 6), 14; DERSCHKA, Der Schwabenspiegel (Fn. 52), 403.

164 Dazu recht ausführlich KASPERS/SCHMIDT-THOMÉ/GERIG/MANSTETTEN, Vom Sachsenspiegel zum Code Napoleon (Fn. 6), 46 ff. 
skriptzeit einige berühmte Vorbilder 165 wie das Rote Stadtbuch von Hamburg (1301) oder das Soester Nequam-Buch. Die Druckausgaben zeichnen sich vor allem durch schöne Titelbilder aus. Das gilt auch für manche Territorialrechte. Der erste selbständige Titelholzschnitt findet sich in der 1484 bei Koburger erschienenen "Reformation der Statut und Gesetze, die ein erbar Rat der Stadt Nürmberg vorgenommen hat". In der Mitte eines gotischen Gebäudes steht das Reichswappen, links auf einem Sockel der bärtige Sebald, der in der einen Hand einen Stecken, auf dem anderen Arm die Kirche hält; rechts Lorenz im Priesterornat mit der Palme in der rechten, dem Rost in der linken Hand. $\mathrm{Zu}$ den Füßen der beiden Heiligen sind die bekannten Nürnberger Wappen, links das mit dem Jungfernadler, rechts das gewöhnliche Stadtwappen angebracht. ${ }^{166}$ Ganz neu dekoriert ist das doppelseitige Titelbild in "Der Stat Nürmberg verneute Reformation" von 1564, gedruckt von Valentin Geissler. Das linke Blatt ist nun mit einer allegorischen Darstellung von Justitia, Pax und Liberalitas gefüllt, rechts sind die beiden Heiligen in einen Torbogen eingefügt. Im Inneren enthält der Band noch einen "Baum der Sippschaft".

Aus Worms ist die 1499 erschienene und 1509 wiederholte "Reformation der Stadt Worms Recht, Gesetze, Ordnung und Statuta" zu nennen, die außer einem Wappen auf der Rückseite des Titelblattes einen sehr altertümlichen Holzschnitt hat: Der Kaiser sitzt auf dem Throne in einem ummauerten unbedeckten Raume, daneben der römische König mit den sechs Kurfürsten, davor knien zwei Knaben, die ein Buch halten, zu den Füssen jedes der Fürsten ist sein Wappen angebracht. ${ }^{167}$ Von Hans Holbein stammen die beiden schönen Blätter mit den Schutzpatronen und dem Wappen von Freiburg, welche er 1520 für die von Adam Petri veranstaltete Ausgabe der Freiburger Stadtrechte lieferte. ${ }^{168}$ Inhaltlich jeweils ähnliche Titelholzschnitte finden sich in Ausgaben des Bayerischen Landesrechts von 1516, 1518 und 1529. So sieht man auf dem Titel der "Gerichtsordnung im Fürstenthumb Obern- und Nidern Bayrn Anno 1520 aufgericht" in einem großen Zimmer rechts und links Patrizier, im Vordergrunde einen Postboten; im Hintergrunde ist ein überwölbter Erker, der durch ein Fenster mit zwei runden Glasgemälden sein Licht empfängt. In dem Erker steht ein Tisch, dessen Fuß ein Löwe bildet, welcher das bayerische Wappen trägt. Daran sitzen die beiden Herzöge Wilhelm und Ludwig. Der links, welcher einen großen Pelzmantel und eine goldene Kette trägt, spricht lebhaft, während der rechts sitzende, einfa-

${ }^{165}$ Für weitere Beispiele vgl. die Fußnoten 44-46 und 209.

166 Nach MUTHER, Die Deutsche Buchillustration (Fn. 155), 56, Nr. 421.

${ }^{167}$ Nach Muther, Die Deutsche Buchillustration (Fn. 155), 102, Nr. 768/769.

${ }^{168}$ Nach MUTHER, Die Deutsche Buchillustration (Fn. 155), 199, Nr. 1300. 
cher gekleidete eine abwehrende Handbewegung macht. Links stehen auf einer Tafel die Buchstaben H. W., rechts H. L.; auf einer dritten Tafel in der Mitte liest man die Jahreszahl 1520 und auf einer Stufe gegen den Tisch zu die Buchstaben C. C, die auf Caspar Clofigl deuten, der Hofmaler des Herzogs Wilhelm IV. war. ${ }^{169}$

Mit elf Holzschnitten vergleichsweise umfangreich ist die Bildausstattung einer frühen Druckausgabe der Goldenen Bulle aus dem Jahre 1485. Passend zum Gegenstand dieses Wahlgesetzes stellen die Bilder die Kaiserkrönung, den Einzug der Kurfürsten am kaiserlichen Hof und deren besondere Aufgaben dar. Die Bilder sind überwiegend halbseitig über dem zugehörigen Text angeordnet. Spätere Drucke der Goldenen Bulle, die meist dem Clag- und dem Rechtenspiegel beigefügt wurden, waren nur noch auf dem Titel bebildert. Die Motive wurden dem Clagspiegel oder dem Layenspiegel entnommen. Die speziell für die Goldene Bulle geschaffenen Holzschnitte der frühen Druckausgabe wurden anscheinend nicht weiter verwendet. Drucke des 17 . Jahrhunderts sind bilderlos. 170

Die Bambergische Halsgerichtsordnung von 1507 erschien alsbald in zahlreichen Ausgaben und Nachdrucken. Der Erstdruck von 1507 ist das Hauptwerk von Johann Pfeyl. Er enthielt bereits 21 Holzschnitte, von denen die meisten ganze Seiten einnehmen (h. 245 oder 175, br. $175 \mathrm{~mm}$ ) und viele aus zwei Platten zusammengesetzt sind. Sie zeigen ein Weltgericht, Szenen aus den verschiedenen Stadien des Gerichtsverfahrens und auch justizkritische Darstellungen. ${ }^{171}$ Die Mehrzahl der Bilder wird

169 Nach MUTHER, Die Deutsche Buchillustration (Fn. 155), 252, Nr. 1757-1760. Die Holzschnitte der Reformationen von 1518 und 1520 sind bei MUTHER, Bd. II, als Tafel 263 und 264 wiedergegeben.

170 Zwei Ausgaben von 1612 und 1658 werden im Katalog Nr. 302: Bücher von 1501-1700 des Hamburger Antiquariats (2003) unter Nr. 274 und 275 beschrieben. 1697 erschien dann von Heinrich Günter Thülemeyer eine Kupferstichwiedergabe des Codex Vindobonensis 338: Copia Manuscripti Aureae Bullae Caroli IV. Aureae Bullae Versio Germanica. Diese liegt wiederum in einer von Armin Wolf herausgegebenen Faksimileausgabe der Akademischen Druck- und Verlagsanstalt, Graz 1978, vor.

171 MUTHER, Die Deutsche Buchillustration (Fn. 155), 94 f., Nr. 669) hat die Bilder wie folgt beschrieben: "Der Titelholzschnitt zeigt rechts die Richter in ihrem Versammlungszimmer, links in einer Landschaft wird ein Mann hingerichtet, dahinter werden drei andere, die an einen Baum gebunden sind, betäubt. Hinter dem Register folgt die Darstellung verschiedener Marterinstrumente, Galgen, Rad, Fußschellen, Pranger, Zange, Schwert; dann auf der Rückseite das von zwei Löwen gehaltene Familienwappen des Bischofs Georg Schenk, Freiherm von Limburg, - Dem eigentlichen Hauptteil geht die Darstellung des Jüngsten Gerichtes voraus: In der Mitte sitzt Christus auf der Erdkugel, zu jeder Seite bläst ein Engel, unten steigen zwei Seelen aus dem Grabe auf, von denen die rechts von einem Teufel gepackt und in die Hölle gestoßen wird. Dazu die Überschrift: Gedenck allezey der letzten ding/ so würt dir Rechttun gar gering. Neben Christus links stehen die Worte: Kumptt her Thr gebenedeiten, rechts: Geht hin thr vermaledeiten. Der folgende Holzschnitt zeigt Moses und davor seinen Schwager Jethro. Auf dem Streifen 
durch Spruchbänder mit gereimten Versen erläutert. Die Holzschnitte der verschiedenen bebilderten Ausgaben unterscheiden sich zum Teil sehr stark in der künstlerischen Ausführung; die Motive bleiben jedoch stets die Gleichen. Auch die Spruchbänder werden, von Korrekturen der Rechtschreibung abgesehen, unverändert übernommen.

darüber steht: Das volks kumt zu mir und sucht die Urteil gotes/ Moyses Exodi am XXVI. Darauf kommen die einzelnen Vorgänge des Gerichts. Drei Männer stehen in einem Zimmer vor einem Richter, der ein Papier hält und zu ihnen spricht: Gesellen mercket ewer pflicht/ Seel und Ere verwürcket nicht. Ein Gefesselter ist von zwei Schergen vor dem Richter geführt worden. Sie sagen: Auf ewern Befehl uns getan/Bring wir gefangen disen man. Der Richter antwortet: Mein Ambt und pflicht mir gepeut/ zu strafen boshaftig leut. - Ein Kläger steht vor dem Richter und bringt eine Beschuldigung vor: Herr Richter lasst mir nehmen an/ einen schadhaftigen man. Der Richter fragt: Was ist die sach oder argkwan/ Das der verclagt hat getan? - Das nächste Bild wendet sich gegen das üppige Leben, als das erste, was dazu führt, dem Gericht zu verfallen. Jünglinge schmausen mit Mädchen an einer reich besetzten Tafel: Viel verthün und wenig haben/ Zaigt argk wenig dise knaben/ Zu übel viel die trefflich seyn/dadurch sie kommen oft in peyn - Daran schließt sich der Marterhof. Das Urteil eines Mannes ist unterschrieben und er wird geknebelt: Seyt sich auff dich erfunden hat/ Fürstu mit Unschuld aus nach radt./ Redlich anzaygung der Missetat/ die peinlich frag soll haben statt. Zwei Männer müssen in der Gerichtsversammlung schwören: Du sollst nicht falsches Zeugnis geben/ als lieb dir sey das ewig leben. - Der Mann ist verurteilt. Der Henker steht vor dem Richter und fragt ihn: Herr Richter setzt mir einen Tag/ das ich mein Recht volfüren mag. Nachdem sie auf den Platz der Hinrichtung geführt sind, werden die Verbrecher noch einmal von dem Richter ausgehorcht: Richt wir nach dises buches lere/ Domit verwar wir seel und ere. - Dann wird er zum Tode geführt. Man rät ihm noch: Wo du Geduld hast in der peyn/ so wird sie Dir gar nützlich sein/ drum gib Dich willig darein. - Er wird durch den Scharfrichter hingerichtet; daneben kniet ein Priester; hinten wird ein Rad aufgestellt, auf das ein zweiter Verbrecher gebunden ist: Wem trewe straff nit bringe frucht/ der kumpt dick in des Meisters Zucht/ des werck und zeug wirt hie anzeygt. Wol dem der sich zu Tugend neigt. - Dann kommen die einzelnen Fälle, die an die Richter herantreten können. Ein ermordeter Mann ist ihnen auf einer Bahre zugeführt worden und wird von ihnen betrachtet. Welcher unverursacht diese leich hat gemacht, soll kommen in die mordtacht. - Ein Verbrecher ist geflohen und es werden seine Güter konfisziert: Dieweyl der tetter ist hindan/ seyn güter schrajbent eben an. - Von einem Kriegsknecht werden sie um Geleit angegangen. Herr Richter, alleyn zurecht/ Bit geleyt ich armer knecht. - Aber auch der Tadel und der Spott gegenüber den Richtern bleibt nicht aus. Ein Holzschnitt zeigt zwei Richter, einen Kriegsknecht, einen Henker, an einem Galgen einen großen Geldbeutel oben in der Luft die Hand Gottes. Gott ruft herab: $O$ Richter hier in dieser Welt / Eur eer und sel gebt nit umb gelt. Unten ist man anderer Ansicht. Der Kriegsknecht links fragt, indem er auf den Richter hinweist: Auf Land und Wasserr raubt man ser/ noch rauben Taschenrichter mehr. Auch der Henker weiß Bescheid; er ruft der Tasche, die gehängt werden soll, zu: Tasch, wölt ihr länger leben/ meinem Herrn müsst ihr Geld geben. Die Tasche lässt sich das nicht zweimal sagen: Mit Geld was ich wol beschwert/ Falschrichter haben mich gelert. Und die Worte des Richters zeigen, dass er nicht abgeneigt ist: Tasch, was wilt du geben mir/ mein Urteil wirdt genedig dir. - Das andere Mal sieht man Richter mit Narrenkappen eine Versammlung halten. Auf bös Gewohnheit Urteil geben/ die dem Rechten widerstreben/ ist dieser blinden Narren Leben. - Der letzte Holzschnitt schlägt wieder einen ernsten Ton an Fünf Richter sitzen auf einer Bank im Gerichtssaal, davor stehen zwei Häscher, die sie fragen: Lieben herren rat uns Schlechten/ wie halt wir uns gemäß dem Rechten." 


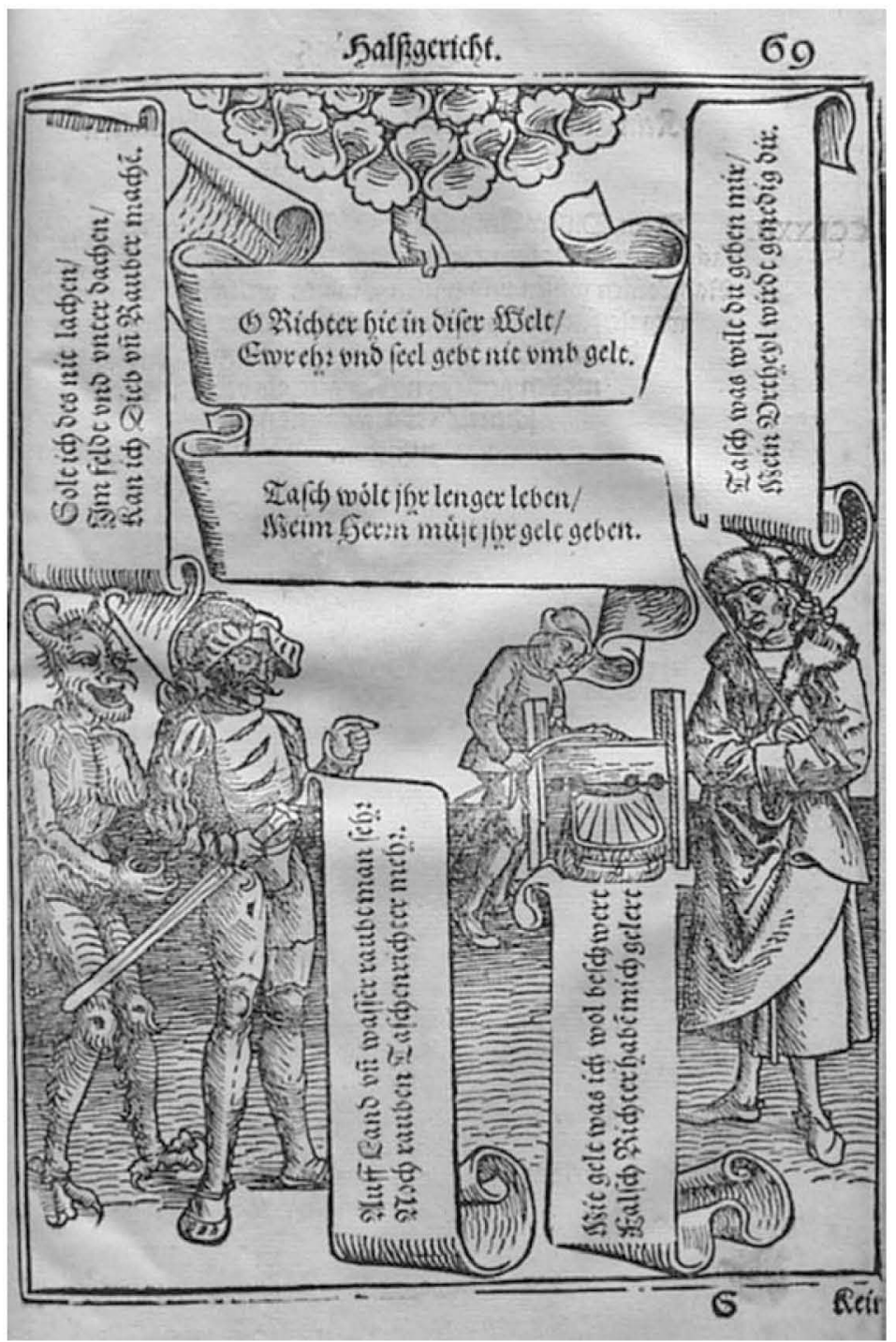

Abb. 8: Holzschnitt von Wolfgang Katzenheimer aus der Bambergischen Halsgerichtsordnung, gedruckt von Johann Wagner in Bamberg, 1508. Das Bild hat mit dem Text der gegenüberliegenden Seite, der vom Totschlag handelt, nichts $\mathrm{zu}$ tun, sondern wendet sich gegen die Bestechlichkeit der Richter. Links ist der dem Teufel verfallene Raubritter zu sehen, der nach rechts auf den "Taschenrichter" zeigt. Das obere Spruchband in der Mitte besagt: "O Richter hie in dieser Welt/ Ewr ehr und seel gebt nit umb gelt." (Aus der Sächsischen Landesbibliothek Dresden, Aufnahme Franziska Wieczorek) 
In Mainz war seit 1502 Johann Schöffer als Drucker tätig. Muther beschreibt die 22 Holzschnitte des 1510 von ihm veranstalteten Nachdrucks der Bambergensis: Sie schließen sich an diejenigen der Originalausgabe an. Nur sind sie kleiner als dort; außerdem hat Schöffer in solchen Fällen, wo vorhandene Holzstöcke aus einer von ihm 1505 gedruckten Liviusausgabe passten, die Bambergischen Zeichnungen nicht verkleinern lassen, sondern jene verwendet. Oft kommt es auch vor, dass Holzschnitte aus einem Liviusholzstock und einem des Bambergischen Künstlers zusammengesetzt sind. ${ }^{172}$ Die letzte Ausgabe der Bambergensis durch Johann Schöffer aus dem Jahre 1531 enthält immer noch 22 Holzschnitte. ${ }^{173}$ Eine 1580 bei J. Wagner in Bamberg gedruckte Ausgabe verfügt über einen Holzschnitt-Titel und 21 meist ganzseitige Textholzschnitte. Eine ganzseitige Darstellung des Jüngsten Gerichts stammt von Jobst Amman. Die weiteren Bilder sind überwiegend Wiederverwendungen der Originalstöcke von Wolf Traut aus einer früheren Ausgabe. ${ }^{174}$

Mit insgesamt 29 teilweise blattgroßen Holzschnitten sticht die 1516 in Nürnberg von Jobst Gutknecht gedruckte „Brandenburgische Halsgerichtsordnung" hervor. Das Titelblatt (Abb. 9) demonstriert ähnlich wie zuvor der Titel der Bambergensis die gebräuchlichen Strafen und Richtstätten. Ein anderes Bild zeigt Christus als Symbol der Gerechtigkeit auf einer Weltkugel sitzend; dieses Motiv ist ebenfalls der Bambergensis entnommen und wurde 1512 auch schon im Layenspiegel verwendet.

\footnotetext{
${ }^{172}$ Muther, Die Deutsche Buchillustration (Fn. 155), 250, Nr. 1730.

173 Vom Antiquariat Dr. Jörn Günther wurde ein Exemplar mit Druckermarke und 22 Holzschnitten als letzter vom 20. Mai 1531 datierter Druck Johann Schöffers angeboten (Katalog wie Fn. 159), 51.

${ }^{174}$ Nach der Beschreibung im Katalog Nr. 302: Bücher von 1501-1700 des Hamburger Antiquariats (2003), Nr. 566 (Sammelband mit sechs Schriften).
} 


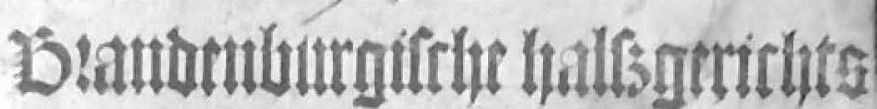

o2011115

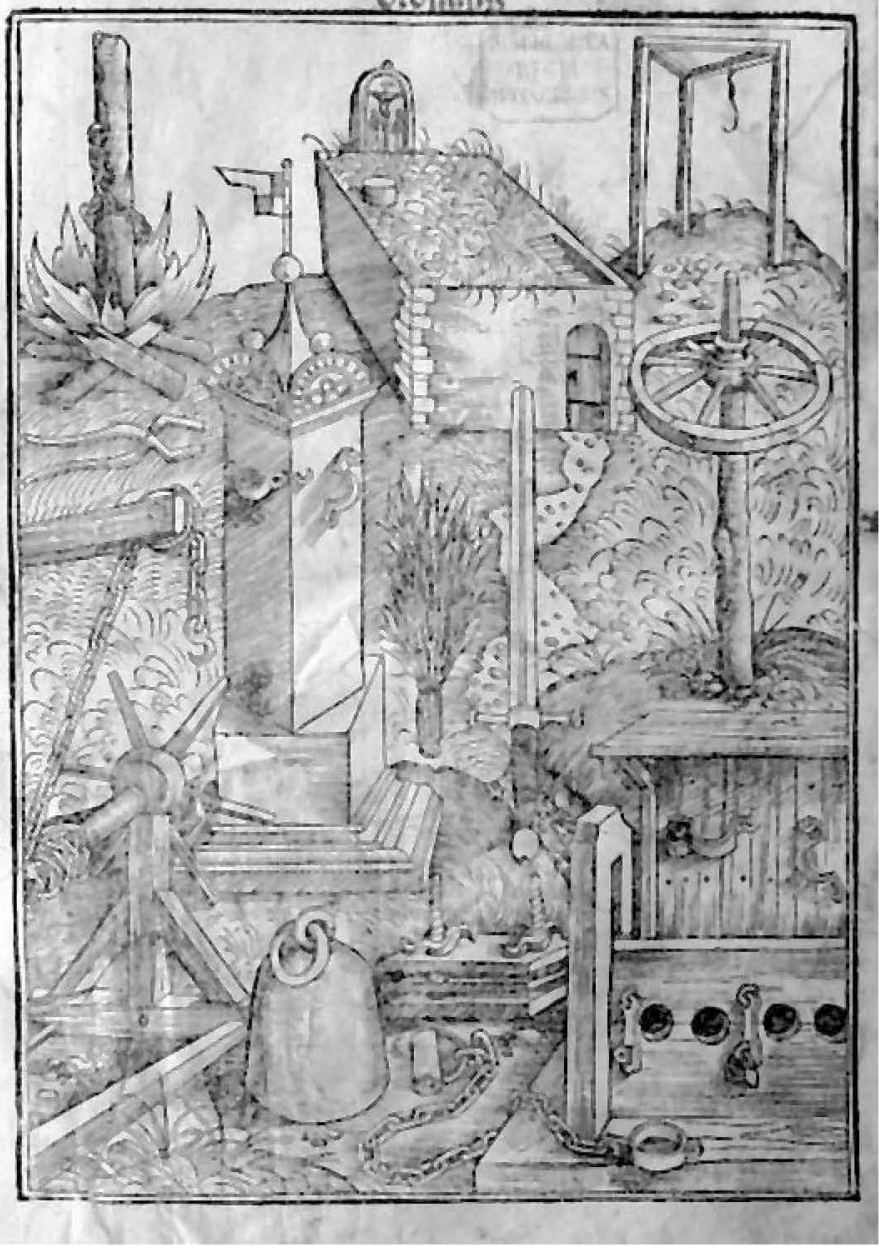

Abb. 9: Titelblatt der Brandenburgischen Halsgerichtsordnung, gedruckt von Jobst Gutknecht, Nürnberg 1516. Das Motiv findet sich ähnlich in verschiedenen Ausgaben der Bambergensis. Das Werk enthält insgesamt drei Holzschnitte, und zwar auf der Rückseite des Titels ein ganzseitiges Wappen und zwischen Register und Gesetzestext ein gleichfalls ganzseitiges Gerechtigkeitsbild. Unter ihnen sind links Menschen im Himmel und rechts Menschen in der Hölle dargestellt. Ein Spruchband über dem Bild sagt: "Gedenck all zeyt der letzten ding/ So wirt dir rechttun ar gering." (Aus der Bayerischen Staatsbibliothek München, Aufnahme Franziska Wieczorek) 
Kaiser Maximilian I. (1493-1519) war ein Freund und Förderer der Buchkunst. Dürer und Cranach schmückten seine Gebet- und Stundenbücher. Über 100 Bücher soll er herauszugeben beabsichtigt haben. ${ }^{175}$ Juristische Bücher waren anscheinend nicht darunter. Aber Peter Schöffer d. Ä (1427-1503), Johann Schöffer († 1531) und Ivo Schöffer (der 15311555 druckte) wurden in Mainz mit kaiserlichen Privilegien zur Dynastie der "Reichsdrucker", die viele "amtliche" Drucksachen anfertigte. Diese zeichneten sich in der Regel aber nicht durch besonderen Bilderschmuck aus. Die Editio Princeps der Carolina von 1532, gedruckt 1533 von Ivo Schöffer, war mit vier Holzschnitten ausgestattet.

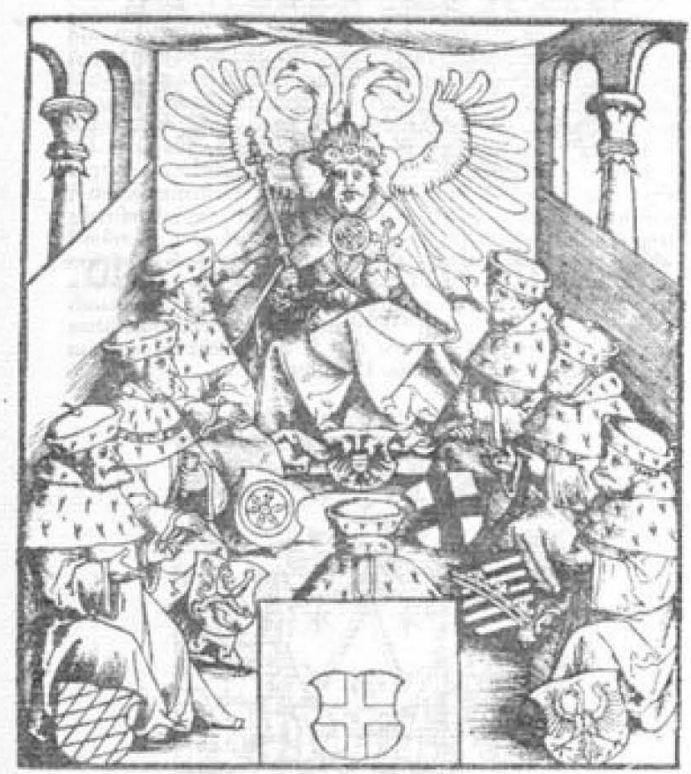

Abb. 10: Der Kaiser im Kreise der Kurfürsten. Letzte Seite der Carolina, gedruckt von Ivo Schöffer, 1533

Die Motive der Titelblätter und der Bilder im Werk wechseln von Jahr zu Jahr. Einige Ausgaben sind gänzlich unbebildert. Frankfurter Drucke durch Nikolaus Basse von 1581 und 1594 haben einen großen Titelholzschnitt und sechs etwa halbseitige Textholzschnitte. Die Bilder zeigen Gerichtsverhandlungen und verschiedene Folter- und Hinrichtungsmethoden.

175 KUNZE, Geschichte der Buchillustration (Fn. 31), 224 ff., 230; MUTHER, Die Deutsche Buchillustration (Fn. 155), Bd.1, Xf. 
Zahlreicher sind die Bilder in der von Stintzing ${ }^{176}$ so genannten populären Literatur des römisch-kanonischen Rechts im Anfang des sechzehnten Jahrhunderts. Hier bestätigt sich ein allgemeiner Trend der Zeit, vor allem volkssprachliche Bücher mit Illustrationen zu versehen. ${ }^{177}$ Der "Layenspiegel ${ }^{\prime \prime 178}$ von Ulrich Tenngler begann in der ersten Auflage mit drei Holzschnitten. Das Frontispiz zeigte Tenngler als alten, bärtigen Mann, von seinen drei Frauen und 24 Kindern umringt, der dem Kaiser sein Werk kniend überreicht, das zweite Bild eine Satansszene, das dritte die ganze Breite mittelalterlicher Strafen. Tenngler starb kurz vor Vollendung der zweiten Auflage von 1511.

Seither wurde das Werk von Sebastian Brant herausgegeben, der schon an der ersten Ausgabe mitbeteiligt war. In den folgenden sechzehn Ausgaben stieg die Zahl der Bilder auf über dreißig. ${ }^{179}$ Zahl und Art der

176 STINTZING, Geschichte der populären Literatur des römisch-kanonischen Rechts (Fn. 78).

177 KUNZE, Geschichte der Buchillustration (Fn. 31), 92.

${ }^{178}$ Zum Layenspiegel StINZTING, Geschichte der populären Literatur des römischkanonischen Rechts (Fn. 78), 411 ff.; KASPERS/SCHMIDT-THOME/ GERIG/MANSTETTEN, Vom Sachsenspiegel zum Code Napoleon (Fn. 6), $122 \mathrm{ff}$.

${ }^{179}$ Nach dem Antiquariatskatalog Dr. Jörn Günther enthält eine 1514 von Matthias Hupuff in Straßburg gedruckte Ausgabe 38 Holzschnitte von 24 Stöcken. MUTHER, Die Deutsche Buchillustration (Fn. 155), 92, Nr. 1508) beschreibt eine Ausgabe, die 1509 von Hans Othmar für den Verleger Rynmann gedruckt wurde: Sie enthielt $29 \mathrm{Holz}$ schnitte (h. 190, br. $133 \mathrm{~mm}$ ), von denen neun (die Nummern 7, 8, 12, 13, 20, 23, 24, 25, 27) wiederholt werden. Der Titelholzschnitt zeigt über einem Portal in den Wolken Gott Vater und die Maria, unter ihnen den heiligen Geist, recht und links Engel. Unten rechts sitzt ein Mann an einem Pult, auf dem ein offenes Buch liegt. Vor ihm stehen fünf andere, die mit ihm disputieren. - Die übrigen Holzschnitte sind ähnlichen Inhalts. In einer weiten Landschaft, durch die sich eine Mauer hinzieht, steht in der Mitte Christus, der in der linken Hand eine Wage hält, mit der rechten den Segen erteilt. Vor ihm knien nackt mit gefalteten Händen links Adam, rechts Eva. Ein König mit Szepter und Reichsapfel sitzt auf erhöhtem Throne im Kreise weltlicher und geistlicher Fürsten. Vor ihm auf der Treppe kniet ein Mann, untern sind Ritter zu Pferde. Ein Greis sitzt unter einem Baldachine, links stehen Flötenbläser, rechts Ritter. Über dem Baldachin schwebt Gott Vater, der mit der rechten Hand den Segen erteilt. Männer disputieren, einer sitzt an einem Tisch, auf welchem Papier und Schere liegen, und hält in der linken Hand eine Feder, in der rechten ein Buch. Vor ihm steht ein anderer mit einem Stock. In den Wolken schwebt Christus als Weltenrichter. - Bürger sprechen in einem Hofe lebhaft mit einem rechts aus einem Fenster herausschauenden Mann, der ihnen eine Papierrolle vorliest. - Zehn Männer sitzen im Kreise in einem Zimmer; der mittlere, der ein Szepter hält, sitzt auf einem großen Sessel, der vordere rechts kniet und hält ein mit hebräischen Buchstaben versehenes Buch. - Ein alter Mann mit Szepter sitzt von vier anderen umgeben vor einem Zelte, davon stehen ein Teufel, ein Priester und ein Engel. Untern rechts sitzen zwei Männer an einem Lesepult, links gehen zwei andere spazieren, in der Mitte sitzt ein Hund, der an einem Knochen nagt. - Ein alter König reicht einem vor ihm knienden Priester einen Brief. Ein alter Mann mit Szepter sitzt zwischen vier anderen unter einem Baldachin. Davon stehen andere, die lebhaft zusammen sprechen. Im Vordergrunde links sitzt an einem Tische ein Schreiber. - Gott Vater und Christus, über denen die Taube des heiligen 
Bilder wechseln je nach Druckort und Ausgabe. Es überwiegen die Darstellungen aus den verschiedenen Stadien des Strafprozesses (Anklage, Folter, Urteilsverlesung, Gefängnis und Hinrichtung). Bemerkenswert sind aber auch eine instruktive Zeichnung zum Mühlrecht und drei Baumstrukturen, eine davon in der Form einer Fahne (vexillum).

Der "Richterlich Clagspiegel" 180 war in den ersten Druckausgaben im 15. Jahrhundert noch bilderlos. Die zahlreichen seit 1516 von Sebastian Brant edierten Auflagen enthielten je drei Holzschnitte mit Gerichtsszenen, davon einer als Frontispiz und je einer zu Beginn des zivilrechtlichen und des strafrechtlichen Teils. Die beiden letzteren sind sich sehr ähnlich. Der auf dem Titel zeigt eine Gerichtsstube mit dem Richter und den Parteien, der zweite den Kaiser mit den Kurfürsten, davor einen Mann mit einem Buche, oben in den Wolken die Krönung der Maria, daneben Gott Vater und Christus. Ein Motiv wurde aus Tennglers Layenspiegel übernommen.

Geistes schwebt, sitzen auf dem Wolkenthrone. Unten in der Landschaft knien zwei Teufel, der männliche mit Bockshörnern und Bocksfüßen, der weibliche mit Froschkopf, Froscharmen und Froschbeinen, und lesen aus Büchern vor. - Adam und Eva stehen unter dem Baume der Erkenntnis, darüber schwebt der Engel mit dem Schwerte, der sie aus dem Paradies treiben will; ein anderer Engel posaunt zum jüngsten Gericht; unten schmachten die Sünder im Fegefeuer, davon stehen verschiedene Teufel - Christus schwebt von den Heiligen umgeben in der Glorie. Darunter steht Maria und breitet ihren Mantel über die nackten Seligen, die mit gefalteten Händen vor ihr knien. Daneben sehen Engel und Teufel, ganz unten sitzen schreibend die Evangelisten. - Maria wird von Gott Vater und Christus im Beisein von Engeln und Heiligen gekrönt. Untern kämpfen Engel gegen Teufel; in der Mitte unten ist das Monogramm H. F. - Ein geharnischter König sitzt von vier alten Männern umgeben auf dem Throne. Davon stehen vier andere, von denen einer einen Stock, ein zweiter ein Schwert trägt, und sprechen mit einem rechts an einem Schreibpult sitzenden Jüngling. - Ein Pförtner steht mit einem großen Schlüssel am Stadttor, zu dem drei gefesselte Männer von Häschern hereingeführt werden. - Ein Verbrecher, an dessen Füssen eine schwere eiserne Kugel befestigt ist, wird an einem Seile in die Höhe gewunden; ein anderer wird mit Öl bestrichen, um verbrannt zu werden; einem dritten werden mit einem schweren Klotz die Hände zerschlagen. - Dann kommt auf dem Raum zweier Seiten (h. 190, br. $285 \mathrm{~mm}$ ) die Darstellung der verschiedenen Strafen. Ein Manu muss beichten, ein zweiter wird gehängt, ein dritter gerädert, ein vierter verstümmelt, ein fünfter gepeitscht, ein sechster geköpft, einem siebenten der Bauch aufgeschnitten. - Die letzten Holzschnitte haben wieder die gewöhnlichen Maße. Im Hofe einer königlichen Burg sieht ein alter Mann zum Fenster heraus und liest mehreren unten stehenden Lanzenträgern aus einer großen Papierrolle vor, links vor dem Eingangstor patrouilliert eine Schildwache. - Die jugendliche Maria, über welcher die Taube des heiligen Geistes schwebt, wird von Gott Vater und Christus gekrönt; unten disputiert der Papst mit den rings um ihn sitzenden Erzbischöfen und Kardinälen. Davor kniet ein Jüngling, der ein Buch hält.

180 Zum Klagspiegel STINTZING, Geschichte der populären Literatur des römisch-kanonischen Rechts (Fn. 78), 337 ff.; ferner PETER JENTZNIK (Hrsg.), Sebastian Brant. Der Rich. terlich Clagspiegel. 2. Aufl., Limburg 1993. 
$\mathrm{Zu}$ der für die „Halbgelehrten"181 bestimmten Rechtsliteratur zählt auch der in vielen Auflagen und Versionen gedruckte "Belial" des Jacobus de Theramo, ein volkstümliches Lehrbuch, welches das römisch-kanonische Verfahrensrecht am Beispiel eines Prozesses zwischen Christus und dem Teufel vor König Salomon als Richter darstellte, in dem der Prophet Jeremia als Sachwalter des Teufels und der Philosoph Aristoteles als Vertreter Christi agieren. ${ }^{182} 21$ seit 1472 gedruckte illustrierte Ausgaben waren mit bis zu 60 Holzschnitten ${ }^{183}$ versehen, die freilich überwiegend unter Benutzung der gleichen Druckstöcke hergestellt wurden. Hier gehen Bild und Text eine engere Verbindung ein. Der Ablauf des Verfahrens wird geradezu in Bildergeschichten erzählt.

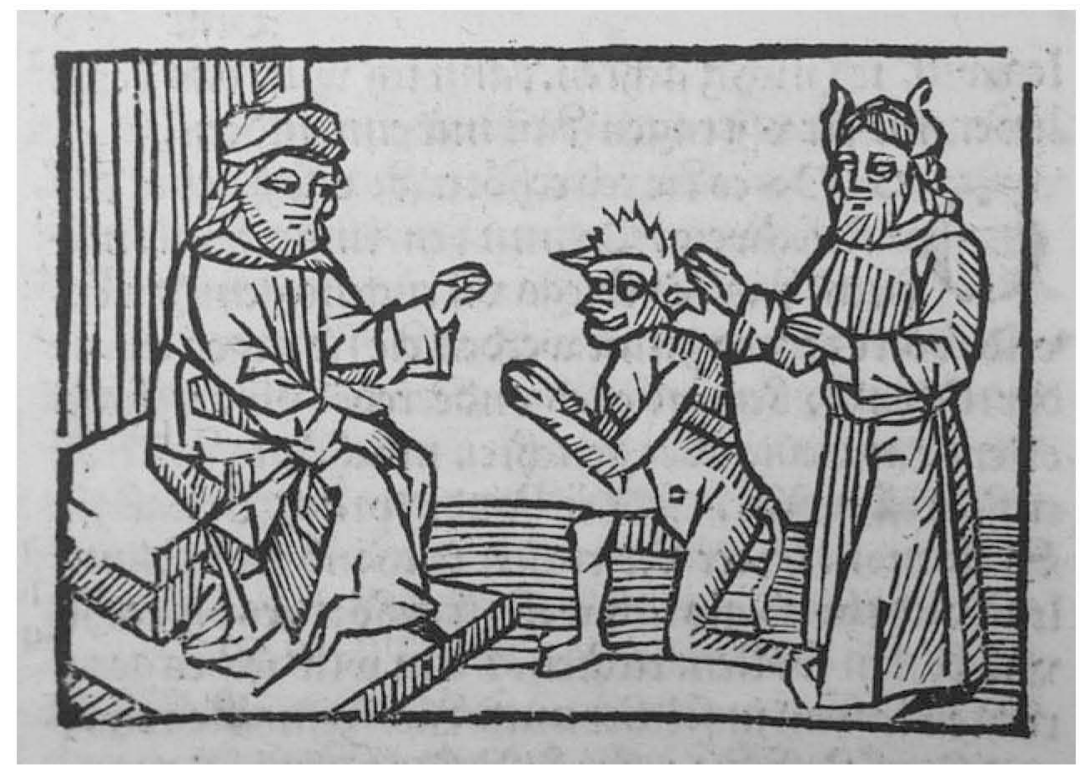

Abb. 11: Siebentes Bild aus Jacobus de Theramo, Belial, Straßburg 1508: Belial überreicht Salomon die Klageschrift (Sächsische Landesbibliothek Dresden, Aufnahme Franziska Wieczorek).

${ }^{181}$ STINTZING, Geschichte der populären Literatur des römisch-kanonischen Rechts (Fn. 78), XXVII.

182 Dazu STINTZING, Geschichte der populären Literatur des römisch-kanonischen Rechts (Fn. 78), 271 ff., sowie ausführlich OTT, Rechtspraxis und Heilsgeschichte (Fn. 53), 193, $210 \mathrm{ff}$.

${ }^{183}$ Spätere Ausgaben zeigten auch Kupferstiche: KUNZE, Geschichte der Buchillustration (Fn. 31), 119. 
Ein halbes Jahrhundert jünger ist eine gleichfalls noch an „Halbgelehr$t^{\prime \prime}$ gerichtete Literaturgattung, nämlich Formularbücher für das Notariat. ${ }^{184}$ Darin finden sich aber nur noch vereinzelte Bilder. So enthält z. B. Abraham Saurs „Penus Notariorum“ in der ersten Auflage von 1582 außer einem Titelblatt in üppigem Rot-Schwarz-Druck mit Druckersignet (Nicolaus Bassum, Frankfurt a. M.) nur einen Holzschnitt. In der Ausgabe von 1595 waren es drei Holzschnitte. Das „Formula/Jurament und Eidtbuch" des gleichen Autors von 1586 ist immerhin mit vierzehn Holzschnitten ausgestattet, darunter vier Wappen. Die anderen Bilder sind recht unspezifisch und tauchen teilweise auch in einem mit $25 \mathrm{Holz}$ schnitten illustrierten Erbrechtsbuch des gleichen Autors von 1593 wieder auf ("Güldiner Fluß und Außzug. Von Erbschaften ... "). Von Abraham Saur gibt es auch einen "Fasciculus de poenis, volgo Strafbuch", das weitgehend auf die Carolina zurückgreift. Er wurde, gleichfalls bei Nicolaus Basse in Frankfurt, seit 1577 mindestens vier Mal gedruckt. Eine Ausgabe von 1581 zeigt, neben einer kleinen Holzschnittdruckermarke und hessischem Wappenholzschnitt, erstmals neun Textholzschnitte zu verschiedenen Straftaten wie Gotteslästerung, Totschlag, Münzfälschung, Aufruhr, Beihilfe zur Flucht und Bestechlichkeit der Richter (zwei Wiederholungen). ${ }^{185}$ Die Ausgabe von 1594 war anscheinend wieder ohne Bilder. ${ }^{186}$

Reich bebildert waren einige $z \mathfrak{u}$ ihrer Zeit offenbar weit verbreitete Lehrdarstellungen von Johannes Millaeus, Justin Gobler (1504-1569) und Iodocus (Jost) Damhouder (1507-1581). Das 1541 in Paris gedruckte Strafrechtsbuch von Millaeus verweist schon im Titel auf seine Bilder: "Praxis criminis persequendi elegantibus aliquot figuribus illustrata". Es ist bekannt wegen der detailliert realistischen Folterszenen. ${ }^{187}$ Großzügig illustriert waren die Bücher von Justin Gobler, nämlich der „Rechtenspiegel" von 1558 und das "Statute Buch" von 1558/1564. Im "Rechtenspiegel" von 1558 und 1564 finden sich 39 Bilder zu den verschiedensten Rechtsgebieten; im "Statutebuch" von 1558 sind vier Illustrationen enthalten, in einer Ausgabe 1572 neunzehn Bilder, von denen sieben aus

\footnotetext{
${ }^{184} \mathrm{Zu}$ diesen näher KASPERS/SCHMIDT-THOMÉ/GERIG/MANSTETTEN, Vom Sachsenspiegel zum Code Napoleon (Fn. 6), 171 ff.

185 Nach der Beschreibung im Katalog Nr. 302: Bücher von 1501-1700 des Hamburger Antiquariats (2003), Nr. 566 (Sammelband).

186 Ebd. Nr. 512.

187 Vgl. FRANZ HEINEMANN, Der Richter und die Rechtsgelehrten. Justiz in frïheren Zeiten. Leipzig 1900 (Nachdruck Düsseldorf 1969), 64 f., Abb. 61 f.; KASPERS/SCHMIDTTHOMÉ/GERIG/MANSTETTEN, Vom Sachsenspiegel zum Code Napoleon (Fn. 6) SCHILD, Alte Gerichtsbarkeit (Fn. 46), 163, Abb. 345-347.
} 
dem "Rechtenspiegel" übernommen wurden. ${ }^{188}$ Die Bilder nehmen in der Regel die Hälfte oder ein Drittel der Seite ein und sind jeweils nach den Überschriften angeordnet. Sie dienen sozusagen als Einstimmung in das Thema.

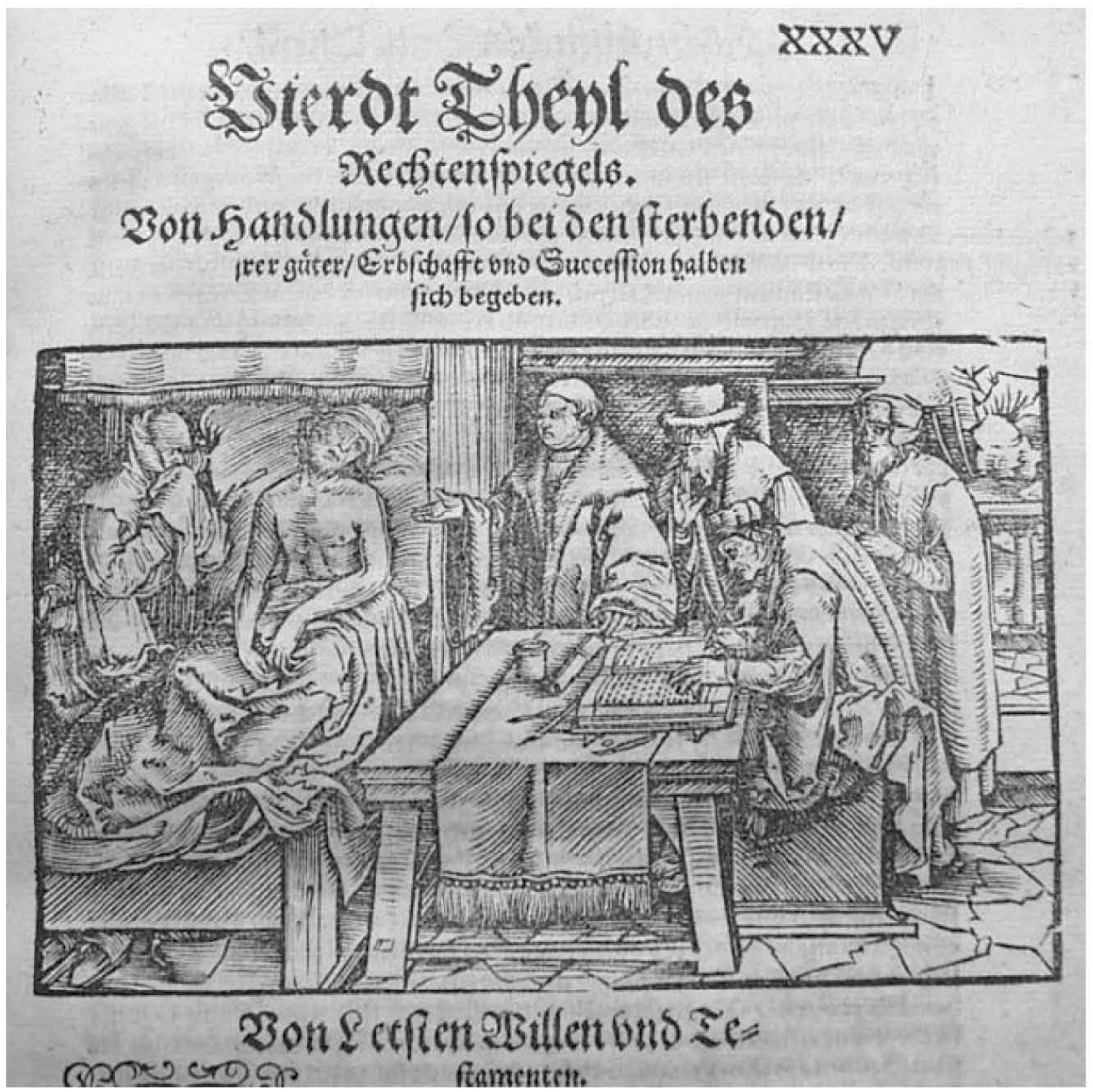

Abb. 12: Aus dem Rechtenspiegel von Justin Gobler (1558), gedruckt bei Christian Egenolffs Erben, Frankfurt am Main (Aufnahme Franziska Wieczorek)

188 Holzschnitte aus dem Rechtenspiegel wurden auch noch in anderen Werken GOBLERS verwendet. Zwölf illustrieren das Buch "Keyserlicher und des H. Reichs Rechten/die Vier Bïcher der Instituten und Underweisung Keysers Justiniani. [...]", Frankfurt am Main 1561. 
Der Bilderreichtum in den Werken Goblers wurde von den Büchern Damhouders ${ }^{189}$ noch übertroffen. Es spricht für die Prominenz Damhouders, dass in der Titelei vieler seiner Bücher stattliche Porträts des Autors zu finden sind.

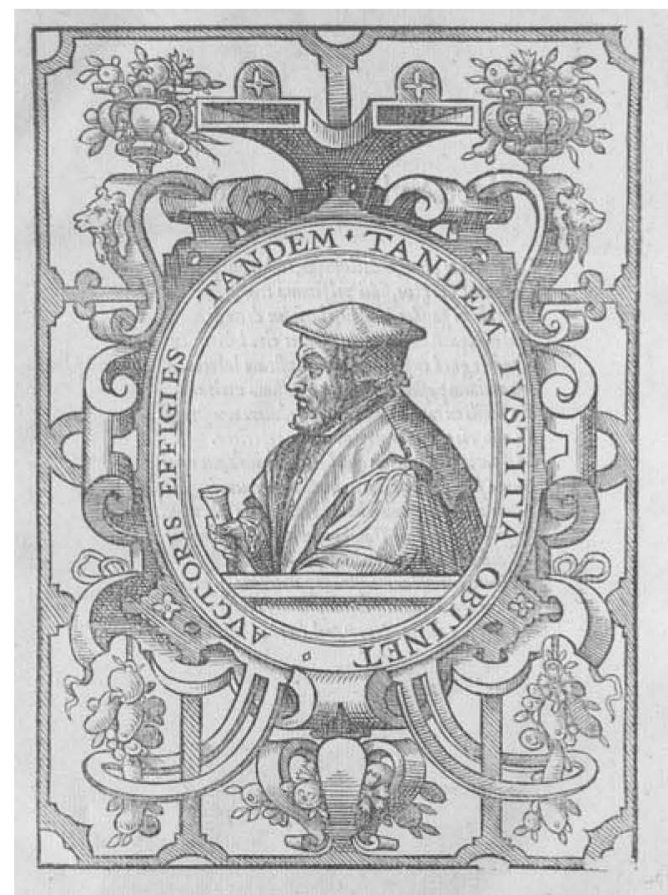

Abb. 13: Bild des Autors, aus Jost Damhouder, Practica Gerichtlicher Handlungen in Bürgerlichen Sachen, gedruckt bei Nicolaus Basseus. Frankfurt am Main 1575 (Bayerische Staatsbibliothek München, Aufnahme Franziska Wieczorek)

Eine deutsche Ausgabe von Damhouders "Praxis rerum criminalium" von 1565 ragt mit 64 Textholzschnitten heraus, die sich sämtlich in einer 1571 in Frankfurt am Main erschienenen Auflage wiederfinden. ${ }^{190}$ Auch bei Damhouder sind die Bilder in der Regel nach den Kapitel-

${ }^{189}$ Ausführlich zu Person und Werk, insbesondere auch zu den Bildern, ANDREAS BAUER, Joos de Damhouder und seine Praxis gerichtlicher Handlungen in Bürgerlichen Sachen, in: JOST HAUSMANN/THOMAS KRAUSE (Hrsg.), Zur Erhaltung guter Ordnung. Festschrift fiur Wolfgang Sellert. Köln 2000, 269-318.

190 Eine Faksimile-Ausgabe wird von Auvermann \& Keip für die Reihe „Bibliothek des Deutschen Strafrechts. Alte Meister" vorbereitet. 
überschriften angeordnet. Den deutschen Ausgaben ging eine Antwerpener Ausgabe voran 1544, die schon weitgehend die gleichen Holzschnitte zeigte. Aber die Linien in den späteren Ausgaben sind nicht mehr so klar. Anscheinend waren die Druckstöcke an den Frankfurter Drucker (Joann Wolf) weitergegeben worden und hatten sich im Laufe der Zeit abgenutzt.

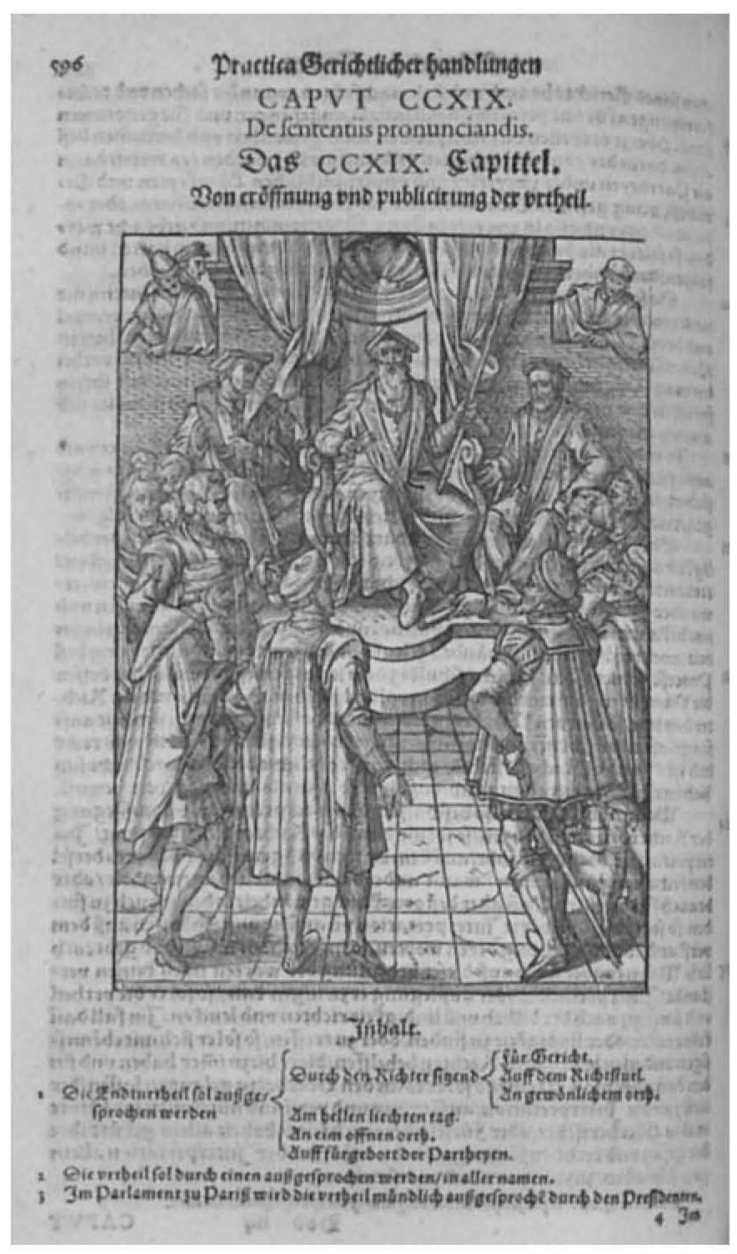

Abb. 14: Die Verkündung des Urteils, aus Jost Damhouder, Practica Gerichtlicher Handlungen in Bürgerlichen Sachen, gedruckt bei Nicolaus Basseus, Frankfurt am Main 1575 (Bayerische Staatsbibliothek München, Aufnahme Franziska Wieczorek) 
Spätere Frankfurter Ausgaben verwenden neue Bildmotive zur Illustration. Zugleich geht die Anzahl der Bilder zurück. In der Ausgabe des "Praxis rerum criminalium" von 1591 finden sich außer einem Porträt des Autors nach dem Titel nur noch zwölf Bilder zum Text. Gleichfalls im Jahr 1591 erschien in Köln eine nur taschenbuchgroße Ausgabe der „Praxis rerum criminalium" ganz ohne Bilder.

Im Strafrecht bieten sowohl die Tat als auch die Sanktionen konkretere Vorwürfe für Illustrationen als die Tatbestände und Rechtsfolgen des Zivilrechts. Ganz allgemein widmen sich daher die meisten Bilder strafrechtlichen Themen. Deshalb ist es bemerkenswert, dass auch ein ganz dem Zivilrecht gewidmetes Werk bebildert wurde. Damhouders „Praxis rerum civilium" von 1567 ist wegen ihres ganzseitigen Titelholzschnitts bekannt, der eine Justitia mit zwei Gesichtern zeigt, deren eines verhüllt ist. ${ }^{191}$ Insgesamt enthält das Werk 14 ganzseitige Holzschnitte, die überwiegend aus der "Praxis rerum criminalium" übernommen wurden. Die Übernahme war problemlos möglich, weil die Bilder Verfahrensabläufe zeigen, die in Zivilsachen ganz ähnlich sind. Deutsche Ausgaben erschienen 1575, 1581 und 1591 bei Nikolaus Basse in Frankfurt am Main. Dafür wurde zwar eine Serie von 14 neuen Holzschnitten angefertigt. Sie setzen jedoch nur in etwas kleinerem Format das Bildprogramm aus der lateinischen Ausgabe um. ${ }^{192}$

\section{Zur Ästhetik gedruckter Rechtsbücher}

Obwohl die spätmittelalterlichen Bilderhandschriften in großer Zahl hergestellt wurden, waren sie doch durchweg von guter handwerklicher und teilweise sogar von künstlerischer Qualität. Dagegen fallen die gedruckten Bücher deutlich ab. Das liegt nur teilweise an der Technik des Holzschnitts. Die Buchillustrationen des 16. Jahrhunderts waren selten von wirklichen Künstlern ausgeführt. Künstler wie Dürer hätten ihre Arbeiten kaum zur Illustration von Texten hergegeben, denn sie sahen in ihren Bildern die Hauptsache. ${ }^{193}$ Das schließt nicht aus, dass insbesondere Dürer, aber auch Cranach, Holbein und andere zeitgenössische Künstler auch auf die Gebrauchsgrafik im Buchdruck Einfluss hatten, dass sie stilbildend wirkten, vielfach nachgeahmt wurden und gelegentlich sogar selbst Vorlagen beisteuerten.

Die Bildausstattung der Bücher war Sache der Drucker, die zugleich als Verleger das wirtschaftliche Risiko trugen und die Bebilderung vor

191 Bei OtTO RuDOLF KISSEL, Die Justitia. München 1984, 120.

192 Näher BAUER, Joos de Damhouder (Fn. 189), 289 ff.

${ }^{193}$ GOLDSCHMIDT, The Printed Book (Fn. 71), 56. 
allem als verkaufsfördernde Maßnahme ansahen. In der Regel ließen sie die Holzschnitte von handwerksmäßig arbeitenden Illustratoren herstellen, die nach Vorlagen oder gar mit Schablonen arbeiteten. Sie statteten aus Sparsamkeit neue Bücher oft mit alten Holzschnitten aus, die sie für andere Bücher hatten anfertigen lassen oder die sie von anderen Druckern erwarben. Sie verstümmelten die Druckstöcke, um sie kleineren Formaten anzupassen; sie zersägten sie, um ihre Teile neu zu kombinieren. Nicht selten findet sich dasselbe Bild in einem Buch wiederholt zur Darstellung verschiedener Personen, Örtlichkeiten oder Begebenheiten. ${ }^{194}$ Auffällig ist, wie unsystematisch die Bilder über die Bücher verteilt wurden. Auf genaue Übereinstimmung von Bild und Text kam es nicht an. Die Phantasie der Beschauer musste einspringen, ${ }^{195}$ und solche Nachhilfe fiel nicht schwer, denn das Publikum erwartete, anders als heute, keine "authentischen" Bilder.

Kaspers betont, das gedruckte Rechtsbuch habe in der Geschichte der Typografie keine Sonderstellung eingenommen. Es sei aber doch wegen seiner Bedeutung und "Amtlichkeit" Gegenstand besonderer Aufmerksamkeit gewesen, was zum „schönen Rechtsbuch in drucktechnisch vollendeter Gestalt" geführt habe. ${ }^{196}$

„Die Drucktypen sind dem Gewicht des Inhalts angemessen, die Abbildungen häufig von namhaften Künstlern hergestellt. Hinzu kommen Wappen, allegorische Darstellungen, Druckerzeichen und im Bild veranschaulichte Rechtshandlungen, die rechtsgeschichtlich, kulturhistorisch und kunstgeschichtlich in gleichem Maße Beachtung verdienen."

Kaspers stellt als Meister der "schönen gedruckten Rechtsbücher" Christian Egenolff (1502-1555) heraus, der 1530 die erste ständige Druckerei in Frankfurt am Main einrichtete. So scheint das gedruckte Rechtsbuch, jedenfalls im 16. Jahrhundert, in ästhetischer Hinsicht doch eine gewisse Sonderstellung eingenommen zu haben.

Gedruckte Bücher unterscheiden sich von den spätmittelalterlichen Manuskripten nicht zuletzt durch die fehlende Farbe. Im 15. Jahrhundert versuchte man zunächst, die farbigen Manuskripte nachzuahmen. Dazu wurden die Blätter, insbesondere Holzschnitte und Initialen, nachträglich von Hand koloriert. Solche Handarbeit machte jedoch den Rationalisierungsvorsprung der Drucktechnik zunichte. Gutenberg wollte ursprünglich zweifarbig drucken, und einige Exemplare seiner Bibel tragen auch rote Überschriften. Doch diese Technik erwies sich als zu schwierig,

${ }^{194} \mathrm{Zu}$ Mehrfachverwendung von Holzschnitten KUNZE, Geschichte der Buchillustration (Fn. 31), 108 f.; MuTHER, Die Deutsche Buchillustration (Fn. 155), Bd. 1, VI f.

195 SONDHEIM, Die Illustrationen zu Thomas Murners Werken (Fn. 104), 6.

196 KASPERS/SCHMIDT-THOME/GERIG/MANSTETTEN, Vom Sachsenspiegel zum Code Napoleon (Fn. 6), 258 f. 
so dass der monochrome Druck sich schnell durchsetzte. Immerhin gibt es gelegentlich, im 17. Jahrhundert etwas öfter, neben dem schwarzen Textblock rote Überschriften und Initialen.

Erstaunlich ist die "Verbildlichung" des Textes ${ }^{197} \mathrm{im}$ monochromen Buch. Bereits in der ersten Hälfte des 16. Jahrhunderts dienten typografische Hilfsmittel an Stelle von Farbe dazu, den Leser durch komplexe Texte zu führen. Vorbildlich in dieser Hinsicht war der Pariser Wissenschaftler und Drucker Robert Estienne (1503-1559). Er verwendete gedruckte Initialen und eine Vielzahl unterschiedlicher Schriftgrößen und Typen, um verschiedene Teile des Textes gegeneinander abzuheben. ${ }^{198}$ Dieser Stil prägt bald darauf das Layout vieler Pandektenausgaben. Sie sind zweispaltig gehalten. In der Mitte der Seite, bei Bedarf nach oben oder unten versetzt, wird in einer etwas größeren Type der Pandektentext abgedruckt. Er wird auf beiden Seiten gerahmt von der etwas kleiner gedruckten Glosse. Diese Seiteneinteilung zur Gegenüberstellung von Text und Glosse war schon seit dem Ende des 12. Jahrhunderts bekannt. Jetzt wurde sie perfektioniert. Zusätzlich verweisen auf beiden Rändern Marginalien auf die Kommentatoren. Ein schönes Beispiel (Abbildung 15) mit kunstvollen Bildinitialen und farbigen Majuskeln bietet eine siebenbändige Pandektenausgabe aus Lyon von 1575.199

197 Begriff von MIKE SANDBOTHE, Zur Semiotik der Hypertextualität. Bild, Sprache und Schrift im World Wide Web, in: GünTER BeNTELE/Michael Malder (Hrsg.), Aktuelle Entstehung von Öffentlichkeit. Akteure - Strukturen - Veränderungen. Konstanz 1997, 587594.

${ }^{198}$ MiCHAEL TWYMAN, The British Library Guide to Printing. History and Techniques. London $1998,30 \mathrm{f}$.

199 Zentrales Rechtswissenschaftliches Seminar der Ruhr-Universität Bochum, Sign. 29 N 32. 


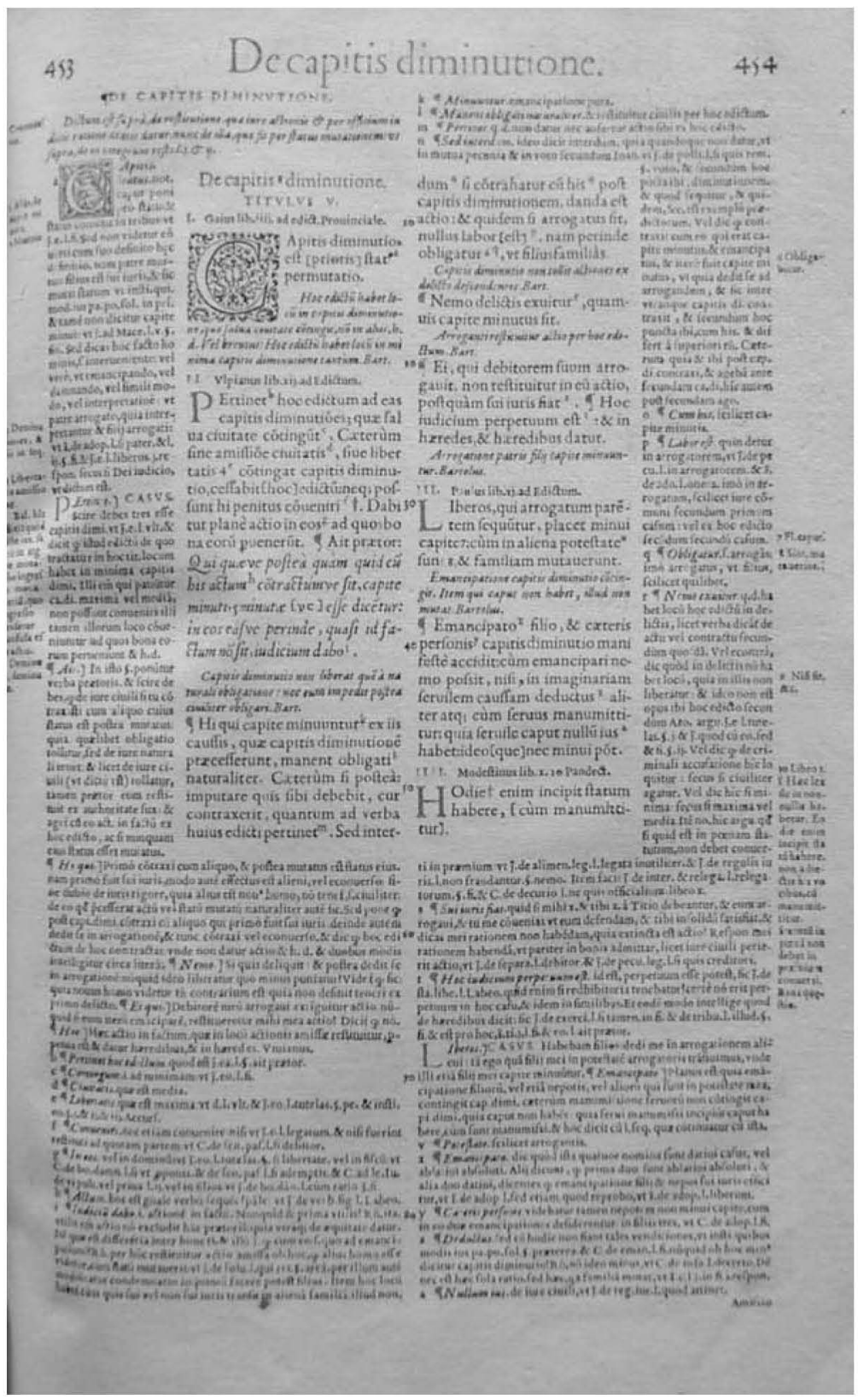

Abb. 15: Druckseite aus Digestum Vetus, Band 1, Lyon 1575, ohne Angabe des Druckers (eigene Aufnahme) 
Zur Standardausstattung der Ausgaben des Corpus Juris gehörten im 16. Jahrhundert neben dem Holzschnitt-Titel eine oder mehrere Arbores sowie ein Kaiserbild. Eine in Lyon erschienene Ausgabe von 1549/50 enthielt darüber hinaus vierzig Textholzschnitte. Es handelt sich um kleine Bilder in Spaltenbreite, die jeweils vor einzelnen Titeln angeordnet sind. Dazu kommen in dieser Ausgabe neben dem Kaiserbild und der Arbor Jurisdictionum drei weitere ganzseitige Arbores, eine Arbor de interdictis, eine Arbor exceptionum und eine Arbor super interesse. Eine jüngere Ausgabe von 1575 enhält nur noch die verzierte Arbor Jurisdictionum und zwei (fast identische) Kaiserbilder. In den Gothofredus-Ausgaben des Corpus Juris, 200 die ab 1583 erscheinen, sind die Bilder dann verschwunden. Als Schmuck blieben nur noch Bordüren auf dem Titel, Initialen und Schlussvignetten, so in einer von Johannes Fehi edierten Ausgabe, die 1627 in Lyon erschien. ${ }^{201}$ Dafür sind die Inhaltsübersichten in ramistischer Klammertechnik gehalten.

Ähnlich wie das Corpus Juris Justinians wurden im 16. Jahrhundert auch die Druckausgaben des Corpus Juris Canonici ausgestattet. Eine Ausgabe des Liber Decretalium Gregors IX., gedruckt 1511 in Basel, zeigt neben einer großen Holzschnittdruckermarke auf dem Titel drei große Textholzschnitte, und zwar je eine Arbor consanguinitatis und affinitatis sowie ein Bild des Papstes bei der Entgegennahme des Liber decretalium aus den Händen seiner Rechtsgelehrten und Theologen. ${ }^{202}$ Der gleiche Holzschnitt wurde auch für andere Bücher des Kirchenrechts verwendet, in denen er jeweils einen anderen Papst darstellt. ${ }^{203}$

$200 \mathrm{Zu}$ diesen TroJE, Graeca Leguntur (Fn. 74), $90 \mathrm{ff}$.

201 Der Nachdruck durch Otto Zeller, Osnabrück, 1965, zeigt den Titel mit Rot-SchwarzDruck. Es lässt sich nicht erkennen, ob auch das Corpus der Bände im Original noch Rot-Schwarz-Druck enthielt.

202 Nach der Beschreibung im Katalog Nr. 302: Bücher von 1501-1700 des Hamburger Antiquariats (2003), Nr. 119.

${ }^{203}$ MuTHER, Die Deutsche Buchillustration (Fn. 155), 196, Nr. 1288 und 197, Nr. 1291) nennt die Clementis Quinti Constitutiones in concilio vienensi edite - Sextus decretalium liber a Bonifacio VIII in Concilio Lugdunensi editus - und Gregorii IX Decretalium liber accuratissime emendatus cum concordantiis annotationibus et additionibus marginalibus und schreibt dazu: „Der (h. 235, br. $195 \mathrm{~mm}$ ) Holzschnitt ist in allen drei Büchern derselbe, nur dass er das eine Mal Papst Clemens V., das andere Mal Bonafacius VIII., das dritte Mal Papst Gregor IX. darzustellen hat, wie sie auf ihrem Throne sitzen und eine Deputation von Rechtsgelehrten und Mönchen empfangen. Die Umrahmung bilden zwei reich verzierte Pfeiler. Der Bogen, welcher sich über dieselben spannt, ist mit spielenden und sich tummelnden Engelknaben bemait, der Raum zwischen dem Bogen und den Ecken des Holzschnittes ebenfalls mit zwei geflügelten Engeln ausgefüllt. Durch dieses Gehäuse hat man Einblick in das Innere der Kirche. Hier sitzt links unter einem großen Baldachine, der Papst mit der dreifachen Krone auf dem Haupte und hält mit beiden Händen ein aufgeschlagenes Buch, das ihm ein davor kniender Priester mit der Rechten hinreicht. Dahinter stehen noch mehrere andere Mönche, andere Männer drängen sich zur Kirche herein. An der Hinterwand sieht 


\section{4. ,Illustrierende“ und "dekorative“Bilder}

Die Funktion der Bilder in den juristischen Handschriften und gedruckten Rechtsbüchern ist nicht von vornherein klar. Im lateinisch gelehrten kirchlichen Bereich bezeugte der Buchschmuck den gehobenen Anspruch des Textes, der sich in der Ausstattung mit kostbaren Deckfarbenminiaturen auf Goldgrund materialisierte. Die mit Federzeichnungen illustrierten Handschriften volkssprachlicher Texte und ebenso die Frühdrucke waren dagegen für den Laiengebrauch bestimmt, Laien freilich, die alles andere als "kleine Leute" waren und durchaus auch bibliophile Ansprüche hatten. ${ }^{204}$ Informationsvermittlung stand kaum im Vordergrund. Das gilt verstärkt seit dem Beginn der Massenproduktion von Büchern um die Wende zum 16. Jahrhundert. In erster Linie ging es wohl um ästhetische Ansprüche der Kundschaft, denen Drucker und Verleger entsprechen wollten. Adressat war jetzt das allgemeine Publikum, zu jener Zeit das aufstrebende, lesekundige Bürgertum. Anders als in den mittelalterlichen Handschriften hatten die Bilder neben dem Text nur noch eine untergeordnete Funktion. ${ }^{205}$ Ganz überwiegend wurde das Buch zum Medium des Textes.

man Bücher und Flaschen. An der Decke hängt eine runde Lampe. Von dem Buche, das der Papst in der Hand hält, geht ein großer Ast nach untern aus, der in feinen Zweigen fünf runde Medaillons mit Darstellungen aus dem Inhalt der fünf Bücher (Judex, Iudicium, Clerus, Sponsalia, Crimen) einschließt. Das Monogramm Grafs befindet sich oben an der Decke der Baldachins. Das Seitenstück zu diesem Holzschritt ist das (h. 230, br. $190 \mathrm{~mm}$ ) Titelbild des 1512 erschienenen Decretum Gratiani der nämlichen Verleger, welches darstellt, wie Gratianus die Decretalen sammelt. Ähnlich wie beim vorigen Holzschnitt ist auch hier die bildliche Darstellung von einem Gehäuse von Holzarchitektur umgeben. Ein Priester sitzt mit einem Buch auf dem Schoß in einem Zimmer am Schreibpulte und schaut sich nach drei Männern um, die rechts vor ihm knien und ihm aufgeschlagene Bücher vorhalten. Andere drängen zur Tür herein. An der Hinterwand stehen Bücher und Gefäße, durch die Fenster links hat man Ausblick ins Freie. Auf den breiten Rahmen ist besondere Sorgfalt verwendet. Oben sieht man durch Ranken voneinander getrennt Hieronymus und Augustin, auf dem linken Querstreifen Moses, Hiob, David, Jesaias und Jeremias, auf dem rechten Johannes, Matthaeus, Lucas, Marcus und Paulus; untern durch einen Engel voneinander getrennt Ambrosius und Gregorius. Übrigens sind beide Blätter in der Erfindung keineswegs neu, sondern schließen sich in ihrer allgemeinen Disposition den in früheren Ausgaben dieser Bücher enthaltenen an. Der erste Holzschnitt kam in ähnlicher Darstellung bereits in den von den nämlichen Verlegern 1494 und 1500 veranstalteten Ausgaben, sowie in der Pariser Folio-Ausgabe von 1490 und der Quart-Ausgabe von 1509 vor. Der zweite hat seine Vorgänger in den beiden von den nämlichen Verlegern 1493 und 1500 veranstalteten Quartausgaben. Grafs Holzschnitte wieder wurden in den späteren in Lyon 1519 erschienenen Ausgaben kopiert."

204 OTT, Rechtspraxis und Heilsgeschichte (Fn. 53), 197, 201.

205 GOLDSCHMIDT, The Printed Book (Fn. 71), 27. 
Die Bilderhandschriften waren nur möglich in einer Zeit, in der das Recht und seine Durchführung im Gericht und außerhalb drastisch und sinnfällig ausgestaltet war, in der es sich durch plastische und feierliche Rechtshandlungen unter reichhaltiger Verwendung von Rechtssymbolen dem Anschauungsvermögen von jedermann einprägen konnte. Entsprechend zeigen die Bilderhandschriften keine realistische Darstellung, sondern eine schematische, die Norbert Ott treffend charakterisiert hat:

„Ein knapper Bodenstreifen ohne Tiefe, auf dem sich die Szene abspielt (und der für Landschaft und Innenraum stehen kann), Reduzierung auf die nötigsten, für die Handlung gerade geforderten Personen, Hinweis auf Landschaft oder, Stadt' durch ein einziges, für alles stehendes Attribut wie Baum oder Gebäudeteil, eventuell Andeutung von Innenraum durch einen Blick in diesen, hindurch zwischen säulenbegrenzte Tore und Fensterdurchbrüche. Dieses zitathaft mit Versatzstücken arbeitende Verfahren erleichtert die Austauschbarkeit der Bildtypen und ihre Benutzung quer durch alle Gattungen sehr, ja ermöglicht sie erst." 206

Die speziell zur Illustration juristischer Texte nützliche Rechtssymbolik hat von Amira eingehend beschrieben: Bürgerliche Tracht, Standesund Amtstrachten des Papstes, des Kaisers und des Königs, des Grafen, des Schultheißen und der anderen Gerichtspersonen, Rüstungen zur Heerfahrt und zum Zweikampf, Stuhl und Thron, Urteilsbank, Dingstätte, Stab, Schwert und Fahne, Handschuh, Zweig, Scholle, Trauring, Fronkreuz, Marktkreuz und Kerze und schließlich Handgebärden und Körperhaltungen vor Gericht, etwa bei Eidesleistungen, oder die Positur des Richters, des Lehnsherren oder des Königs. Das alles war sehr anschaulich und ließ sich auch durch Bilder gut zeigen. Dennoch sah von Amira die Besonderheit der Dresdener Bilderhandschrift gar nicht in der vorgegebenen (objektiven) Symbolik des Rechts, sondern in der vom Künstler geschaffenen (subjektiven) Symbolsprache. Die Sachsenspiegelillustrationen haben über das 14. Jahrhundert hinaus keine Nachfolge gefunden. Dafür hat von Amira denn auch nicht die Abnahme des Verständnisses der Rechtssymbolik verantwortlich gemacht, die in dem Maße im 15. Jahrhundert noch gar nicht eintrat, sondern ein verändertes Kunstverständnis, das sich von dem mittelalterlichen Symbolismus abwandte.207 Wichtiger dürfte aber wohl der Umstand sein, dass mit der Erstarkung der Schriftkultur die Beglaubigungsfunktion der Bilder überflüssig wurde.

Im Anschluss an von Amira hat von Schwerin die bildlichen Darstellungen in Handschriften und frühen Drucken in zwei Gruppen oder

206 OTT, Rechtspraxis und Heilsgeschichte (Fn. 53), 199.

207 AMIRA, Die Dresdener Bilderhandschrift des Sachsenspiegels (Fn. 47), Bd. 1, Einleitung, 34 . 
Typen eingeteilt.208 Der „illustrierende“ Typ zeichnet sich durch den deutlichen und durchgehenden Bezug von Bild und Text aus. Prototypen sind natürlich die großen Bilderhandschriften des Sachsenspiegels mit ihren fortlaufenden, den gesamten Text begleitenden Illustrationen. ${ }^{209} \mathrm{Zu}$ diesem Typ zählen auch solche Bücher, die zwar nicht durchgehend illustriert sind, aber doch passend zum Text mit Bildern in größerer Zahl aufwarten. Der Gegentyp ist bloß dekorativ; er hat "vor allem des Schmuckes wegen einzelne Bilder aufgenommen“. Der Abstand zum Text zeigt sich schon durch die Platzierung, „insoferne das dekorative Bild als ganzseitige oder halbseitige Einlage oder in Initialen am Beginn einzelner Abschnitte erscheint, während die illustrierende Darstellung die $z u$ veranschaulichende Textstelle begleitet". Die dekorativen Bilder sind weniger zahlreich; und sie sind in der Regel am Kapitelanfang angeordnet. Solche Bilder eröffnen oder rahmen den Text, aber sie begleiten ihn nicht. Der Unterschied zeigt sich auch im Bildinhalt. Dekorative Bilder können für sich stehen und erscheinen oft austauschbar. Es handelt sich um verhältnismäßig wenige, häufiger wiederkehrende Motive, die zu mehr oder weniger allen Rechtstexten passen. Auch die Größe der Bilder spielt eine Rolle. Ganzseitige Bilder stehen zwangsläufig für sich, während kleinere in den Text eingebettet sind, so dass auch der inhaltliche Textbezug leichter hergestellt wird.

\footnotetext{
208 AMIRA/SCHWERIN, Rechtsarchäologie (Fn. 156).

209 AMIRA/SCHWERIN, Rechtsarchäologie (Fn. 156), 118, nennen als weitere Beispiele für den ersten Typ einige "verwandte sächsische Rechtsbücher", die Renessehandschrift des Schwabenspiegels und Handschriften des Belial sowie als Beispiel nichtrechtlicher Art den "Willehalm". Die Liste der "dekorierten" Rechtsbücher ist sehr viel länger. Als Beispiele werden genannt „Handschriften des Iglauer Rechts, des Brünner Schöffenbuchs, des Frankenspiegels und des Purgoldtschen Rechtsbuchs, das Soester Nequambuch, die Soester Sammelhandschrift mit Femegerichtsbild, die sogen. Kaiserbildhandschrift des Münchener Stadtrechts, ein Codex statutorum des Zwickauer Ratsarchivs, Kemptener Landgerichtsbücher, ein Revaler Codex des lübischen Rechts, das Würzburger Zentgrafenbuch, ein Herforder Rechtsbuch, ein Kampener Statuten buch, ein Volkacher Amtshandbuch, ein Ingolstädter Privilegienbuch, ein Regensburger Privilegienbuch, eine Magdeburger Schöffenchronik, ein Codex des Znaimer Stadtrechts, ein Memmelsdorfer Zentbuch, eine Handschrift des Aarauer Stadtrechts, eine Handschrift der Rottweiler Hofgerichtsordnung. Einzelne Handschriften des Schwabenspiegels sowie des Sachsenspiegels und anderer sächsischer Rechtsbüicher." Dekoration und Illustration halten sich die Waage insbesondere "in der Handschrift des Hamburger Stadtrechts von 1497, in einer Prachthandschrift der Goldenen Bulle, die König Wenzel 1400 herstellen ließ, sowie in einer Handschrift mit Krakauer Zunftordnungen".
} 


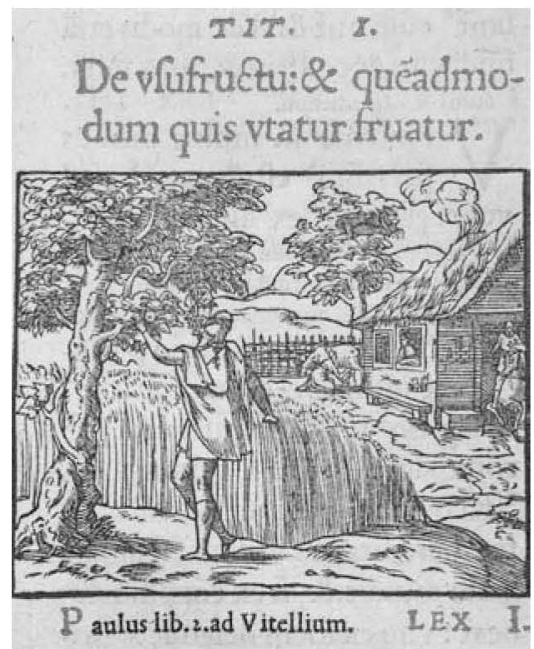

Abb. 16: Eine Pandektenausgabe aus Lyon von 1549/50 enthält vierzig Bilder, die, abgesehen von ganzseitigen Arbores und einem Kaiserbild, jeweils vor den einzelnen Titel angeordnet sind.

Ein Indiz für die bloß dekorative Bedeutung der Bilder ist der schnelle Wechsel der Bildausstattung von Ausgabe zu Ausgabe. Bei fast jedem Nachdruck wurden die Bilder nach Art und Zahl verändert. Diese Bilder hatten keine informative Funktion mehr. Stintzing schenkt den Bildern in seiner ausführlichen "Geschichte der populären Literatur" daher auch keine Beachtung. Er beschreibt einzig einen Holzschnitt aus dem "Layenspiegel", weil sich daraus die Familienverhältnisse Tennglers ablesen lassen:

„Tenngler, zu dessen Füßen sein Wappen, ein bärtiger alter Mann, überreicht kniend dem Kaiser, umgeben von den Kurfürsten, seinen Layenspiegel. An Tennglers linker Seite knien vierzehn Söhne, an seiner rechten zehn Töchter und drei Frauen. Unter den Söhnen zeichnet sich einer, am weitesten vorne kniend, durch die Tonsur aus: es ist Christoph, der uns durch jenen Briefwechsel näher bekannt geworden. Er war Professor in Ingolstadt ..."210

An direktem Textbezug fehlt es bei Widmungs- und Legitimationsbildern, etwa bei den häufigen Darstellungen des thronenden Königs oder Kaisers. 211 Diese Bilder zeigen meistens einen anonymen Idealherrscher, der nicht selten mit Karl dem Großen identifiziert wurde und die

${ }^{210}$ STINTZING, Geschichte der populären Literatur des römisch-kanonischen Rechts (Fn. 78), 412.

$211 \mathrm{Zu}$ den Kaiserbildern DERSCHKA, Der Schwabenspiegel (Fn. 52) S. 391 f., 415; OTT, Rechtspraxis und Heilsgeschichte (Fn. 53), 257. 
Rechtsquelle symbolisieren sollte. Aber auch die kaum weniger zahlreichen Gerechtigkeitsbilder stehen losgelöst vom konkreten Text. Sie sollen die Betrachter durch die Warnung vor der ewigen Strafe für Todsünden zu einem gerechten Urteil nach dem Vorbild des göttlichen Richters ermahnen. ${ }^{212}$

Natürlich ist der Gegensatz zwischen illustrierenden und bloß dekorativen oder symbolhaften Bildern fließend. ${ }^{213} \mathrm{Da}$ sich gleitende Übergänge aber nur schwer handhaben lassen, sei hier eine etwas genauere Abstufung vorgeschlagen. ${ }^{214}$

1. Systematische Illustration: Für die planmäßige und fortlaufende Bebilderung eines Textes gibt es keine besseren Beispiele als die Bilderhandschriften des Sachsenspiegels. Die Brüsseler Bilderhandschrift des Schwabenspiegels gehört schon eher in die nächste Gruppe der textnahen Anschauungsbilder.

2. Textnahe Anschauungsbilder: Solche Bilder erscheinen mehr oder weniger systematisch meist zu Beginn eines neuen Textabschnitts und stellen eine im Text behandelte Konfiguration vor, indem sie mehr oder weniger realistisch rechtlich bedeutsame Handlungen oder Verfahrenskonstellationen zeigen. Typische Beispiele geben Digestenausgaben von der Mitte des 16. Jahrhunderts oder die Lehrbücher Goblers und Damhouders. Solche Bilder fanden sich

${ }^{212} \mathrm{Zu}$ den Weltgerichtsbildern Lederle, Gerechtigkeitsdarstellungen (Fn. 5); Wolfgang Schild, Bemerkungen zur Ikonologie des Jüngsten Gerichts, in: Forschungen zur Rechtsarchäologie und Rechtichen Volkskunde 10 (1988), 163-201; DERS., Gott als Richter, in WOLFGANG PLEISTER/WOLFGANG SCHILD (Hrsg.), Recht und Gerechtigkeit im Spiegel der europäischen Kunst. 1988, 44-85; TROESCHER, Weltgerichtsbilder in Rathäusern und Gerichtssälen (Fn. 5), 139-214.

213 AMIRA/SCHWERIN, Rechtsarchäologie (Fn. 156) S. 118.

${ }^{214}$ HANS FeHR, Das Recht im Bilde. Erlenbach-Zürich 1923, 20 ff., unterschied Schriftbilder, Schmuckbilder, Tendenzbilder und Kunstbilder. Seine Einteilung ist schon deshalb wenig geeignet, weil sie Bilder aller Art erfassen wollte, nicht bloß Textillustrationen. Kunstbilder sind nach der Definition Fehrs solche, die zufällig einen Gegenstand aus der Welt des Rechts zum Thema haben, stehen also von vornherein außerhalb des Rechtssystems. Schriftbilder sind solche, die einen Text anschaulich machen. Diese Gruppe ist $\mathrm{zu}$ inhomogen. $\mathrm{Zu}$ ihr rechnen systematische Illustrationen ebenso wie textnahe Anschauungsbilder und instruktive Bilder. Die Gruppe der Schmuckbilder bleibt undeutlich. Tendenzbilder „wollen im Beschauer eine ganz bestimmte Gemütsbewegung erzielen" (S. 25). Hier unterscheidet Fehr fünf Unterfälle, nämlich Abschreckungsbilder, Gerechtigkeitsbilder "mit dem Willen, mahnend und belehrend auf den Richter einzuwirken", Verherrlichungsbilder, "die den Glanz, den splendor des Besteller und seiner Kirche oder Familie verkünden sollten", Spottbilder, "deren Absicht war, durch Spott, Satire, Hohn zu geißeln, Schaden aufzudecken und Moral und Recht $z u$ bessern" sowie Wahrzeichen, die, wie die Rolandsfiguren, Freiheiten und Rechte der Städte symbolisierten. 
auch schon in Handschriften des Corpus Juris ${ }^{215}$ und des kanonischen Rechts. ${ }^{216}$

3. Textferne Anschauungsbilder: Als spezifische Gruppe der Anschauungsbilder müssen zahlreiche Darstellungen des Strafvollzugs und der Folter angeführt werden, denen in der Regel der konkrete Textbezug fehlt. Fehr sprach in soweit von Abschreckungsbildern, die er den von ihm so genannten Tendenzbildern zuordnete..$^{217}$

4. Instruktive Bilder: Gemeint sind Bilder, die sprachlich schwer darstellbare Zusatzinformationen zum Text bieten. Sie sind in juristischem Zusammenhang selten, aber kommen vor. Schöne Beispiele geben die Darstellungen von Fischen in Fanggröße in verschiedenen Polizeiordnungen (siehe unten S. 342), die Abbildung von Münzen oder zeichnerische Darstellungen in verschiedenen Anleitungen zur Landvermessung.

5. Logische Bilder: Die wichtigste Form bilden die bekannten Arbores.

6. Symbolische und allegorische Bilder: Sie haben nur noch einen allgemeinen Bezug zum Recht, dagegen nicht mehr zum konkreten Text. Hierher gehören neben den bereits genannten Legitimations-, Widmungs- und Gerechtigkeitsbildern auch Wappen, Embleme und allegorische Darstellungen im engeren Sinne.

7. Bloßer Buchschmuck - ihm fehlt jeder Textbezug: Hier zählen dekorierte Titelblätter, kunstvolle Initialen, Bordüren oder Vignetten.

Zusammenfassend kann man festhalten, dass im Buchdruck systematische Illustrationen fehlen. Immerhin gab es im 16. Jahrhundert in beträchtlicher Anzahl Anschauungsbilder. Mehr oder weniger alle Bücher zeigten einen gewissen Buchschmuck und die meisten auch jedenfalls soviel an Symbolen, dass sie auf den ersten Blick als Rechtsbücher zu erkennen waren. Auf das Ganze gesehen blieb die Bildausstattung aber doch vor allem verkaufsfördernde Dekoration. Das gilt selbst für die textnahen Anschauungsbilder. Sie dienten im Kontext kommerzieller Massenproduktion in erster Linie buchhändlerischen Belangen.

${ }^{215} \mathrm{Zu}$ den letzteren GERNOT KOCHER, Sachsenspiegel, Institutionen, Digesten, Codex Zum Aussagewert mittelalterlicher Rechtsillustrationen, in: Forschungen zur Rechtsarchäologie und Rechtlichen Volkskunde 3 (1981), 5-34; MARGARIET A. BECKER MOELANDS, Die Pandekten in bildlicher Darstellung. Niederländische Abbildungen von Pandektentiteln im 17. Jahrhundert, in: Forschungen zur Rechtsarchäologie und Rechtlichen Volkskunde 12 (1990), $121 \mathrm{ff}$.

216 MELNIKAS, The Corpus of the Miniatures (Fn. 37).

${ }^{217}$ Vgl. FeHR, Das Recht im Bilde (Fn. 214). 
5. Das Ende der Bilder im 17. und 18. Jahrhundert

Im 17. Jahrhundert reduzierte sich der Bildschmuck in juristischen Büchern fast ausnahmslos auf dekorierte Titelkupfer ${ }^{218}$ und/oder Autorenportraits. ${ }^{219}$ Hofmanns „Praxis Juris et Processus Cameralis Novissima ..." von 1721 zeigt auf dem Titel über einer Ansicht der Stadt Wetzlar ein detailliertes Bild der Kanzlei des Reichskammergerichts. ${ }^{220}$ Ungewöhnlich reich geschmückt mit kunstvollen Kupferstich-Initialen und Marken vor und hinter den einzelnen Kapiteln ist ein "Dictionarium juridicum" von Heineccius.221 Carl Friedrich Hommels zweibändige "Jurisprudentia numismatibus illustrata nec non sigillis gemmis aliisque picturis vetustis varie exornata" von 1763 verspricht und bietet allerhand Bildchen, die aber mit dem Text nichts mehr zu tun haben. Etwas aus der Reihe fällt in diesem Werk eine ganzseitige Darstellung vom Urteil des Königs Zaleucus, ein Motiv, das seit der Renaissance zum Katalog der geläufigen Allegorien gehörte.222 Die Bilder sind vollends zur Dekoration geworden, und auch Dekoration begegnet einem nur noch selten.

\footnotetext{
218 Vgl. MARG ARIET A. BECKER-MOELANDS, De juridische titelprent in den zeventiende eeuw. Muiderberg 1985. Moelands hat 1000 juristische Bücher durchgesehen, die zwischen 1600 und 1750 in den Niederlanden erschienen sind, und darin 198 ganzseitige Titelbilder gefunden. Davon waren 140 Kupferstiche. Die Titelkupfer beruhen allerdings nur auf 109 Originalen. Einige wurden mehrfach verwendet, einige kopiert. Justitia erscheint auf über der Hälfte der Bilder. Ein Viertel der Bücher, hauptsächlich mit römisch-rechtlichen Themen, trägt das Bild Justinians. 20 Bilder stellen Gerichtssitzungen dar (het Hof van Holland).

${ }^{219}$ Folgende Beispiele entnehme ich dem Antiquariatskatalog Nr. 599 von Auvermann \& Keip (in zeitlicher Reihenfolge): MODESTINUS PISTORIS, Quaestionum tum communis tum Saxonici partes quatuor. Leipzig 1600; MATTHIAS COLER, Tractatus de processibus executivis ... Jena 1615; Hugo GROTIUS, Annales et historiae de rebus Belgicis. Amsterdam 1657; BENEDIKT CARPZOV, Jurisprudentia forensis Romano-Saxonica secundum ordinem. Leipzig 1656; PETRUS THEODORICUS UfF GROSSEN, Judicium Criminale Practicum fere novum. Jena 1671; DANIEL CLASEN, Commentarius in Constitutiones Criminales Caroli V. Imperatoris, Frankfurt/Leipzig 1685; SAMUEL STRYK, Specimen usus moderni pandectarum ... Yalle 1708; SAMUEL PUFENDORF, De officio hominis et civis juxta legem naturalem libri duo. Marburg und Frankfurt 1702; DERS., Introductio ad historiam Europeam. Frankfurt 1704. JOHANNES BRUNNEMANN, Tractatus juridicus de inquisitionis processu. Frankfurt 1714; HEINRICH DE COCCEJI, Exercitationum curiosarum Palatinarum. Trajectinarum et Viadrinarum. Lemgo 1722; JEAN-PAUL MARAT, Plan de législation criminelle. Paris 1790.

220 Bei LÜPKES, Bild und Recht (Fn. 36), Abbildung 1, 36.

221 JOHANN GOTTLIEB HEINECCIUS, Barnabas Brissonius de Verborum Significatione, seu Dictionarum Juridicum. Magdeburg 1743 (Zentrales Rechtswissenschaftliches Seminar der Ruhr-Universität Sign. 24 A 153A).

222 Vgl. EDWARD ANDREW MASER (Hrsg.), Cesare Ripa. Baroque and Rococo Pictorial Imagery. The 1758-60 Hertel Edition of Ripa's ,Iconologia' with 200 Engraved Illustrations. New
} York 1971, 117 . 
Bis in das 18. Jahrhundert hinein starben gegenständliche Bilder allerdings nicht völlig aus. Das Zeitalter der Aufklärung war zwar getragen vom verbalen und literarischen Diskurs und verstärkte damit noch einmal die Vormacht der Schrift. Aber deswegen verzichtete es nicht auf die Vorzüge instruktiver "technischer Zeichnungen".

Einige Polizeiordnungen und Strafgesetze wurden illustriert. Auch die geltenden Münzen werden im Bild gezeigt. Ein sächsischer Codex Augusteus von 1724, der zuletzt 1824 erscheint, bildet die verschiedenen Fischund Krebsarten in der erlaubten Mindestfanggröße sowie die zugelassene Größe der Netzmaschen im Originalmaßstab. Insoweit war eine 1533 in München gedruckte Bairische Landtsordnung ihrer Zeit weit voraus. Sie ist vor allem wegen ihrer vielen Bildern von Fischen in Originalgröße bekannt.

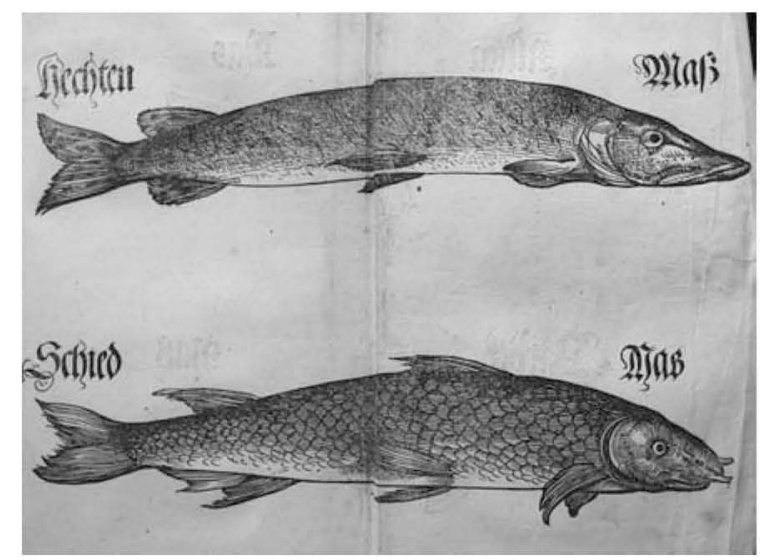

Abb. 17: Holzschnitt aus Bairische Landtsordnung, München 1553 (Institutsbibliothek des Leopold-Wenger-Instituts München, Aufnahme Franziska Wieczorek)

Ein Druck der österreichischen Constitutio Criminalis Theresiana von 1769 war mit 30 Kupferstichen ausgestattet. 223 Dieses Strafgesetzbuch der Aufklärungszeit verzichtete zwar nicht auf die Folter, band sie aber an strenge Regeln. Dazu erhielt das Gesetz Bilder von der kunstgerechten Ausführung der unterschiedlichen „Peinigungsarten", die den Eindruck illustrierter Gebrauchsanweisungen wecken.

223 Constitutio Criminalis Theresiana. Vollständiger Nachdruck der Trattnerschen Erstausgabe Wien 1769. Mit einem Nachwort von EGMONT FOREGGER. Graz 1993. 
Figura I. Latus L.

Der Grad Des Daumftoffer.

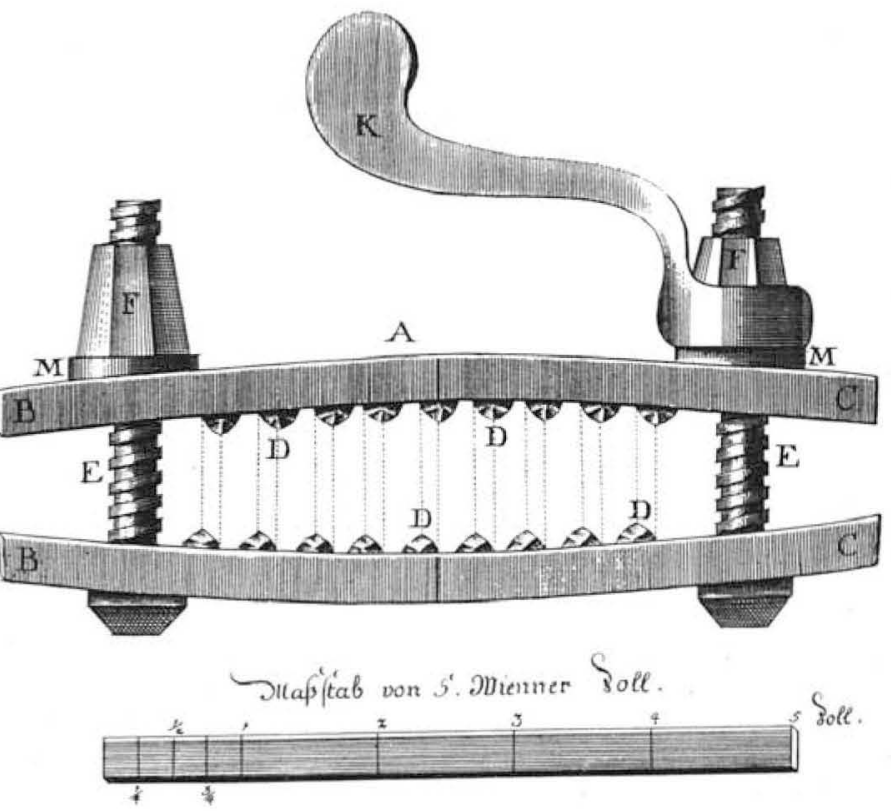

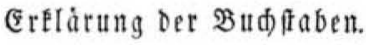

A. Die zur peinliden Tortur gebórige Daumenftóde.

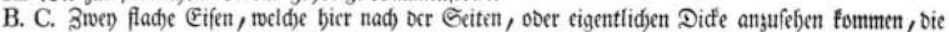
mit fitumpfigen, uno in Edfen zufammenlaufenben fervorftebenben finspfen D. Dergeffalt befecket, Saf Die obere ber) Leberfammenlegung Denen unteren ausweidjen, unb nidjt úbereinanber treffen. $\left.\begin{array}{l}\text { E. Sdjraubenfpindel } \\ \text { F. Sdfraubenmutter }\end{array}\right\}$ Die bie fladje Eifen jufammen falten.

F. Edfraubenmutter $\}$ Die bie fladje Eticn zujammen balten.

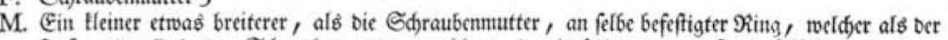

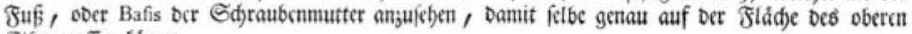
Eifen paffen fónne.

K. Der Edbraubenfdsluffel, mit meldem Dic Edfraubenmutter F. an Der Edfraubenfinbel E. ans gejogen, uno Die flache Eifen Daburd) ancinanber gebrudet recroen Fónnen.

Das obere Eifen bicfes petulicten Inftruments iub A rirb in idee vorgeffellet, als of fels bes auf benoen Geiten aufgeboben werbe, Damit man bie innwenbige Lage ber Eifon, unb ber finópfen erfecten mỏge.

C 2

Abb. 18: Darstellung einer Daumenschraube in der Erstausgabe der Constitutio Criminalis Theresiana, Wien 1769 
Ob diese Bilder allerdings wirklich als „Instruktion“ zur Folter dienten, ist zweifelhaft. Sie stießen schon bei Zeitgenossen wegen ihres grausamen Realismus auf Ablehnung, und von Historikern wird geltend gemacht, diese Tafeln hätten in erster Linie der Abschreckung gedient; in der Praxis sei man viel milder mit den Inquisiten umgegangen.224

Es ist wohl kein Zufall, dass mit den Leibesstrafen auch die Bilder endgültig aus dem Recht verschwanden. Damit entfiel ein wichtiges Sujet für die Anschauungsbilder. Für Legitimations- und Widmungsbilder war nach dem Ende des Absolutismus kein Bedarf mehr. Auch als bloßes Beiwerk waren die Bilder im 19. Jahrhundert nicht mehr geduldet. Nur noch Druckersignets hielten sich auf den Titelblättern. Nachdem das wissenschaftliche Buch zur Massenware geworden war, brauchte man Bilder in Rechtsbüchern nicht einmal mehr zur Dekoration.

Zwar waren die Bilder im Recht damit verschwunden. Doch Bilder vom Recht gab es weiterhin in großer Zahl. In der bildenden Kunst wurden die Darstellungen von Rechtsthemen seit der Renaissance häufiger. ${ }^{225}$ Die zahlreichen Justitia-Darstellungen aus alter Zeit haben längst auch bei Juristen hinreichende Aufmerksamkeit gefunden. ${ }^{226}$

224 EGMONT FOREGGER, Constitutio Criminalis Theresiana. Graz 1993, 25; ERNEST VON KWIATKOWSKI, Die Constitutio Criminalis Theresiana. Innsbruck 1903, 30; SCHILD, Alte Gerichtsbarkeit (Fn. 46), 164; EDUARD DULLER, Maria Theresia und ihre Zeit. Bd. II. Wiesbaden 1844, 323; HUGO HOEGEL, Geschichte des österreichischen Strafrechts. Bd. I. Wien $1904,3 f$.

225 HaNs FEHR, Das Recht im Bilde, Erlenbach-Zürich 1923; GEORG FROMMHOLD, Die Idee der Gerechtigkeit in der bildenden Kunst. Greifswald 1925; LEDERLE, Gerechtigkeitsdarstellungen (Fn. 5); WOLFGANG PLEISTER/WOLFGANG SCHILD (Hrsg.), Recht und Gerechtigkeit im Spiegel der europäischen Kunst. Köln 1988; vgl. dazu die Besprechung von KLAUS GUNTHER, Juristenästhetik, in: Rechtshistorisches Journal 9 (1990), 25-34; WOLFGANG SELLERT, Recht und Gerechtigkeit in der Kunst. Göttingen 1993.

226 JULIANE BAER-HENNEY, Wie kommt die Jungfrau zu Waage, Schwert und Augenbinde? - Zur Darstellung der Justitia, in: Juristische Arbeitsblatter (1997), 610-613; PAOLO FERREIRA DA CUNHA, Die Symbole des Rechts, in: Archiv fiur Rechts- und Sozialphilosophie 80 (1994), 85-95; DENNIS E. CURTIS/JUDITH RESNIK, Images of Justice, in: Yale Law Review 96 (1987), 1927-1987; UlF-DIETRICH VON HIELMCRONE, Die Darstellung der Justitia im Landesteil Schleswig. Diss. Kiel 1974; LAMBERTE E. VAN HOLK, Justitia. Bild und Sinnbild im 17. Jahrhundert in den Niederlanden, in: Forschungen zur Rechtsarchäologie und Rechtlichen Volkskunde 3 (1981), 155-199; RUDOLF KISSEL, Die Justitia. München 1984; WOLFGANG SCHILD, Gerechtigkeitsbilder, in: PleISTER/SCHILD (Hrsg.), Recht und Gerechtigkeit (Fn. 225), 86-171. 


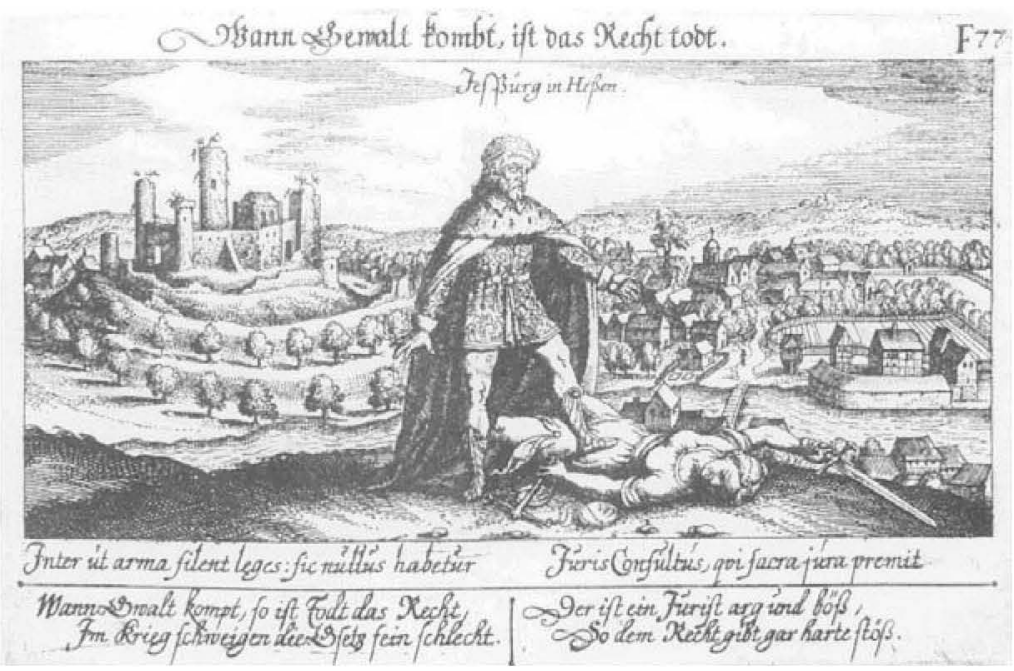

Abb. 19: „Wenn Gewalt kombt, ist das Recht todt“ aus dem Thesaurus Philopoliticus, Teil vier, Frankfurt am Main 1627 (Aufnahme Stephan Prinz)

Die Emblemkunst erfreute sich, offensichtlich gefördert durch den Buchdruck,227 bis ins 17. Jahrhundert großer Beliebtheit. Viele Themen, etwa die Bibel oder antike Sagen, wurden emblematisch verarbeitet. ${ }^{228}$ Es gab Emblembücher zu speziellen Themen (z. B. Politik, Philosophie, Wetter, Sport, Liebe), jedoch keine vergleichbare Sammlung zu Rechtsthemen. Embleme mit Rechtsbezug lassen sich aber in stattlicher Zahl aus Emblembüchern zu anderen Themenkreisen heraussuchen.

Eine gewisse Verwandtschaft zu den Emblemen weisen die zeitweise weit verbreiteten Flugblätter auf. Auch sie sind insbesondere wegen der Verbindung von Bild und Text interessant. Man kann sie wohl als Vorläufer der neuzeitlichen Massenmedien ansehen.229 In der ersten Hälfte des 19. Jahrhunderts entdeckte Honoré Daumier die Karikatur als

227 NiKLAS LUHMANN, Die Kunst der Gesellschaft. Frankfurt. 1997, 276.

${ }^{228}$ Emblemata. Handbuch zur Sinnbildkunst des XVI. und XVII. Jahrhunderts. Herausgegeben von ARTHUR HENKEL und ALBRECHT SCHÖNE. Stuttgart 1967, Taschenbuchausgabe 1996. Eine gute Einführung bietet der Artikel "Emblem" von DIETMAR PEIL in: Kleine literarische Formen in Einzeldarstellungen. Stuttgart 2002, 71-88.

229 WOLFGANG HARMS/MiCHAEL SCHILLING (Hrsg.), Das illustrierte Flugblatt in der Kultur der Frïhen Neuzeit. Frankfurt am Main 1998; DIETMAR PEIL, Strafe und Ritual. Zur Darstellung von Straftaten und Bestrafungen im illustrierten Flugblatt, in: WOLFGANC HARMS/ALFRED MESSERELLI (Hrsg.), Wahrnehmungsgeschichte und Wissensdiskurs im illustrierten Flugblatt der Frïhen Neuzeit (1450-1700). Basel 2002, 465-489. 
Medium der Justizkritik. ${ }^{230}$ Neben dieser in kritischer Absicht und mit künstlerischer Qualität gearbeiteten Karikatur entstand im 19. Jahrhundert auch schon das Genre der humoristischen Justizkarikatur. ${ }^{231}$ Doch alle diese Bilder dienten weder dem Rechtsverkehr noch der juristischen Fachkommunikation. An die Stelle der „Bilder im Recht" treten die „Bilder vom Recht". Immerhin erscheint bemerkenswert, dass die Juristen selbst Hauptabnehmer juristischer Karikaturen geworden sind. Solche Karikaturen dienen wohl in erster Linie zur Demonstration von Rollendistanz.

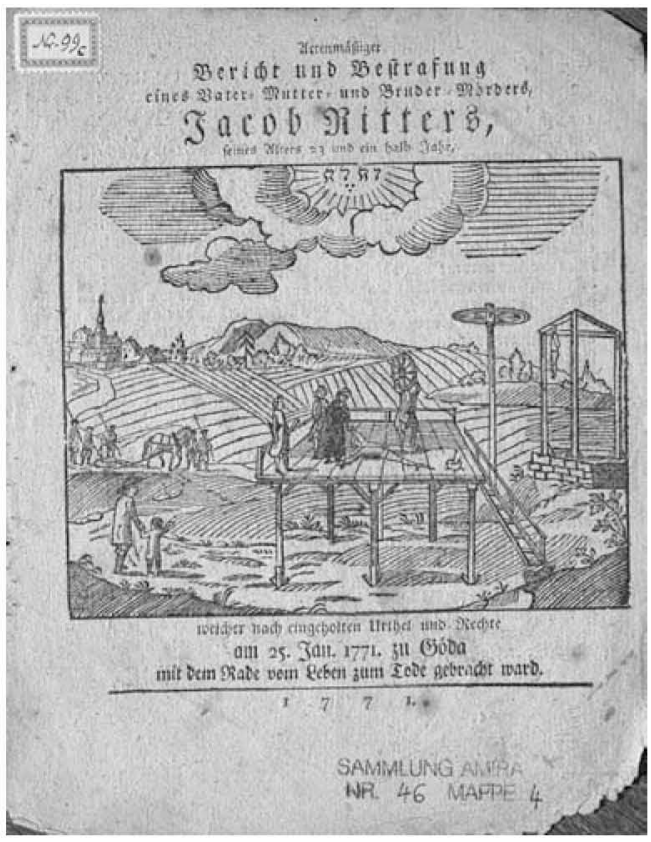

Abb. 20: Ein Flugblatt von 1771 als Vorläufer der modernen Presse. Aus dem Leopold-Wenger-Institut München (Aufnahme Stephan Prinz)

230 GUSTAV RADBRUCH, Karikaturen der Justiz. Lithographien von Honoré Daumier. Göttingen 1957 (1947). CORNEL.rUS VETH, Der Advokat in der Karikatur. Berlin 1927. Schon vor Daumier war die politische Karikatur zum "gesprochenen Schriftstück" der Revolution geworden, siehe ROLF E. REICHARDT, Das Blut der Freiheit. Französische Revolution und demokratische Kultur. Frankfurt am Main 1998, $198 \mathrm{ff}$.

${ }^{231}$ EDUARD VON SECKENDORFF, Der Civil-Prozeß. Parodie auf Schillers Glocke mit HolzschnittIllustrationen von W. B. Breitschwert. 2. Aufl., Stuttgart 1867 - Faksimile-Ausgabe mit einem Nachwort von Hans Hattenhauer, Neuwied 1996; als neueres Beispiel vgl. Die it lustrierte Strafprozefordnung von PHILIPP HEINISCH. Königswinter 1990. 
Zusammenfassend ist festzuhalten: Die Verwendung von Bildern zur systematischen Bebilderung von Rechtstexten ist nach der kurzen Blütezeit im Mittelalter nicht wieder in Gang gekommen. Nur vorübergehend gab es danach noch symbolische und Anschauungsbilder in nennenswerter Zahl. Doch sie waren weitgehend nur noch dekorativ und damit mehr oder weniger funktionslos. Modernere Bilder mit Rechtsbezug sind nicht länger „Bilder im Recht", sondern „Bilder vom Recht”. Sie zählen zur Kunst, bieten Unterhaltung oder mediale Information über das Recht, dienen aber nicht mehr der rechtsinternen Kommunikation.

Das Verschwinden der Bilder ist nicht selbstverständlich, denn die Erneuerung der Drucktechnik, die in der zweiten Hälfte des 18. Jahrhunderts einsetzte, erleichterte noch einmal die Bildwiedergabe, und Naturwissenschaft, Technik, populärwissenschaftliche Literatur und die Presse machten davon alsbald ausgiebigen Gebrauch. Zunächst entwickelte Bewick 1780 eine neue Holzschnitttechnik, die es gestattete, weitaus feinere Linien und Schattierungen zu drucken, vorausgesetzt allerdings, man verfügte über hinreichend feines und glattes Papier. 1798 erfand Robert in Frankreich eine Papiermaschine, die bald darauf in England perfektioniert wurde. Mit dampf- oder wassergetriebenen Walzen konnte man nun dünnes und glattes Papier in großen Mengen produzieren. 1815 konstruierte König für die Londoner Times die erste maschinelle Druckpresse, die laufend verfeinert wurde. Von nun an war es möglich, preiswerte Massendrucksachen mit qualitativ guten Bildern herzustellen. Jetzt erst wurde das bebilderte Sachbuch wirklich zum Informationsmedium. Damit verloren viele Techniken ihr Geheimnis, das bis dahin sozusagen von Auge zu Auge weitergegeben worden war. Wer lesen konnte, konnte sich alsbald über alle möglichen handwerklichen Techniken und Werkzeuge informieren. Der Zugang zur Technik, der bis dahin einer kleinen Schicht von Gebildeten vorbehalten war, stand nun jedermann offen. Schnell wurde das 19. Jahrhundert zum Jahrhundert der technischen Erfindungen, und zwar der Erfindungen nicht länger durch Gentleman-Techniker, sondern durch jedermann. Voraussetzung war die massenhafte Information über Techniken und Technologien, wie sie nur durch eine Verbindung von Schrift und Bild möglich ist. Am Recht ist diese Entwicklung vorbeigegangen, denn zur Information über das Recht genügte die Schrift. Das Recht hatte sich schon längst von dem lesenden Laienpublikum abgekoppelt.

In der zweiten Hälfte des 19. Jahrhunderts verbreiteten sich die Bilder über die Drucksachen hinaus in den städtischen Alltag. Panoramen, Dioramen und Museen standen hoch in der Gunst des Publikums. Illustrierte Zeitschriften, Plakate und Warenhäuser sprachen das Auge an. Fotografie wurde zum Bestandteil der Lebenswelt. Die Großstädte prä- 
sentierten sich selbst als Ausstellungsstück und ihre bunten Wände wurden zur „Kunstgalerie des armen Mannes“. Die zahllosen Plakate in Paris entfachten Diskussionen über die Wirkungen der Bilderflut und weckten bei manchen die Furcht, sie könnten die Stadtbewohner in "badauds" (Gaffer) verwandeln und sie hypnotisieren. ${ }^{232}$ "For ordinary people in the late nineteenth century, the word and the image were linked as never before. “233 Emeut ließ der Medienwandel das Recht unberührt.

Die Entwicklung von Film und Fernsehen im 20. Jahrhundert hat zwar viele Bilder vom Recht gebracht. ${ }^{234}$ Aber erst die Digitalisierung der Bilder auf dem Personalcomputer, die jedem Autor Grafikelemente an die Hand gibt, könnte nun einen Wandel herbeiführen, indem die Bilder in das Recht selbst eindringen. ${ }^{235}$

232 KAREN CARTER (Miyazaki International College, Japan) in einem anscheinend noch unveröffentlichten Vortrag im Huizinga Institut in Amsterdam am 22.11.2002 ("The Passant, the Badaud and the Spectatorship of French Fin-de-Siècle Posters"). Vgl. auch VANESSA SCHWARTZ, Spectacular Realities: Early Mass Culture in fin-de-siècle Paris. Berkeley 1998.

233 SCHWARTZ, Spectacular Realities (Fn. 232), 2.

$234 \mathrm{Zu}$ diesen ausführlich Stefan MAChura/Peter Robson (Hrsg.), Law and Film. Oxford 2001; STEFAN MaCHuRa/STEFAN UlbRicH (Hrsg.), Recht im Film. Baden-Baden 2002.

235 Näher KLAUS F. RÖHL, Das Recht nach der visuellen Zeitenwende, in: Juristenzeitung 2003, 339-344. 